\title{
ADAM15 in Apoptosis Resistance of Synovial Fibroblasts: Converting Fas/CD95 Death Signals into the Activation of Prosurvival Pathways by Calmodulin Recruitment
}

\author{
Dissertation \\ zur Erlangung des Doktorgrades \\ der Naturwissenschaften \\ vorgelegt beim Fachbereich 15 \\ der Johann Wolfgang Goethe -Universität \\ in Frankfurt am Main
}

von Tomasz Janczi

aus Płock

Frankfurt (2019) 
vom Fachbereich 15 der Johann Wolfgang Goethe - Universität als Dissertation angenommen.

Dekan: Prof. Dr. Sven Klimpel

Erster Gutachter : Prof. Dr. Jörg Soppa

Zweiter Gutachter: Prof. Dr. Harald Burkhardt

Datum der Disputation:................... 



\section{Table of Contents}

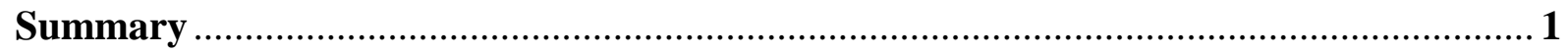

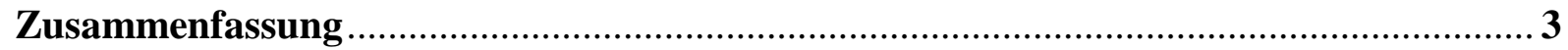

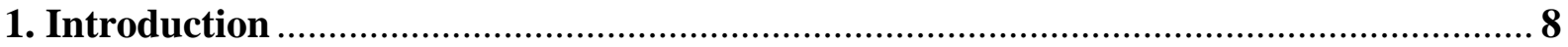

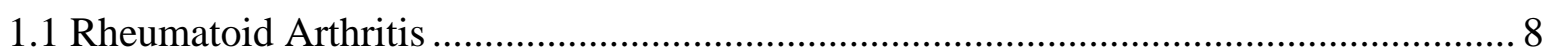

1.1.1 Apoptosis resistance of Rheumatoid Arthritis Synovial Fibroblasts (RASFs) ......... 9

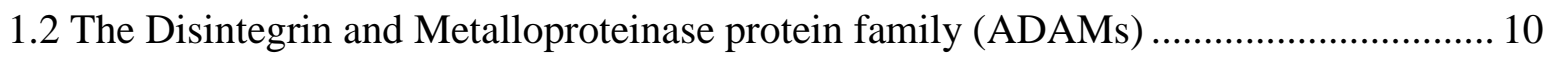

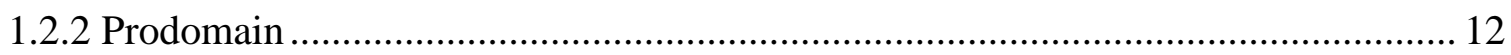

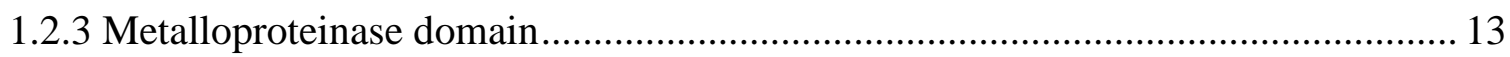

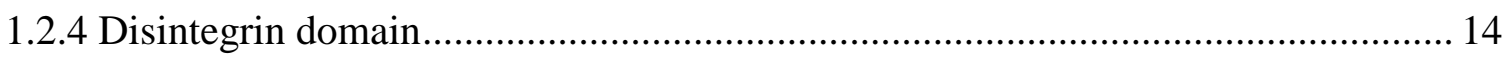

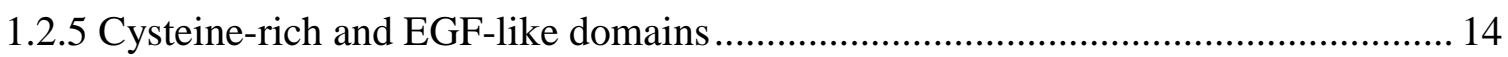

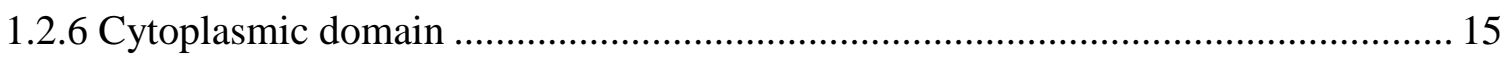

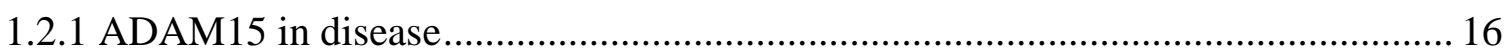

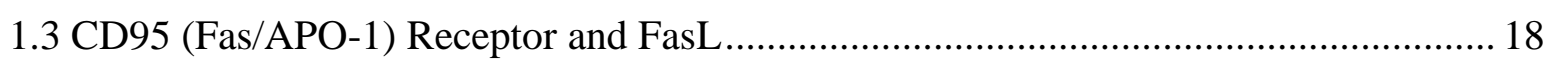

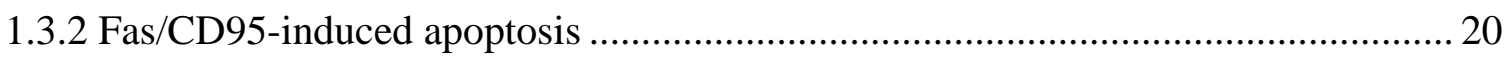

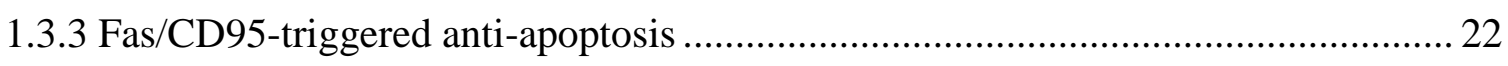

1.4 Src and FAK signaling as key molecules in apoptosis resistance .............................. 23

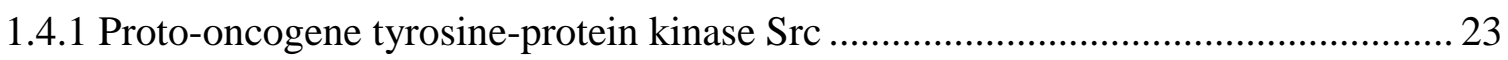

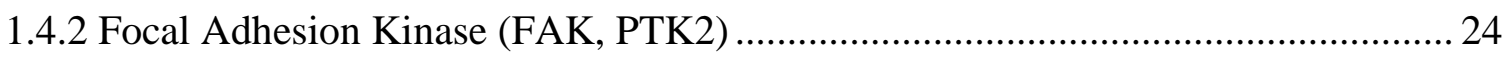

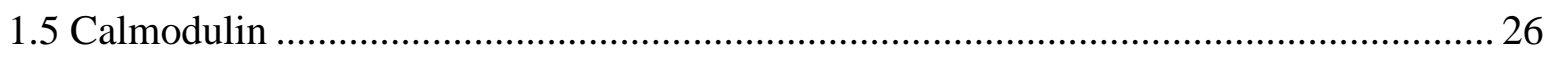

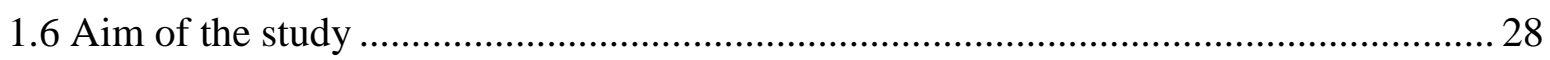

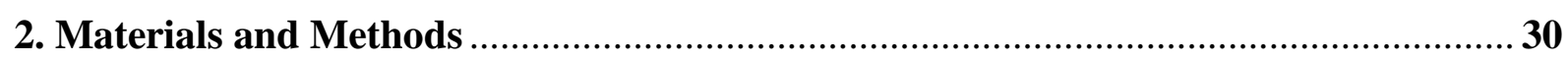

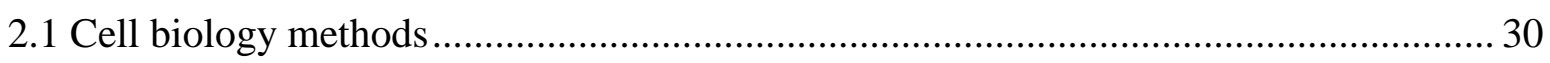

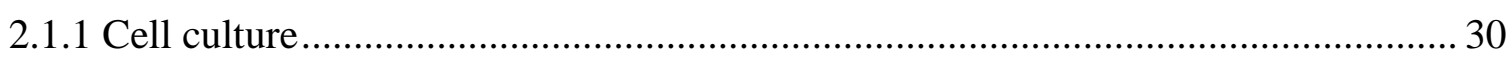

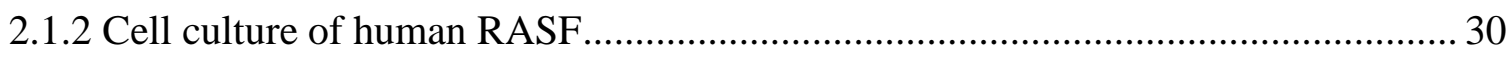

2.1.3 Downregulation of ADAM15 by siRNA in primary RASF ............................... 31

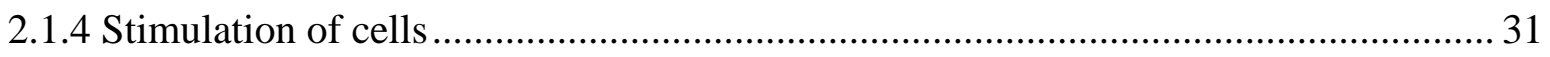

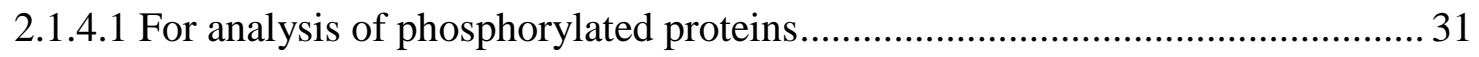

2.1.4.2 For double immunofluorescence stainings.................................................. 32

2.4.4.5 For total apoptosis rate determination ............................................................ 33

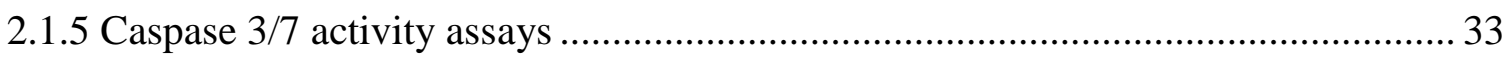

2.2 Biochemical and molecular biology methods ........................................................ 33

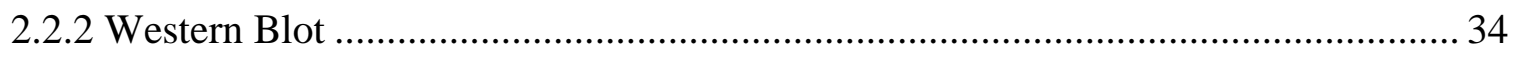

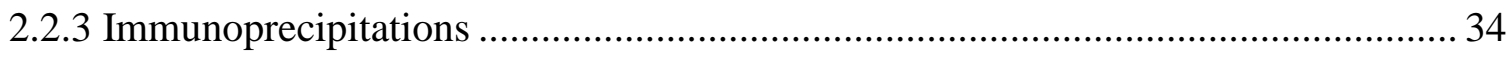

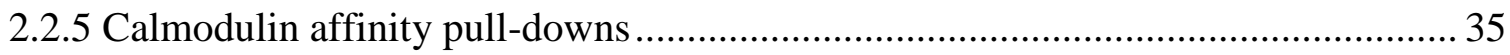

2.2.6 Production of recombinant cytoplasmic domain of ADAM15 (ADAM15cyto) ..... 35 
2.2.7 Protein interaction ELISA (Enzyme Linked Immunosorbent Assay) 36

3. Results 37

3.1 ADAM15 dependent pro-survival signaling induced by FasL 37

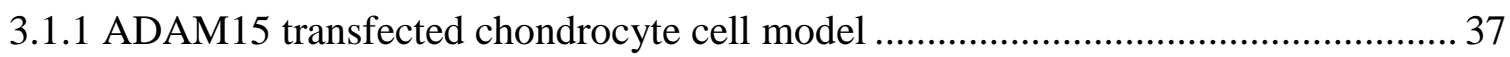

3.1.2 ADAM15-mediated resistance to FasL induced apoptosis.................................... 38

3.1.3 ADAM15 dependency of FasL-triggered phosphorylations of Src and FAK ......... 39

3.2 Role of calmodulin in ADAM15-dependent Fas/CD95 signal transduction.

3.2.1 Calmodulin inhibition of ADAM15-dependent phosphorylations of Src and FAK 41

3.2.2 Interactions of calmodulin with Src, FAK and CD95 ........................................ 43

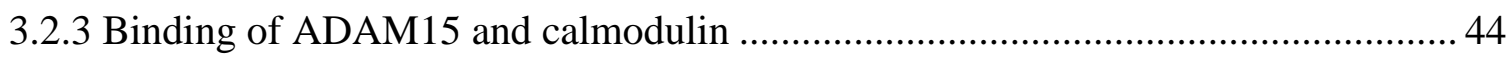

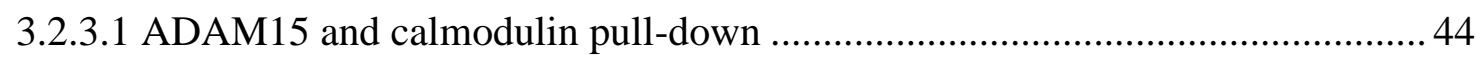

3.2.3.2 ADAM15 and calmodulin protein binding assays ......................................... 45

3.3 Recruitment of calmodulin to ADAM15 and Fas/CD95 upon Fas ligation .................. 48

3.3.1 Double immunofluorescence staining of calmodulin and ADAM15 in RASFs...... 48

3.3.2 Co-Immunoprecipitation of calmodulin with ADAM15 ...................................... 49

3.4 Fas/CD95 -induced interaction of calmodulin and Fas/CD95 ..................................... 50

3.4.1 Double immunofluorescent staining of calmodulin and Fas/CD95 in RASFs ........ 50

3.4.2 Co-Immunoprecipitation of calmodulin with Fas/CD95 in RASFs ........................ 51

3.5 Fas/CD95 activation-induced interaction of Fas/CD95 and ADAM15 ........................ 53

3.5.1 Double immunofluorescence stainings of Fas/CD95 and ADAM15 in RASFs ...... 53

3.5.2 Co-Immunoprecipitation of ADAM15 with Fas/CD95 in T/C28a4 cells ............... 54

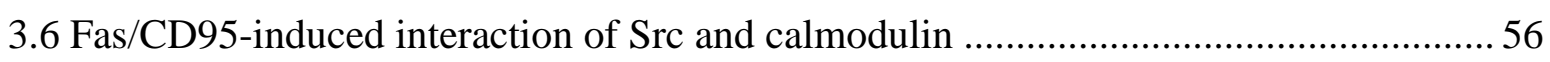

3.7 Effect of CRAC channel inhibition on the phosphorylation of Src and FAK ................57

3.8 Influence of ADAM15/Src/Calmodulin signaling on the resistance of RASFs to FasL induced apoptosis

3.8.1 Influence of calmodulin and CRAC channel inhibition on FasL induced Caspase

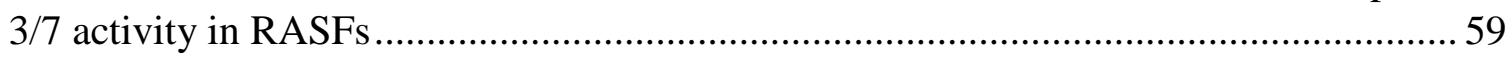

3.8.2 Influence of calmodulin and CRAC channel inhibition on the total apoptosis rate of

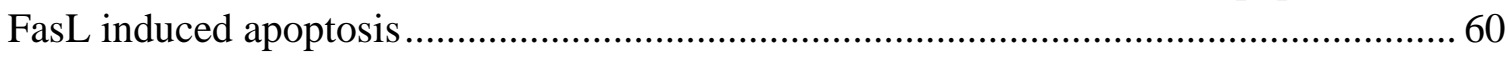

3.8.3 The synergistic effect of ADAM15-knockdown and of calmodulin or CRAC/Orai1

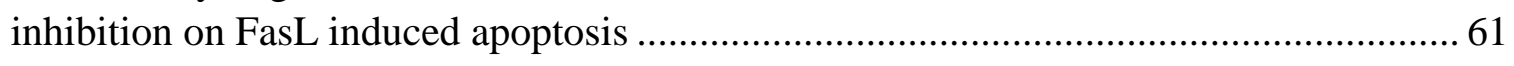

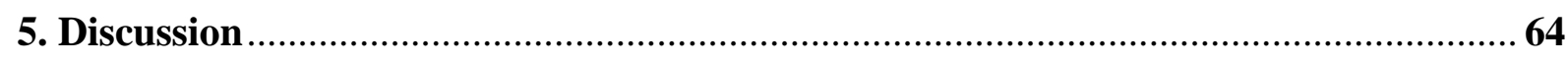

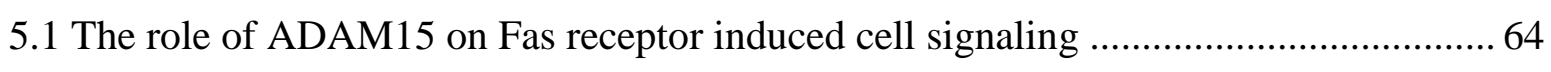

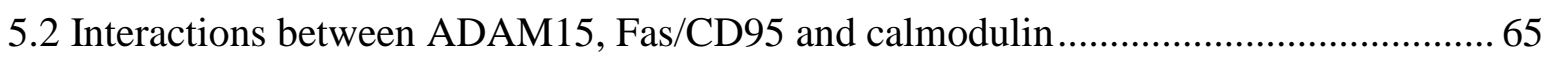

5.3 Interactions of calmodulin and either Src or focal adhesion kinase (FAK) .................. 67

5.4 The ADAM15-dependent pro-survival signaling pathway upon Fas/CD95 stimulation. 
5.5. The role of ADAM15-Fas-calmodulin complex signaling in apoptosis resistance of RASFs

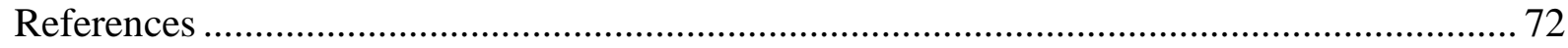

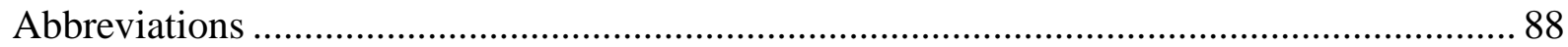

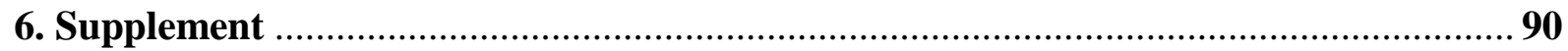

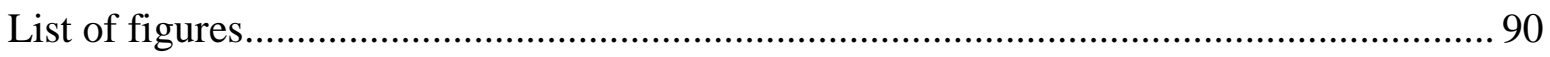

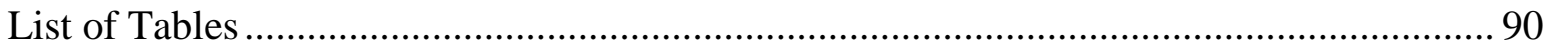

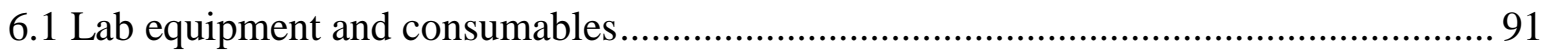

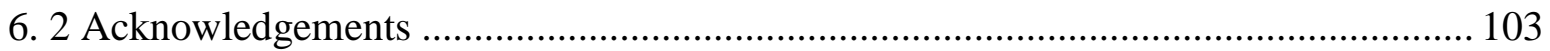

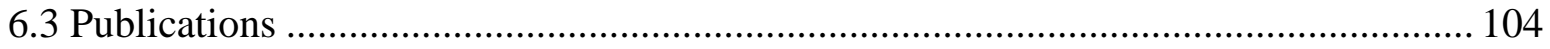

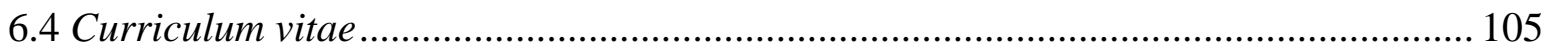




\section{Summary}

ADAM15, which belongs to the family of the disintegrin and metalloproteinases, is a multi-domain transmembrane protein. A strongly upregulated expression of ADAM15 is found in inflamed synovial membranes from articular joints affected by osteoarthritis and especially rheumatoid arthritis (RA). During the chronic inflammatory process in RA the synovial membrane gets hyperplastic, resulting eventually in the formation of a pannus tissue, which can invade into the adjacent cartilage and bone thereby destroying their integrity. Previously, the expression of ADAM15 in fibroblasts of the RA synovial membrane was found to confer a significant anti-apoptotic response upon triggering of the Fas receptor, which resulted in the activation of two survival kinases, focal adhesion kinase (FAK) and Src. The Fas receptor, also named CD95, belongs to the death receptor family of the tumor necrosis factor receptors and stimulation of Fas/CD95 by its ligand FasL results in the execution of apoptotic cell death in synovial membranes of RA patients. However, the occurrence of apoptotic cell death in vivo in RA synovial tissues is considerably low despite the presence of FasL at high concentrations in the chronically inflamed joint. Accordingly, a general apoptosis resistance is a characteristic of RA-synovial fibroblasts that contributes considerably to the formation the hyperplastic aggressive pannus tissue. The objective of this study was to investigate the mechanisms underlying the capability of ADAM15 to transform FasL-mediated death- inducing signals into pro-survival activation of Src and FAK in rheumatoid arthritis fibroblasts (RASFs).

In the present study, the down-regulation of ADAM15 by RNA interference resulted in a significant increase of caspase 3/7 activity upon stimulation of the Fas receptor in RASFs. Likewise, chondrocytes expressing a deletion mutant of ADAM15 $(\Delta C)$, lacking the cytoplasmic domain, revealed increased caspase activities upon Fas ligation in comparison to cells transfected with full-length ADAM15, clearly demonstrating the importance of the cytoplasmic domain for an increased apoptosis resistance. Furthermore, activation of the Fas receptor triggered the phosphorylation of Src at Y416, which results in the active conformation of Src, as well as the phosphorylation of FAK at Y576/577 and Y861 - the target tyrosines phosphorylated by Src - in full-length ADAM15-transfected chondrocytes. However, cells transfected with ADAM15 mutant $(\Delta C)$ or with vector control did not exhibit any activation of Src and FAK upon Fas ligation. This suggested the presence of an as yet unknown protein interaction mediating the Fas triggered activation of the two kinases.

In order to identify this mechanism, the application of signal transduction inhibitors interfering with Calcium signaling either by inhibiting calmodulin with trifluoperazine (TFP) or the Calcium release-activated channel (CRAC/Orai1) with BTP-2 efficiently inhibited the phosphorylation of FAK and Src, revealing a role of calmodulin, the major $\mathrm{Ca}^{2+}$ sensor in cells, in ADAM15-dependent and Fas-elicited activation of the two survival kinases. Also, a direct $\mathrm{Ca}^{2+}$-dependent binding of calmodulin to ADAM15 could be demonstrated by pull-down 
assays using calmodulin-conjugated sepharose and by protein binding assays using the recombinant cytoplasmic domain of ADAM15 and calmodulin.

Furthermore, it could be demonstrated in living synovial fibroblasts by double immunofluorescence stainings that triggering the Fas receptor by its ligand FasL or a Fasactivating antibody resulted in the recruitment of calmodulin to ADAM15 as well as to the Fas receptor in patch-like structures at the cell membrane. Simultaneously, Src associated with calmodulin was shown to become engaged in an ADAM15 complex, also containing cytoplasmic-bound FAK, by co-immunoprecipitations.

Additional studies were performed to analyze the efficacy of TFP and BTP-2 on apoptosis induction in synovial fibroblasts from 10 RA patients. Using caspase 3/7 and annexin $\mathrm{V}$ stainings for determining apoptosis, it could be shown that both inhibitors did not possess any apoptosis inducing capacity. However, when co-incubated with FasL both compounds synergistically enhanced apoptosis rates in the RASFs. Moreover, an additional silencing of ADAM15 revealed a further significant rise in apoptosis rates upon incubation with FasL/TFP or FasL/BTP-2, providing unequivocal evidence for an involvement of ADAM15 in facilitating apoptosis resistance in RASFs.

Taken together, these results demonstrate that ADAM15 provides a scaffold for the formation of calmodulin-dependent pro-survival signaling complexes upon CRAC/Orai1 coactivation by Fas ligation, which provides a new potential therapeutic target to break the apoptosis resistance in RASFs that critically contributes to joint destruction in RA. 


\section{Zusammenfassung}

\section{Einleitung}

ADAM15 ist ein Transmembranprotein, das aus mehreren extrazellulären Domänen besteht, und ein Mitglied der Familie der Disintegrin Metalloproteinasen ist. Der extrazelluläre Bereich setzt sich aus einer Prodomäne, einer Metalloproteinase Domäne, einer Disintegrin,-- sowie Cystein-reichen und EGF-ähnlichen Domäne zusammen, gefolgt von einer Transmembran- und zytoplasmatischen Domäne. Immer mehr Untersuchungen deuten darauf hin, dass verschiedene Mitglieder der ADAMFamilie (z.B. ADAM15, ADAM17) einen großen Einfluss auf die zelluläre Signaltransduktion ausüben. Eine stark erhöhte Proteinexpression von ADAM15 ist in entzündlich-veränderten synovialen Geweben bei Erkrankungen, wie der Osteoarthrose und insbesondere der rheumatoiden Arthritis (RA), nachgewiesen worden. Im Verlauf der Entzündung wird die RA-Synovialmembran hyperplastisch und kann zur Formation eines sogenannten Pannus führen, der den umliegenden Knochen und Knorpel infiltrieren und damit zur Zerstörung dieser Gewebe führen kann. Eine Ursache für die Hyperplasie der Synovialmembran bei der RA liegt in dem Ungleichgewicht von Zellproliferation und Zelltod.

In Vorarbeiten konnte nachgewiesen werden, dass die erhöhte ADAM15 Expression in den Fibroblasten der Synovialmembran von RA-Patienten nach Stimulation des Fas Rezeptors in der Aktivierung von zwei „Überlebens-Kinasen“, der fokalen Adhäsionskinase (FAK) und Src, resultiert und damit in einer signifikant erhöhten Apoptose-Resistenz resultiert. Beide Proteine gehören zu den Nicht-Rezeptor-Tyrosinkinasen und sind an einer Vielzahl von Signalwegen beteiligt, welche - einmal aktiviert - Zellsterben verhindern und so durch vermehrte Proliferation der Fibroblasten zur Hyperplasie des Synovialgewebes führen können. In diesem Kontext gibt es eine Vielzahl von Literaturhinweisen auf eine Beteiligung analoger Wirkmechanismen in der Pathogenese maligner Tumore, da die erhöhte Expression beider Kinasen mit der Aggressivität und Invasivität unterschiedlicher neoplastischer Erkrankungen korreliert.

Der Fas Rezeptor (Synonym: CD95) gehört zur Familie der Tumor Nekrose Faktor Rezeptoren und seine Stimulation durch den spezifischen Liganden FasL löst eine intrazelluläre Signalgebung aus, die zum apoptotischen Zelltod führt. Die Bindung des FasL führt zur Homotrimerisierung des Rezeptors, wodurch es zur Bildung des so genannten death inducing signaling complex (DISC) und damit der Initiierung von Effektormechanismen des programmierten Zelltodes (Apoptose) kommt. Allerdings lassen sich Apoptosevorgänge ex vivo im RA-Synovialgewebe nur in sehr geringem Ausmaß trotz hoher FasL-Konzentrationen im chronisch entzündeten Gelenkkompartiment nachweisen, weshalb ein Charakteristikum von synovialen RA-Fibroblasten ihre 
hohe Apoptose-Resistenz ist, die kritisch zur Ausbildung eines hyperplastischen aggressiven Pannus in der RA beiträgt.

Calmodulin ist ein in Eukaryonten hochkonserviertes, kleines (17 kDa), zytosolisches, ubiquitäres $\mathrm{Ca}^{2+}$ Bindungsprotein. Es ist der wichtigste $\mathrm{Ca}^{2+}$-Sensor in Zellen und kritisch an der $\mathrm{Ca}^{2+}$ Signaltransduktion beteiligt. Dabei bildet die durch $\mathrm{Ca}^{2+}$-Ionen Bindung induzierte $\mathrm{Ca}^{2+}$-Konformation des Calmodulins die für Protein-Protein Interaktionen am häufigsten beteiligte Molekülstruktur, mit einer Bindungskapazität für eine große Anzahl von Proteinen in der Zelle. Aus den entsprechenden Interaktionen mit Phosphatasen und Proteinkinasen, einschließlich Src, resultieren regulierende Wirkungen von Calmodulin auf intrazelluläre Signalkaskaden.

\section{Zielsetzung}

Das Ziel der Arbeit war es, die grundlegenden Mechanismen einer ADAM15-mediierten Transformation von Apoptose-Stimuli ausgelöst durch Stimulation des Fas Rezeptors in intrazelluläre Überlebenssignale in synovialen Fibroblasten von RA Spendern (RASFs), zu untersuchen. Neben der Identifizierung von Proteinen, die den „Crosstalk“ von ADAM15- und Fas/CD95-mediierter Signaltransduktion vermitteln, sollten auch pharmakologische Möglichkeiten der Interferenz in den ADAM15-abhängigen Signalwegen getestet werden, mit dem Ziel neue potenziell therapeutisch umsetzbare Strategien zur Sensibilisierung pathogener RASFs für die FasL-induzierte Apoptose zu identifizieren.

\section{Ergebnisse und Diskussion}

In der vorliegenden Arbeit konnte gezeigt werden, dass die Herabregulation von ADAM15 mittels siRNAs zu einer signifikant erhöhten Caspase 3/7 Aktivität nach Stimulation des Fas Rezeptors in RASFs führt. Ebenso wiesen Chondrozyten Zelllinien, die permanent mit dem kompletten ADAM15 transfiziert sind, eine signifikant erniedrigte Caspase 3/7 Aktivität nach Fas Rezeptor Stimulation auf im Vergleich zu Vektor- oder mit einer Deletionsmutante von ADAM15 ohne die zytoplasmatische Domäne $(\Delta \mathrm{C})$-transfizierten Chondrozyten, und unterstreichen damit die Bedeutung der zytoplasmatischen Domäne für eine gesteigerte Apoptose Resistenz.

Weiterhin führte die Stimulation des Fas Rezeptors in ADAM15-transfizierten Chondrozyten zur Phosphorylierung und Aktivierung von Src am Tyrosin Y416 sowie zur Phosphorylierung von FAK an Y576/577 und Y861 -die Tyrosinreste, die von Src phosphoryliert werden können. Jedoch wiesen Zellen, die mit der ADAM15 Deletionsmutante $(\Delta \mathrm{C})$ oder dem Kontroll-Plasmid transfiziert waren, keinerlei Aktivierung beider Kinasen nach Fas Rezeptor Stimulation auf. Diese Ergebnisse führten zur Hypothese der funktionellen Bedeutung einer noch nicht identifizierten Adaptorprotein-Interaktion in der über die Fas-Rezeptor Stimulation induzierte Src und FAK Phosphorylierung, für deren 
Zustandekommen die Expression des kompletten ADAM15-Proteins eine unabdingbare Voraussetzung ist.

Die Stimulation des Fas/CD95-Rezeptors führt $\mathrm{zu}$ einem $\mathrm{Ca}^{2+}$-Einstrom aus dem extrazellulären Kompartiment über sogenannte CRAC/Orai1-Kanäle (calcium release-activated $\mathrm{Ca}^{2+}$ channel) ins Zellinnere. Deshalb wurde zunächst untersucht, ob eine Hemmung des $\mathrm{Ca}^{2+}$-Einstroms oder des $\mathrm{Ca}^{2+}$-Sensors Calmodulin die ADAM15-abhängigen Phosphorylierungen von FAK und Src beeinflusst. Als Inhibitoren der $\mathrm{Ca}^{2+}$-abhängigen Signaltransduktion wurden der Calmodulin Inhibitor Trifluoperazin (TFP) sowie der CRAC Antagonist BTP-2 eingesetzt. Die Ergebnisse zeigten, dass KoInkubationen von TFP bzw. BTP-2 mit FasL die Phosphorylierung von Src und FAK effizient inhibieren konnten und unterstreichen damit die funktionelle Bedeutung von Calmodulin für die ADAM15-abhängige und Fas Rezeptor-mediierte Aktivierung der beiden Kinasen, Src und FAK.

Um nachzuweisen, ob die an der Fas Rezeptor-induzierten Signalgebung beteiligten Kinasen, Src und FAK, wie auch der Fas Rezeptor selbst an Calmodulin binden und damit potenziell in einem Proteinkomplex aggregieren können, wurden Pull-down Experimente mit Calmodulin-konjugierter Sepharose in ADAM15-, $\triangle \mathrm{C}$ - und Vektor-transfizierten Zellen sowie in RASFs in Gegenwart von $\mathrm{Ca}^{2+}$ oder EDTA durchgeführt. In allen analysierten Zelltypen konnte Src an Calmodulin sowohl in der Anwesenheit von $\mathrm{Ca}^{2+}$-Ionen als auch EDTA binden. Allerdings wurden in allen PulldownExperimenten die stärksten Signale von präzipitiertem Src in den mit dem kompletten ADAM15transfizierten Zellen nachgewiesen, was auf die essenzielle Bedeutung von ADAM15 für die Src/Calmodulin Bindung hinwies. Ebenso konnte auch eine $\mathrm{Ca}^{2+}$-unabhängige Bindung von FAK an Calmodulin in allen Chondrozyten Zelllinien und RASFs detektiert werden. Auch Fas/CD95 kann an Calmodulin binden, jedoch ist die Bindung strikt abhängig von der Anwesenheit von $\mathrm{Ca}^{2+}$-Ionen.

Zudem konnte eine direkte Bindung von ADAM15 an Calmodulin sowohl mittels Pull-down Experimenten an Calmodulin-Sepharose als auch durch Protein Bindungsstudien unter Einsatz der rekombinanten zytoplasmatischen Domäne von ADAM15 und Calmodulin gezeigt werden. Analog zur Fas/Calmodulin Bindung war die ADAM15/Calmodulin Bindung ebenfalls strikt abhängig von der Anwesenheit von $\mathrm{Ca}^{2+}{ }_{-}$-Ionen, da EDTA wie auch TFP die ADAM15/Calmodulin Interaktion effizient inhibieren konnten.

Mittels Ko-Immunpräzipitationen konnte gezeigt werden, dass die Stimulation des Fas Rezeptors in vitro zu einer Bindung von Calmodulin an ADAM15 wie auch an Fas/CD95 führt, die jedoch in unstimulierten Zellen nicht nachweisbar war. Diese induzierten Interaktionen konnten durch TFP gezielt gehemmt werden, was darauf hindeutet, dass die $\mathrm{Ca}^{2+}$ Konformation von Calmodulin wichtig für die Interaktion mit ADAM15 und Fas/CD95 ist. Darüber hinaus konnte in lebenden Synovialfibroblasten mittels Doppel-Immunfluoreszenzfärbungen gezeigt werden, dass die Stimulation 
des Fas Rezeptors mit FasL oder einem Fas Rezeptor aktivierenden Antikörper zu einer Rekrutierung von Calmodulin sowohl an ADAM15 als auch an den Fas Rezeptor in „Flicken-artig“ angeordneten Strukturen an der Zellmembran führt, welche in unstimulierten Zellen nicht detektierbar war.

Außerdem konnte durch Doppel-Immunfluoreszenzfärbungen sowie Ko-Immunpräzipitationsstudien gezeigt werden, dass die Stimulation des Fas Rezeptors zu einer Assoziation von ADAM15 mit Fas/CD95 führt, die jedoch in unstimulierten Zellen nicht nachweisbar war. Dabei übte die Calmodulin Inhibition durch TFP keine hemmende Wirkung auf die durch Fas-Aktivierung ausgelöste ADAM15/Fas Interaktion aus.

Zusammengefasst stellen die Ergebnisse dieser Arbeit folgendes Szenario dar: Durch die Bindung von Fas-Liganden an Fas-Rezeptoren, kommt es zu ihrer Homotrimerisierung bzw. zum weiteren Clustern von Trimeren, welche von fokal limitierten $\mathrm{Ca}^{2+}$-Einströmen in die Zelle über CRAC/Orai1-Kanäle begleitet werden und so die Ausbildung des für die Exekution der Apoptose kritischen DISC-Komplexes verzögern. Nach der Fas-Stimulation erfolgt eine Translokation von ADAM15 in die Mikrodomäne des sogenannten CD95-Caps in der Zellmembran. Calmodulin und Src werden in Abhängigkeit von $\mathrm{Ca}^{2+}$-induzierten Calmodulin-Konformationsänderungen an die Plasmamembran rekrutiert, wo sie an ADAM15 und den Fas-Rezeptor binden. Anschließend assoziiert FAK mit ADAM15, wodurch es in der Lage ist, mit Calmodulin-gebundenem Src zu interagieren, welches FAK an seinen Tyrosinresten Y576 und Y861 phosphoryliert. Die durch FasL-induzierte Bildung von ADAM15-abhängigen 'Überlebenssignal-Komplexen' in der PlasmamembranMikrodomäne des CD95-Caps, kann entweder durch die Blockade des $\mathrm{Ca}^{2+}$ - Einstroms mittels BTP-2 oder des $\mathrm{Ca}^{2+}$-Sensors Calmodulin mittels TFP verhindert werden, so dass es nicht zur Phosphorylierung von Src und FAK kommt.

In zusätzlichen Untersuchungen zur Wirkung von TFP und BTP-2 auf eine ApoptoseInduktion in Synovialfibroblasten von 10 Patienten mit RA, konnte mittels der Apoptose Assays, einer Caspase 3/7 Bestimmung und dem immunzytologischen Nachweis von Annexin V, keine Apoptoseinduzierende Wirkung für beide Inhibitoren unter Bedingungen einer isolierten Gabe gezeigt werden. Jedoch ließ sich unter Bedingungen der Koinkubation der jeweiligen Inhibitoren mit FasL eine synergistisch verstärkte Apoptoserate $(\sim$ 80\%) gegenüber der alleinigen Apoptose-induzierenden Wirkung des FasL ( 50\%) nachweisen. Darüber hinaus war die zusätzliche Herabregulation von ADAM15 mittels siRNAs mit einer weiteren signifikanten Steigerung der durch Inkubation mit FasL/TFP oder FasL/BTP-2 induzierten Apoptose-Raten verbunden. In den mit ADAM15-spezifischer siRNA vorbehandelten RASFs löste die alleinige Zugabe von TFP oder BTP-2 keine über Erhöhungen der Caspase-Aktivität detektierbaren Apoptosevorgänge aus. Allerdings resultierte eine FasLStimulation dieser RASFs mit herunterregulierter ADAM15 Expression in einer signifikanten 
Steigerung ihrer Caspase Aktivität, die unter Inkubationsbedingungen mit zusätzlicher Exposition zu TFP oder BTP-2 noch verstärkt werden konnte.

Somit ist ADAM15 entscheidend an der Entstehung $\mathrm{Ca}^{2+}$-gesteuerter Überlebenssignale nach Aktivierung des Zelltod-auslösenden Fas Rezeptors beteiligt und unterstreicht die kritische Bedeutung von ADAM15 für die pathogenetisch relevante Apoptose-Resistenz von RA Synovialfibroblasten.

\section{Zusammenfassung und Ausblick}

Zusammengefasst zeigen diese Ergebnisse, dass ADAM15 die wichtige Funktion eines Adaptorproteins für die Bildung Calmodulin-abhängiger Proteinkomplexe, die nach Aktivierung des Fas Rezeptors und des damit gekoppelten Einstroms von $\mathrm{Ca}^{2+}$-Ionen durch CRAC/Orai Kanäle signifikant verstärkt Überlebenssignale vermitteln, zukommt. ADAM15 stellt damit eine neue potenzielle Zielstruktur für therapeutische Interventionen dar, um die Apoptose Resistenz von Synovialfibroblasten als einem kritischen pathogenetischen Faktor der Gelenkdestruktion in der RA zu brechen.

Das in dieser Arbeit aufgrund seiner Calmodulin-blockierenden Wirkung eingesetzte TFP ist ein von der „Food and Drug Administration“ zugelassenes antipsychotisch wirkendes Medikament mit bevorzugter therapeutischer Anwendung im Indikationsgebiet der Schizophrenie. Darüber hinaus konnte kürzlich gezeigt werden, dass TFP das metastatische Potenzial von Krebszellen inhibieren kann, indem es Überlebenssignalwege, die abhängig von der Akt-Kinase vermittelt werden, moduliert. Dabei führte die Inaktivierung von Akt in TFP behandelten Prostatakarzinom-Zellen zu einer Verminderung der $\beta$-Catenin-Phosphorylierung und verhinderte so seine Translokation in den Zellkern mit einer resultierenden reduzierten Expression des vaskulären endothelialen Wachstumsfaktors (VEGF) und einer eingeschränkten Zellmigration. Diese in den Tumorzellen pharmakologisch gehemmten Prozesse der Zellmigration und Angiogenese sind auch für die Gelenkdestruktion durch das entzündlich veränderte Synovialgewebe in der RA relevant. Für Wirkstoffe aus der Gruppe der CRACAntagonisten, zu der die in unseren Studien verwendete Substanz BTP-2 gehört, konnte kürzlich ihr antiarthritisches Potenzial im Mausmodell der kollageninduzierten Arthritis über eine Verbesserung der Gelenkentzündung, der Schmerzlinderung und einer 50\%igen Reduzierung der strukturellen Gelenkschäden nachgewiesen werden.

Die in dieser Arbeit identifizierte Bedeutung von Calmodulin und CRAC/Orai1-Kanälen als potenzielle Zielstrukturen einer pharmakologischen Sensibilisierung pathogener RASFs für FasLinduzierte Apoptosevorgänge könnte dazu dienen, weitere Studien mit dem Ziel der Etablierung neuer Behandlungsoptionen der RA anzuregen. 


\section{Introduction}

\subsection{Rheumatoid Arthritis}

Rheumatoid arthritis (RA) is a chronic, systemic, autoimmune disease with a worldwide prevalence of about $1 \%$ in the population (Majitha et al., 2007). The disease is most commonly associated with the inflammation of articular joints, which eventually can lead to severe joint destruction and disability (Aletaha and Smolen, 2018). A synovial joint connects two bones that are covered with hyaline cartilage to provide protection of the bony structures against damage by friction and pressure forces during movement (BC Open Textbook project, Anatomy and Physiology, OpenStax College, 2013). Synovial joints are characterized by the presence of a joint cavity, which is formed by the articular joint capsule, a fibrous connective tissue structure that is attached to each bone just outside the area of the bone's articulating surface (Fig. 1). A thin synovial membrane is lining the inner surface of the articular capsule. The lining layer of the synovial membrane consists of $1-2$ cell layers, which secretes a hyaluronic acidrich synovial fluid that provides lubrication for the joints (Mow et al., 1992). In rheumatoid arthritis, the chronic inflammatory process is initiated and maintained by cells of the innate and adaptive immune system, like T cells, B cells and monocytes, which are also able to infiltrate the synovial membrane in multiple joints (Müller-Ladner et al., 2005; Smolen et al, 2016). The expansion of the synovial fibroblast-like and macrophage-like cells leads to a hyperplastic synovial lining layer, the so-called "pannus," which invades cartilage tissue and the periarticular bone at the cartilage-bone junction, thus leading to bone erosions and cartilage degradation (Fig. 1) (Bartok and Firestein, 2010; Aletaha and Smolen, 2018). During inflammation, the synovial fibroblasts get activated by pro-inflammatory cytokines, chemokines and growth factors, which are secreted by immune cells, and produce themselves an array of cytokines and chemokines (Scrivo et al., 2007; Bartok and Firestein, 2011). Particularly, the cytokines, interleukin-1ß and TNF $\alpha$ (tumor necrosis factor), directly stimulate the production of matrix-degrading enzymes, such as matrix metalloproteinases, leading to the degradation of extracellular matrix (Ospelt, 2017; Müller-Ladner et al., 2005; McInnes, 2011). In addition, the release of cytokines and chemokines by synovial fibroblasts leads to the stimulation of leukocytes, creating a paracrine/autocrine network which drives the progression of the disease (Liu and Pope, 2004; Lefevre et al., 2015).

Taken together, the RA synovial fibroblasts, due to their unusually aggressive phenotype, their ability to contribute to the propagation of inflammation and tissue destruction, are a major interest in RA pathogenesis research. 


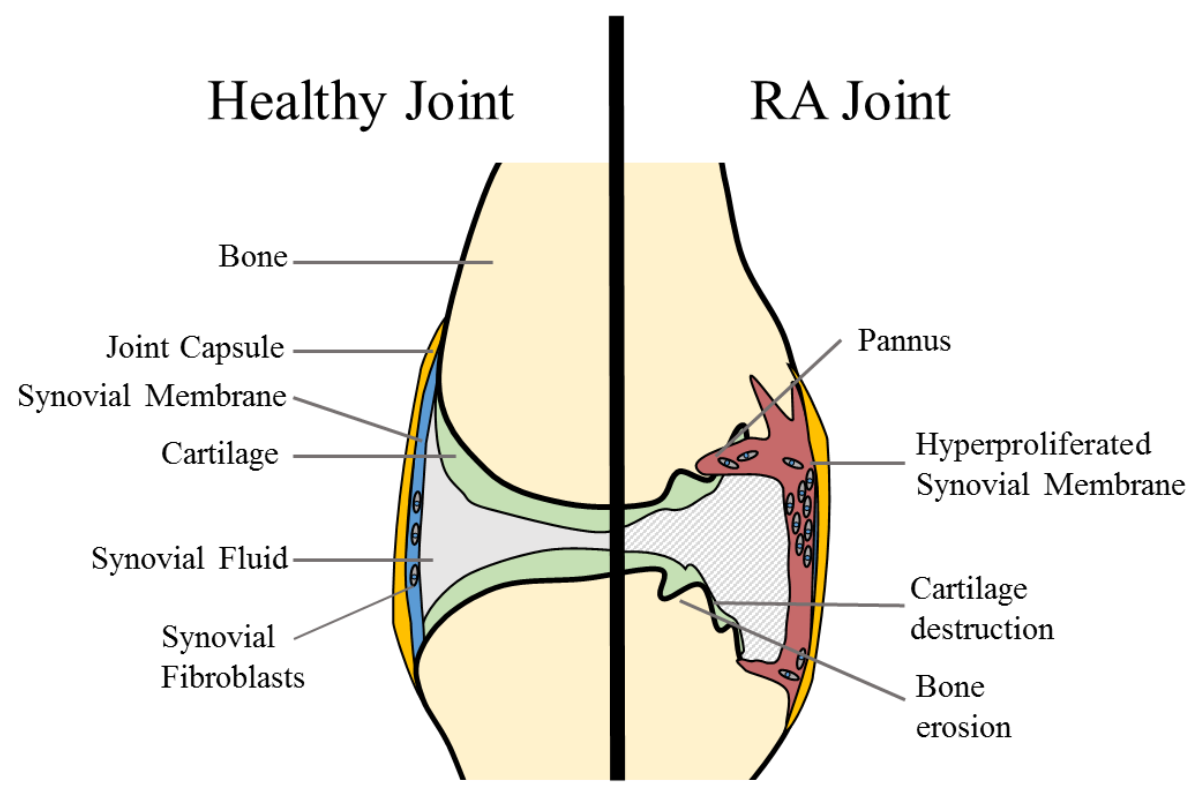

Fig. 1. Schematic diagram of an articular synovial joint. An articular joint connects two bones, which are covered by hyaline cartilage. A joint capsule surrounds the joint and is lined with the synovial membrane, which is directed to the lumen of the joint. In the normal, healthy joint, the lining layer of the synovial membrane is $1-2$ cell layers thick. In inflamed RA joints, the synovial membrane becomes hyperplastic, forming a so-called pannus, which infiltrates cartilage and bone, leading to the destruction of the joint.

\subsubsection{Apoptosis resistance of Rheumatoid Arthritis Synovial Fibroblasts (RASFs)}

The cardinal characteristic of RASFs in the inflamed hyperplastic synovial membrane is their resistance to apoptosis (programmed cell death) (Malemud, 2012). In RA, the hyperplasia of the synovial membrane is the result of an imbalance between cell proliferation and cell death (Bartok and Firestein, 2011; Smolen et al., 2018). Apoptotic cell death is rarely detected in RA synovial fibroblasts, but the occurring apoptosis is mainly mediated via members of the tumor necrosis factor (TNF) superfamily, including the Fas receptor (CD95) a potent and well described death receptor, which is expressed on the surface of synovial fibroblasts (Firestein et al., 1995; Matsumoto et al, 1996; Liu and Pope, 2004).

So far, no genetic mutations responsible for the hyperactive phenotype of RASFs and their resistance to apoptosis have been detected (Karouzakis et al., 2014). Nevertheless, RASFs display a transformed phenotype and utilize multiple mechanisms to avoid programmed cell death (Liu and Pope, 2004). Thus, an upregulation of FLICE inhibitory protein (FLIP), which 
- as a nonfunctional homologue of caspase 8 - hetero-oligomerizes with caspase 8 , thereby reducing its activation, was shown to have a protective effect on RA synovial fibroblasts (Kobayashi et al., 2000; Palao et al., 2004). Also, the expression of sentrin, an anti-apoptotic molecule expressed at sites of synovial invasion, as well as members from the anti-apoptotic Bcl-2 protein family, Bcl-Xl and Mcl-1, confer anti-apoptotic functions (Franz et al., 2000; Jiao et al., 2018). The upregulation of the two latter proteins was dependent on the activation of PI3K/Akt and STAT3 signal pathways, thereby promoting survival signaling.

Furthermore, the disintegrin metalloproteinase ADAM15, which is markedly upregulated in the inflamed, hyperplastic synovial membrane in RA (Böhm et al., 2001), has also been found to confer an anti-apoptotic effect in RASFs upon stimulating the Fas receptor with FasL (Böhm et al., 2013). Triggering of Fas/CD95 initiates programmed cell death by forming the death-inducing signaling complex (DISC) (Malemud et al., 2015). However, in RASFs expressing ADAM15 the stimulation of Fas/CD95 leads to enhanced phosphorylations of the kinases, Src and focal adhesion kinase (FAK), as well as an upregulation of Nf- $\kappa \mathrm{B}$ (Böhm et al., 2013), thus showing that ADAM15 is a major contributor to the apoptosis resistance of RASFs. Moreover, XIAP (X-Linked inhibitor of apoptosis), an inhibitor of activated caspase 3 , is strongly upregulated by ADAM15 in human chondrocytes subjected to genotoxic stress (Böhm et al., 2010).

In recent years the progress in the understanding of cytokine neworks that keep the inflammatory process in the RA-joints active has fueled the development of disease-modifying anti-rheumatic biologic drugs (bDMARDs) considerably and resulted in dramatically improved treatment outcome (Lefevre et al., 2015). However, despite the progress that has been achieved the presently available bDMARDs in clinical use do not address the apoptosis resistance of RASFs as a critical mechanism of joint destruction and accordingly cannot provide cure of the disease. Therefore, the development and discovery of novel agents that target the appropriate dysfunctional apoptosis-related pathways as a characteristic of RA synovium represents a medical need requiring intensified research activities (Ramiro et al., 2016).

\subsection{The Disintegrin and Metalloproteinase protein family (ADAMs)}

The disintegrin metalloproteinase ADAM15 belongs to the family of the A Disintegrin And Metalloproteinases (ADAMs). ADAM15 is a transmembrane protein and is 814 amino acids long with a molecular weight of approximately $100 \mathrm{kDa}$. The ADAM protein family is classified under the superfamily of metalloproteinases, the metzincins (Giebeler and Zigrino, 2016). The family of the ADAM proteins belong to the M12 Adamalysin subfamily of 
metalloproteinases, which comprises also the snake venom metalloproteases (SVMPs) and the protein family of the disintegrin and metalloproteinases with thrombospondin motif (ADAMTS) (Rawlings et al., 2008). All members of the ADAM family are closely related and share the same domain structure (Glassey and Civetta, 2004; Giebeler and Zigrino, 2016). They are composed of a large extracellular part that contains a prodomain, a metalloproteinase domain, a disintegrin domain, a cysteine-rich- and an EGF-like domain, which is followed by the transmembrane domain and the cytoplasmic tail (Fig. 2) (Edwards et al., 2008).

So far, 40 family members have been identified in the mammalian genome, of which 37 are expressed in mice and 20, excluding presumed pseudogenes, are expressed in humans (Takeda, 2016). However, only 12 of the human ADAM members, such as TACE (ADAM17, TNF $\alpha$ converting enzyme) contain a functional catalytic consensus sequence. (Andreini et al., 2005; Khokha et al., 2013). A major function of the catalytic ADAMs is ectodomain shedding of membrane-bound growth factors, receptors, cytokines, chemokines, and proteoglycans (Kelwick et al., 2015; Weber and Saftig, 2012). Another well-characterized feature of ADAMs is their contribution to integrin-mediated cell-matrix and cell-cell interactions via the disintegrin domain (White, 2003). Moreover, growing evidence suggests that some ADAMs, e.g. ADAM17 and ADAM15, exert an influence on cell signal transduction. Thus, ADAM17 was shown to interact with Src and promote tumorigenesis by influencing EGFR and ERK signaling pathways (Maretzky et al., 2011). Also, ADAM15 has been shown to elicit the phosphorylation of Src and FAK upon triggering the Fas receptor as well as upon genotoxic stress induction by camptothecin (Böhm et al, 2013; Fried et al., 2012; Janczi et al., 2018) 


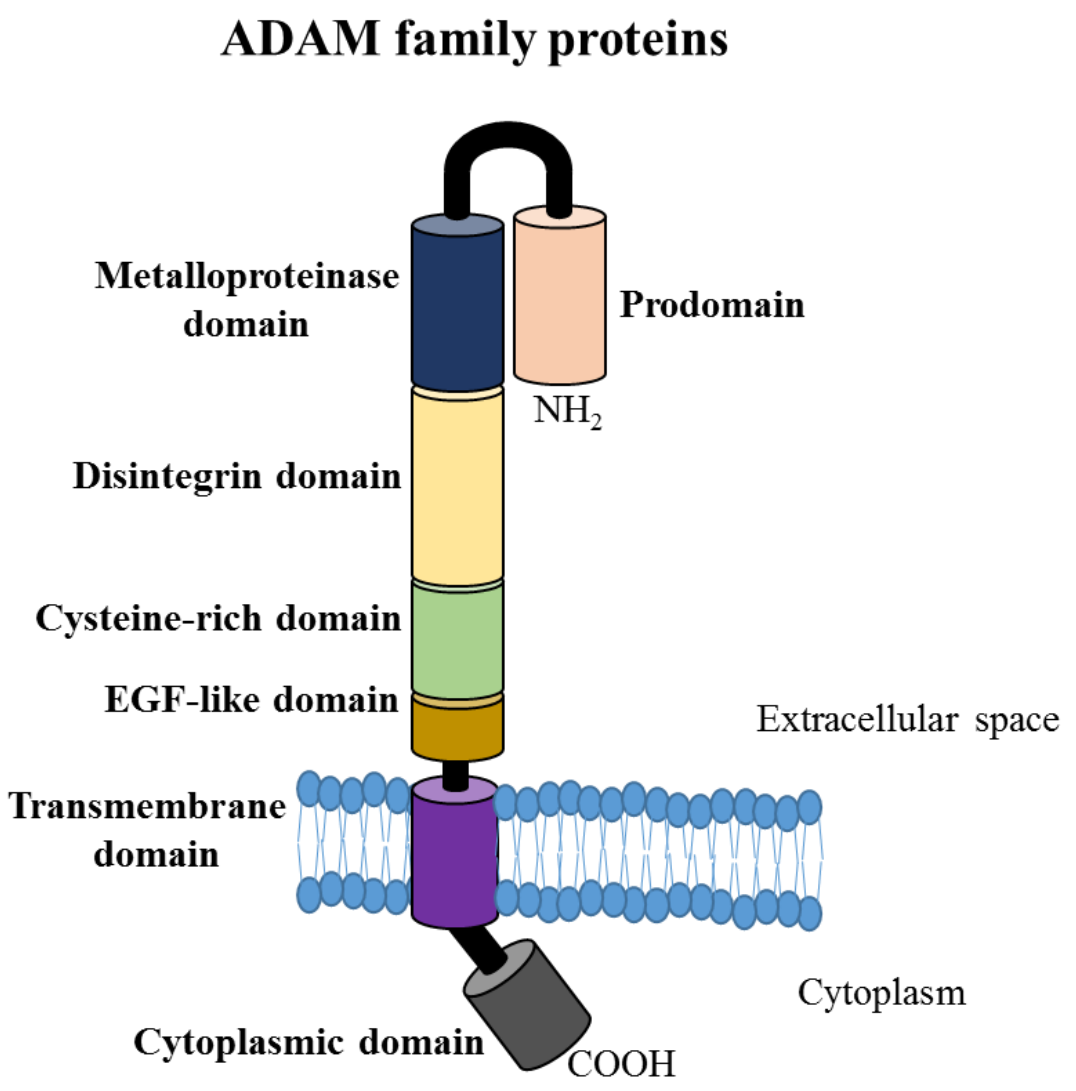

Fig. 2. Structure of the ADAM family metalloproteinases. ADAMs consist of the prodomain, metalloproteinase domain, disintegrin domain and cysteine-rich domain in the extracellular part. All ADAM proteins are cell membrane anchored and possess a cytoplasmic domain.

\subsubsection{Prodomain}

The prodomain in ADAM15 spans a region of approximately 200 amino acid residues and sequence comparison with the prodomains of other ADAMs reveals only a minor degree of homology (Seals and Courtneidge, 2003). Primarily, the prodomain keeps the adjacent metalloprotease domain of matrix metalloproteinases (MMPs) or ADAMs proteolytically inactive, through a so-called "cysteine-switch" mechanism (Van Wart and Birkedal-Hansen, 1990; Grams et al., 1993). All prodomains possess a critical cysteine residue within a conserved motif, which is coordinated to the active-site zinc atom of the metalloproteinase domain in a fashion that blocks the active site (Milla et al., 1999). The proteolytic removal of the prodomain by furin-type serine proteinases leads to the dissociation of the cysteine from the zinc atom and subsequent activation of the metalloproteinase (Schlöndorf et al., 2000; Gomis-Rüth, 2003).

The prodomain of ADAM15 is unique among all ADAM prodomains, as it contains a type II fibronectin collagen- binding domain and a fibronectin type III repeat, which are motifs 
for specific binding to fibronectins and collagens, thereby suggesting that the prodomain might confer binding capabilities to extracellular matrix molecules (Böhm et al., 2009).

\subsubsection{Metalloproteinase domain}

Although the physiological importance of the catalytic function of ADAM15 is still unclear, it has been demonstrated that can be catalytically active (Maretzky et al., 2009; Najy et al., 2008a). ADAMs can be divided into catalytically inactive as well as proteolytically active members (Takeda, 2016). Their catalytic activity comprises the proteolytic cleavage of other transmembrane proteins, such as growth factor receptors or cytokines, at the cell surface (Giebeler and Zigrino, 2016). The catalytic site contains a consensus HEXXHXXGXXH sequence, which is found not only in members of the ADAM family, but also in members of the matrix metalloproteinases (MMP), (Gomis-Rüth, 2009). In humans, several ADAMs, such as ADAM10 and ADAM17, possess this consensus motif (Dreymueller et al., 2015). ADAM10, together with ADAM17, are considered the main ADAM family members to cleave ectodomains of membrane proteins (Kleino et al., 2009; Sahin et al., 2004). ADAM17 (also named TNF $\alpha$-converting enzyme, TACE) was first discovered as a protease cleaving the membrane-bound proform of the pro-inflammatory cytokine TNFa (Black et al., 1997). ADAM17 is considered to be the sheddase with an extremely broad substrate range, cleaving transmembrane growth factors and growth factor receptors, or cytokines (Blobel, 2005).

Although ADAM15 also contains the MMP consensus motif, its repertoire of proteins that are cleaved is of much smaller size. A study analyzing the proteolytic capacity of the recombinant ADAM15 metalloproteinase domain on a library of peptide substrates did not reveal processing of any of the peptide substrates tested, however, in cell based assays cleavage of fibroblast growth factor receptor2 IIIb (FGFR2IIIb) was detected (Maretzky et al., 2009).

The list of substrate proteins for ADAM15 includes several key cell regulatory molecules, including growth factors, such as transforming growth factor $\beta$ (TGF $\beta$ ), and from the family of the epidermal growth factors, the heparin-binding epidermal growth factor (HB-EGF), amphiregulin and epiregulin (Lorenzatti Hiles et al., 2016). In particular, the shedding of the cell adhesion protein E-cadherin by ADAM15 has been shown to be associated with the progression of prostate cancer (Najy et al., 2008a). E-cadherin is an cell-cell adhesion molecule, which is involved in the formation of adherens junctions that are pivotal in embryonic development, epithelial cell behavior, tissue formation and wound healing (van Roy and Berx, 2008; Baum et al., 2011). In breast cancer cells, ADAM15 cleavage of E-cadherin with the release of a proteolytic fragment that can bind to the human epidermal growth factor receptor 
2 (ErbB2) has been demonstrated, suggesting a role of ADAM15 sheddase activity as an initiator of an autocrine cancer signaling loop (Najy et al., 2008b).

\subsubsection{Disintegrin domain}

The "disintegrin" terminology was initially applied in 1990 to describe a family of cysteine-rich proteins, which were found in snakes venoms by interacting with the platelet integrin $\alpha \operatorname{IIb} \beta 3$, thereby inhibiting platelet aggregation and contributing to the hemorrhagic effect of some snake venoms (Blobel and White, 1992; Gould et al., 1990).

The disintegrin domain of human ADAM15 contains an integrin binding RGD (ArgGly-Asp) motif in the disintegrin domain and plays an important role in cell adhesion (Ham et al., 2002; Lu et al., 2006). This unique RGD motif serves as an integrin ligand binding site, through which it plays a pivotal role in interacting with integrin receptors, a large family of heterodimeric transmembrane glycoproteins (Lu et. al, 2010). Integrins function as adhesion receptors and exist as heterodimers, which are formed from one $\alpha$ chain and one $\beta$ chain each (Hynes, 2002). In mammals, 18 distinct $\alpha$ subunits and $8 \beta$ subunits give rise to 28 different heterodimers (Takada et al., 2007). The disintegrin domain of ADAM15 increases cell-matrix adhesion in an RGD-motif dependent manner by binding to integrins $\alpha \mathrm{V} \beta 3$ and $\alpha 5 \beta 1$ (Kratzschmar et al., 1996, Nath et al., 1999, Charrier et al., 2007, Lu et al., 2010). The binding of ADAM15 to the $\alpha 9 \beta 3$ and $\alpha 9 \beta 1$ integrins, however, has been shown to be in an RGDindependent manner (Edwards et al., 2008).

It was shown in in vitro functional cell adhesion and proliferation assays that the recombinant disintegrin domain of ADAM15 exhibited inhibitory activities, by blocking endothelial cell migration as well as most capillary formation in a three-dimensional fibrin gel (Trochon-Joseph et al., 2004). Moreover, the stimulation of melanoma cancer cells with the recombinant disintegrin protein resulted in the phosphorylation of p38 kinase, a mitogen activated protein kinase (MAP), thereby inhibiting melanoma cell proliferation (Wu et al., 2008).

\subsubsection{Cysteine-rich and EGF-like domains}

The cysteine-rich domains of ADAMs are typically 80-150 amino acids long (Takeda et al., 2006). This domain complements the disintegrin domain in driving cell adhesion, but also, together with the disintegrin domain, mediates non-integrin-mediated binding by associating with heparansulfate proteoglycans (Thodeti et al., 2003; Edwards et al., 2008; 
Giebeler and Zigrino, 2016). Furthermore, the cysteine-rich domain contains a highly variable region, which is believed to participate in the recognition of protein binding partners (Takeda et al., 2006). The crystal structure of ADAMTS-1 revealed that the cysteine-rich domain is stacked against the metalloproteinase domain, thus affecting its substrate binding (Gerhardt et al., 2007). Moreover, the cysteine-rich domain of ADAM17 was shown to be crucial for the recognition and cleavage of the IL-6 and IL-1 receptors. It was, however not necessary for ADAM17 to bind and cleave TNF- $\alpha$ (Lorenzen et al., 2012).

Following the cysteine-rich domain, most ADAMs have an EGF-like domain (Edwards et al., 2008). It is a domain of approximately 50 amino acids that is present in all ErbB receptors, which belong to the EGFR family, and in some ECM proteins (Blobel, 2005). There are indications that the EGF-like domain is involved in substrate specificity of certain ADAMs and it has been demonstrated that EGF-like domains are necessary for the oligomerization of ADAM17, however, underlying mechanisms responsible for the effects of EGF-like domains remain to be uncovered (Takeda et al.,2016).

\subsubsection{Cytoplasmic domain}

The length and sequence composition of the cytoplasmic domain of ADAMs is highly diverse (Lu et al., 2010). The ADAM cytoplasmic domains have been shown to interact with proteins involved in intracellular signaling, trafficking and cytoarchitecture (Edwards et al., 2008).

Several family members, e.g, ADAM 10, 12, 15, and 17 possess proline-rich PXXP motifs, which are well conserved in ADAMs, despite the low overall sequence identity of the ADAM cytoplasmic domains (Edwards et al., 2008). The cytoplasmic domain of ADAM15 has 13 proline-rich motifs, which is the highest of all ADAM family members (Edwards et al., 2008). Proteins of the Src kinase family, which possess Src homology 2 (SH2) and Src homology 3 (SH3) motifs, can bind to these proline-rich motifs (Zhong et al., 2008; Duffy et al., 2003). Thus, it was shown that Hck and Lck, two members of the Src kinase family (SFKs), specifically bind to the cytoplasmic domain of ADAM15 in an SH2 and SH3 domain-dependent manner in cells of hematopoietic origin (Poghosyan et al., 2002). A protein binding assay using recombinant proteins containing SH3 motifs revealed that the SFK kinases, Src, Lyn and Yes, also interact with ADAM15 (Kleino et al., 2009). Also, binding of p85a, which is a regulatory subunit of the phosphatidylinositol 3-kinases (PI3K), to the proline-rich regions of ADAM15 in protein binding assays has been detected (Kärkkäinen et al., 2006).

Also, alternative mRNA splicing of exons coding for the cytoplasmic domain was found to influence its interactions with c-Src kinase in breast cancer cells (Zhong et al., 2008). Co- 
immunoprecipitations of breast cancer cells transfected with the diverse ADAM15 isoforms revealed that the most abundant isoform 2 of ADAM15, which constitutes $>90 \%$ of all ADAM15 isoforms expressed in human tissues, does interact only weakly with Src. However, the isoform 1 of ADAM15, which contains an additional exon detected in certain breast cancer cells, displayed stronger binding to Src (Maretzky, 2009). Nevertheless, the expression of both isoforms was associated with worse outcome in patients with breast cancer.

Furthermore, interaction partners of ADAM15, which bind in an SH2/SH3 independent manner, have been detected. Thus, focal adhesion kinase (FAK) was shown to bind the cytoplasmic domain of ADAM15 by pull-down studies and by mammalian two-hybrid assays (Fried et al., 2012). This interaction of ADAM15 in a complex with FAK and Src led to an enhanced phosphorylation of those two kinases upon genotoxic stress induction by camptothecin, thereby contributing to anti-apoptotic signaling. Moreover, it was shown by coimmunoprecipitations and immunofluorescence stainings that cell adhesion triggered a temporo-spatial interaction and colocalization of ADAM15 and the poly(A) binding protein PABP. In addition, ADAM15 and PABP colocalization was detected in focal adhesions at sites of concomitant protein neosynthesis, thereby providing initial evidence for a potential impact of ADAM15 on the regulation of mRNA translation during cell adhesion (Böhm et al., 2018).

In summary, it is hypothesized that the cytoplasmic domain of ADAM15 acts as a platform for assembly of various signaling molecules, such as FAK or Src family kinases, which leads to the induction of signaling pathways associated with growth, invasion and metastasis in cancer cells but also with resistance to apoptosis induced by various stimuli (Zhong et al., 2008; Böhm et al., 2013).

\subsubsection{ADAM15 in disease}

ADAM15 has been implicated in several pathological conditions, involving inflammatory diseases and cancer (Duffy et al., 2009). Thus, an upregulated ADAM15 expression has been detected in melanoma, breast-, bladder-, pancreas-, and prostate cancers (Blobel, 2005; Kuefer et al., 2006; Lucas and Day, 2007; Yamada et al., 2007; Lucas and Day, 2009; Ungerer et al., 2010; Burdelski et al., 2017). In breast cancer, expression of ADAM15 has been associated with an aggressive and invasive phenotype (Zhong et al., 2008). The expression of matrix metalloproteinase-1 (MMP-1) and matrix metalloproteinase-3 (MMP-3) as well as the vascular-endothelial growth factor (VEGF) was demonstrated to be dependent on ADAM15 in pancreatic cancer cells, which implicated ADAM15 in the remodeling of the extracellular matrix (ECM) associated with the inflammation and with the neovascularization required for tumor growth (Alers et al., 2000; Gao et al., 2015). It was also demonstrated that 
in PC-3 cells, a prostate cancer cell line displaying high tumorigenicity and metastatic potential, ADAM15 mediates the cleavage and release of N-cadherin, thereby promoting migration of tumor cells (Lucas and Day, 2009). Also, ADAM15 expression was associated with poor prognosis for breast cancer patients (Maretzky et al., 2009). It was elucidated that ADAM15mediated E-cadherin cleavage leads to the release of an $80 \mathrm{kDa}$ soluble form of E-cadherin, which can bind to and activate HER2/neu/ErbB-2 in breast cancer cells, thus leading to the induction of extracellular-signal regulated (Erk) kinase signaling and cell migration (Najy et al., 2008b). More recently, it was unraveled that knockdown of ADAM15 leads to an in vitro reduction of the migratory and invasive properties of human bladder cancer cells (LorenzatiHiles et al., 2016).

The expression of ADAM15 is not only upregulated in tumors but has also been observed in inflammatory diseases, such as intestinal inflammation, atherosclerosis as well as osteoarthritis (OA) and RA (Charrier-Hisamuddin et al., 2008; Böhm et al., 2001; Duffy et al., 2003). In inflammatory bowel disease it was shown that an overexpression of ADAM15 in a colon cell line increased the adhesion of immune cells, thereby suggesting its participation in the leukocyte migration across the intestinal epithelial barrier and thus a disease modifying potential (Mosnier et al., 2006). The enhancing effect of ADAM15 on those heterotypic cellcell interactions was dependent on both the RGD integrin-binding sequence in the disintegrin domain and the presence of the cytoplasmic tail. Furthermore, in atherosclerosis ADAM15 was found to be upregulated in the atherosclerotic lesions of the human carotid arteries as compared to normal, healthy vascular endothelial cells. Those lesions displayed an increased expression of both ADAM15 and $\alpha 5 \beta 1$ and $\alpha v \beta 3$ integrins, which are known ADAM15 binding partners, and its upregulated expression has been suggested to be to be involved in the progression of artherosclerosis (Ikari et al., 2000; Moiseeva, 2001). Another example of an involvement of ADAM15 in an inflammatory disease is the acute lung inflammation, in which ADAM15 has been suggested to affect the inflammatory process by releasing the ectodomain of ADAM10 from the cell membrane, a pleiotropic sheddase involved in the activation of a variety of pathways thereby amplifying the proinflammatory triggers (Tousseyn et al., 2010; Dreymueller et al., 2015).

Moreover, the highly upregulated expression of ADAM15 in cartilage and synovial membranes of osteoarthritis (OA) as well as RA implicated its involvement as an anti-apoptotic protein in inflammatory joint diseases. (Böhm et al., 1999, Böhm et al., 2001). Thus, it was shown that the expression of ADAM15 in chondrocytes and synovial fibroblasts considerably suppressed apoptosis induced by genotoxic stress using camptothecin as well as FasL-induced apoptosis (Böhm et al., 2013, Fried et al., 2012). In RA synovial fibroblasts, the presence of 
ADAM15 led to the activativation of the phosphorylations of phosphatidylinositol 3-kinase (PI3K), focal adhesion kinase (FAK) and Src as well as an upregulation of the transcription factor NF- $\mathrm{NB}$ in response to Fas receptor activation, thereby promoting pro-survival signaling pathways (Böhm et al., 2013; Fried et al., 2012). NF- $\kappa B$ regulates the transcription of genes, which encode proteins inhibiting the apoptotic signaling pathways, thus contributing to the apoptosis resistance of RASFs (Luo et al., 2005, Böhm et al., 2013). In OA chondrocytes it was shown that ADAM15 upregulates the expression of X-linked inhibitor of apoptosis protein (XIAP), which is an inhibitor of activated caspase 3, upon genotoxic stress induction, thereby protecting OA chondrocytes from programmed cell death (Böhm et al., 2010).

\subsection{CD95 (Fas/APO-1) Receptor and FasL}

The Fas receptor (CD95/Apo-1/ /TNFRSF6) is a type I integral membrane protein and belongs to the tumor necrosis receptor death receptor (TNFR) superfamily (Ward-Kavanaugh et al., 2016). The TNFR family consists of more than 40 members in mammalian cells (Kavurma et al., 2008), and comprises TNF-R1 and the death receptors DR3, DR4, DR5, which all contain death domains (DD) in their intracellular part, providing the capacity for proteinprotein interactions with other DD-containing proteins (Guicciardi and Gores, 2009, Quistad and Traylor-Knowles, 2016). The ligation of a specific ligand of the TNF family to a member of the TNF death receptors most commonly is associated with the execution of an apoptotic response. However, the triggering of death receptors, e.g. Fas/CD95, has been shown to also initiate survival signals (Quistad and Traylor-Knowles, 2016).

The stimulation of the Fas receptor (CD95) by its ligand FasL leads to the induction of cellular apoptosis in an array of different cells, such as cancer and immune cells, and also synovial fibroblasts (Kaufmann et al., 2012). The dysregulation of the Fas/FasL axis has been implicated in the pathogenesis of several diseases, such as cancer, cystic fibrosis, and inflammatory joint diseases, like OA and RA (Li et al., 2014). RA synovial fibroblasts have been shown to express Fas/CD95 and other TNF- $\alpha$ receptors (Pundt et al., 2009). The TNFR protein family is responsible for the majority of the cell death observed in the RA synovial membrane (Bartok and Firestein, 2010; Kaufmann et al., 2012). So, increased levels of Fas/CD95 expressed in OA and RA synovial membranes as well as increased concentrations of both soluble Fas receptor and soluble FasL in the serum and synovial fluid of RA patients have been detected (Nozawa et al., 1997; Hashimoto et al., 1998; Bartok and Firestein, 2010).

The Fas receptor is stimulated by its ligand, the FasL, which belongs to the TNF ligand superfamily. Other members of the TNF family include TNF $\alpha$, TRAIL (TNF-related apoptosis- 
inducing ligand) and receptor activator of NF- $\kappa \mathrm{B}$ ligand (RANKL). TNF ligands are synthesized as membrane-bound proforms, which are proteolytically cleaved by metalloproteinases, like TNF $\alpha$-converting enzyme (TACE, ADAM17) and released as soluble molecules (Liu and Pope, 2004). The members of the TNF family have a high structural homology in their ectodomain, which after assembling into trimers forms a highly efficient clustering mechanism for their specific TNFR superfamily receptor (Peter et al., 2007). FasL is expressed in immune cells and predominantly synthesized in activated $\mathrm{T}$ cells, which are involved in inducing apoptosis in target cells (Liu and Pope, 2004; Korb et al., 2009). The membrane-bound FasL can be shed from the cell membrane by metalloproteinases, like MMP3, MMP7, MMP9 or ADAM10 (Matsuno et al., 2001; Vargo-Gogola et al., 2002; Kiaei et al., 2007; Schulte et al., 2007). Both, the membrane-bound and soluble forms of FasL elicit apoptosis in cells expressing the Fas receptor, however soluble FasL is active only, when it is present in a homo-trimerized state (Siegmund et al., 2017).

\subsubsection{Stimulation of Fas/CD95 and DISC formation}

In an unstimulated cell, Fas/CD95 receptor exists as a monomeric, membrane bound protein. Interaction with its trimeric ligand FasL initiates homotrimerization of the inactive monomeric Fas/CD95 and subsequent trimer clustering in a polarized plasma membrane structure, known as the "CD95- Cap', (Fig. 3) (Peter and Krammer, 2003; Malemud et al., 2015). The multimerization of Fas/CD95 results in the formation of the death inducing signaling complex (DISC) at the cytoplasmic domains of Fas receptors (Wang et al., 2010). Upon Fas ligation, the Fas associated death domain protein (FADD), which contains a death domain (DD) and a death effector domain (DED) domain is recruited to Fas/CD95 at the cell membrane. This facilitates further assembly of DED containing proteins, like pro-caspase 8 and receptor interacting protein (RIP), to FADD into the DISC (Dickens et al., 2012). Also, the recruitment of pro-caspase 8 furthers the attraction of more pro-caspase 8 molecules, leading to multimerization and the formation of so-called DED chains, thereby initiating the activation of caspase 8 and subsequently the execution of the caspase cascade (Kaufmann et al., 2012). 

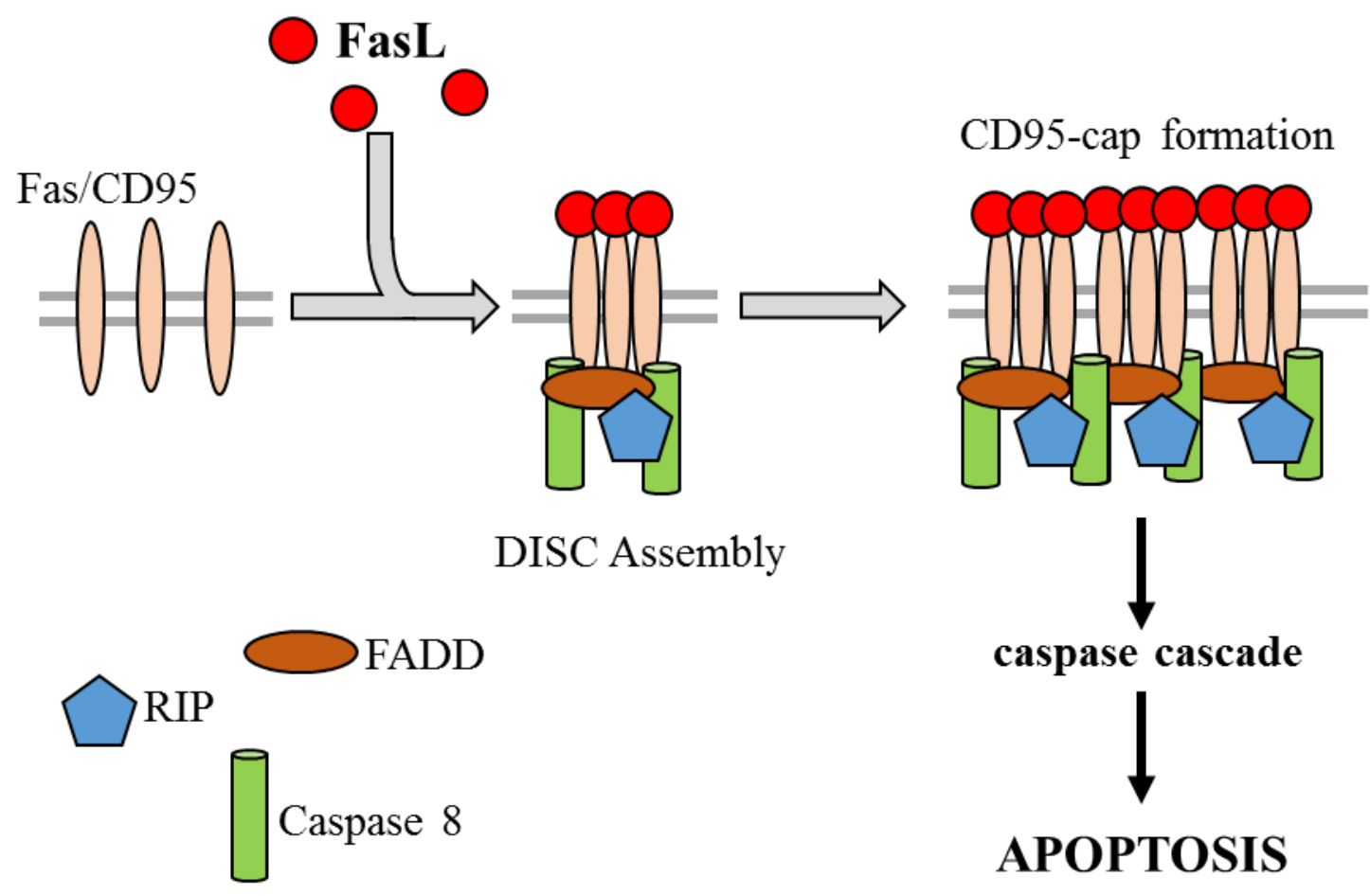

APOPTOSIS

Fig. 3. CD95/Fas-ligation induces pro-apoptotic signaling. Binding of FasL induces the formation of homo-trimerization of Fas/CD95. Subsequently, Fas associated Death Domain (FADD) and receptor interacting protein (RIP) and pro-caspase 8 assemble into a death-inducing signaling complex (DISC) to the Fas homotrimers. The DISC formation enables further clustering of the Fas receptor, forming the so-called 'CD95-cap', thereby leading to the activation of a caspase cascade and execution of apoptosis (programmed cell death).

\subsubsection{Fas/CD95-induced apoptosis}

Programmed cell death (apoptosis) is a highly regulated form of cell death, that is executed by the cells upon stimulation with cell death-inducing factors, such as TNF or FasL but also in response to damage by disease or noxious agents (Elmore, 2007). The execution of apoptosis involves an energy-dependent cascade of molecular events. The main participators of this pathway are the caspases, which are cysteine-aspartic proteases. They can be subclassified into either initiator caspases (caspase-8 and -9) or executioner caspases (caspase-3, -6, and -7) (McIlwain et al., 2013). Upon activation, the initiator caspases cleave off the executor caspases, in a so-called caspase cascade, that perform critical cleavage of specific cellular substrates resulting in the final apoptotic cell death (Tauzin et al., 2011; Pistritto et al., 2016).

The activation of executioner caspases results in DNA fragmentation, as well as cleavage or cross-linking of cytoplasmic proteins. Other changes observed in cells undergoing apoptosis is the redistribution of annexin $\mathrm{V}$ and other cytoplasmic proteins such as calreticulin 
to the outer leaflet of the cell membrane. Recent data have shown that annexin II and V are transported to the cell surface by first binding to negatively-charged suchas phosphatidylserine and phosphatidylethanolamine lipids on the inner leaflet of the membrane before being translocated across to the cell surface together with phospholipids during lipid remodeling (Stewart et al., 2018). Apoptosis leads to morphological changes that include blebbing, cell shrinkage, nuclear fragmentation, chromatin condensation and DNA fragmentation (Lavrik et al., 2014). Ultimately, the blebbing causes the cell fragments to separate into apoptotic bodies, which consist of cytoplasm with tightly packed organelles. These structures are efficiently cleared by phagocytosis mediated mainly by macrophages (Elmore, 2007). Therefore, apoptosis does not propagate inflammation as no cell content is released into the lumen.

Apoptosis is crucial for homeostasis and to balance the amount of newly proliferated cells, billions of cells undergoes apoptosis in the adult human body every day (Kaufmann et al., 2012). Also in tissue development, apoptosis of certain cells is required to create functional structures. In the context of inflammation, apoptosis of immune cells and other cell types involved in the propagation of the disease is necessary for the inflammation to dissipate (Liu and Pope, 2004; McIlwain et al., 2013).

The activation of the Fas receptor induces two distinct pathways of apoptosis (Algeciras-Schimnich, 2002). The first one involves a direct activation of the executioner caspase 3 by the large amounts of active caspase 8 generated at the DISC and is called the extrinsic pathway of apoptosis (Stennicke et al., 1998, Schleich et al, 2012, Dickens et al., 2012). The second, intrinsic apoptotic pathway elicited by Fas triggering depends on the caspase 8-mediated cleavage of a mitochondrial protein Bid, which subsequently leads to an alteration of mitochondrial membrane potential and release of cytochrome $\mathrm{c}$ from the mitochondrium (Peng et al., 2006). This leads to the activation of caspase 9, which belongs to the initiator caspases and can cleave procaspase 3, thereby activating it (Salomoni and Khelifi, 2006; Zhang et al., 2010).

FasL-induced apoptosis is controlled by a complex network of regulators, such as FLIP and XIAP (Lavrik, 2014). Thus, the activation of caspase 8, which is required for both extrinsic and intrinsic pathways, can be inhibited by the recruitment of FLICE interacting protein (FLIP) to the DISC complex (Fricker et al., 2010). FLIP is an enzymatically inactive homologue of procaspase 8 and the formation of the two proteins as heterodimers blocks the activation of the latter, resulting in a reduced release of activated caspase 8 from the DISC (Chang et al., 2002). Also, the X-linked inhibitors of apoptosis proteins (XIAPs) can regulate both the extrinsic and intrinsic apoptotic pathways by blocking the activated caspase 3 and 7. Additionally, the activity of XIAP itself can be inhibited by Smac/DIABLO (second mitochondria-derived 
activator of caspase/direct IAP binding protein with low $\mathrm{pI}$ ), which is released as a result of the induction of the intrinsic apoptosis pathway (Rehm et al., 2006; Kaufmann et al., 2012). Both FLIP and XIAP have been found to be upregulated in RASFs, thereby contributing to the apoptosis resistance of RASFs (Firestein et al., 1995; Liu and Pope, 2004).

\subsubsection{Fas/CD95-triggered anti-apoptosis}

Fas/FasL signaling is not invariably transducing signaling leading to programmed cell death but can also convey pro-survival signals (Strasser et al., 2009). It has been shown that FasL can induce the activation of ERK1/2, p38, JNK, Src and phosphatidylinositol 3-kinase (PI3K)/Akt, thereby activating the anti-apoptotic pathways controlled by these kinases (Krammer et al., 2007; Kober et al., 2011; Yuan et al., 2011; Lavrik and Krammer, 2012; Poissonier et al., 2016). Furthermore, Fas/FasL ligation leads to the activation of NF- $\kappa B$, which in turn causes a transcriptional upregulation of FLIP and another anti-apoptotic protein, Bcl-2 (Oeckinghaus et al., 2011; Tauzin et al., 2011).

Apart from the FADD and pro-caspase 8, which are the core components of DISC, other proteins such as receptor interacting protein (RIP) and FLICE-interacting protein (FLIP) are recruited into the DISC upon the activation of the Fas receptor. The death domain (DD) of RIP1 was shown to bind to several death receptors including Fas/CD95, thereby mediating extracellular signal-regulated kinase (ERK) activation, which has been shown to participate in a large variety of processes including cell adhesion, cell cycle progression, cell migration, cell survival, differentiation, metabolism, proliferation, and gene transcription (Roskoski, 2012).

Recently, Fas/CD95 ligation has been shown to elicit a $\mathrm{Ca}^{2+}$ ion influx through specialized plasma membrane $\mathrm{Ca}^{2+}$ release-activated $\mathrm{Ca}^{2+}$ (CRAC) channels formed by subunits of calcium release-activated calcium channel protein 1 (Orai1), thus allowing $\mathrm{Ca}^{2+}$ ions to selectively enter the cell (Khadra et al., 2011). It was speculated that the influx of $\mathrm{Ca}^{2+}$ ions upon Fas receptor activation inhibited the binding of FADD to the cytoplasmic domain of Fas/CD95 effectively attenuating the DISC formation and the subsequent activation of caspase 8. Another example of anti-apoptotic effect of Fas/CD95 triggering is the recruitment of calmodulin to the DISC in choloangiocarcinoma cells stimulated with FasL, which promoted survival of the cells stimulated with FasL (Fernandez et al., 2013). The role of calmodulin in Fas/FasL survival signaling is still unclear, however, due to a direct binding between calmodulin and FLIP it is speculated that calmodulin promotes the recruitment of FLIP to the DISC, thereby decreasing the generation of active caspase 8 and consequently blocking apoptosis (Gaidos et al., 2015). 
Taken together, despite the majority of published data reveal the FasL/Fas system as the major cause for the induction of apoptosis in RASFs considerable evidence exists that FasL ligation to the Fas receptor is also capable of inducing anti-apoptotic signaling (Strasser et al., 2009; Malhi et al., 2010; Böhm et al., 2013).

\subsection{Src and FAK signaling as key molecules in apoptosis resistance}

Focal adhesion kinase (FAK) and the proto-oncogene tyrosine-protein kinase c-Src (Src) belong to the non-receptor tyrosine kinases and are involved in a plethora of signaling pathways, including signaling initiated by the binding of integrin to extracellular matrix molecules (Bolós et al., 2010). Growing evidence suggests a central role in cancer, as the increased levels of both kinases correlate with aggressiveness and invasiveness in cancer (Agochiya et al., 1999; Westhoff et al., 2004). Furthermore, Src and FAK promote proliferation and anoikis resistance in cancer cells and other cell types implying Src and FAK signal transduction pathways in other diseases with dysregulated apoptosis homeostasis (Westhoff et al., 2004; Bolós et al., 2010).

In RA, the anti-apoptotic effect of ADAM15 on FasL-induced apoptosis in RASFs was shown to be dependent on FAK and Src activation and could be abrogated by inhibitors interfering with FAK and Src signaling (Böhm et al., 2013). Moreover, in osteoarthritis (OA) chondrocytes, genotoxic stress elicited by camptothecin induced phosphorylations of Src and FAK and in addition a direct binding between ADAM15 and FAK could be demonstrated (Fried et al., 2012). Furthermore, several Src family kinases (SFKs) were also shown to bind ADAM15, implying an involvement of ADAM15 in Src-mediated cellular signaling pathways (Poghosyan et al., 2002; Zhong et al., 2008; Maretzky et al., 2009).

\subsubsection{Proto-oncogene tyrosine-protein kinase Src}

Proto-oncogene tyrosine kinase c-Src (cellular Src, Src) belongs to the Src family kinases (SFKs), which consists of nine members (Src, Fyn, Yes, Lyn, Lck, Hck, Blk, Fgr and Yrk). All family members have a molecular weight of approximately 50 to $60 \mathrm{kDa}$ (Roskoski, 2004; Parsons and Parsons, 2004). All SFKs consist of a myristoylated N-terminal domain, a liker region containing $\mathrm{SH} 3$ and $\mathrm{SH} 2$ motifs, tyrosine kinase domain and a short C-terminal domain (Mitra and Schlaepfer, 2006). The regulation of kinase activity is mediated by the phosphorylation of certain tyrosine residues. Src is activated by the phosphorylation of Y416, and inactivated by phosphorylation of Y527, which promotes a closed conformation, in which 
the $\mathrm{SH} 2$ and $\mathrm{SH} 3$ domains of Src are not exposed and therefore cannot bind target proteins (Ingley, 2008; Kim et al., 2009).

Src interacts with a variety of proteins and the majority of those interaction partners can be phosphorylated by Src. One of the main substrates of Src is FAK, which is phosphorylated by Src at the tyrosines Y576/577, Y861 as well as Y925 (Cattaneo et al., 2014). By interacting with FAK, which is localized in focal contacts, Src contributes to the assembly of focal adhesions (FA), thus modulating the ECM-cell signaling (Blume-Jensen and Hunter, 2001; Westhoff et al., 2004). Furthermore, Src can bind and phosphorylate certain growth factor receptor (GFRs) and G protein-coupled receptors (GPCRs), which implicates Src in GFR and GPCR signaling (Cattaneo et al., 2014). At its c-terminus Src interacts with the so-called Cterminal Src kinase (CSK), which can inactivate Src activity by phosphorylating Src at tyrosine Y527 (Wheeler et al., 2009).

Overall, Src activity has a strong influence on processes, such as cell adhesion, migration, proliferation, and survival. It has been shown that the expression and activity of Src is markedly increased in several cancers, such as colon, breast and pancreas cancer (Parsons and Parsons, 2004). Furthermore, growing evidence exists that a correlation exists between cancer malignancy and Src kinase activity (Sen and Johnson, 2011). The pro-survival role of Src signaling, however, is not limited to cancer, as it has been shown that the inhibition of Src by the specific Src inhibitor PP2 induced apoptosis in RASFs, demonstrating that Src is a crucial contributor to the apoptosis resistance of synovial fibroblasts (Böhm et al., 2013).

\subsubsection{Focal Adhesion Kinase (FAK, PTK2)}

Focal adhesion kinase (FAK) is a cytoplasmic protein that has originally been found in focal adhesions of adherent cells. Focal adhesions are are formed during cell adhesion to extracellular matrix molecules (ECM), such as collagens and fibronectin, and define the areas, in which the actin cytoskeleton of the cell interacts with ECM via integrin binding. Signaling originating from focal contacts is essential for cell survival, migration as well as proliferation (Parsons, 2003). One of the major proteins involved in the assembly of focal contacts is FAK, which upon integrin binding undergoes an autophosphorylation of tyrosine Y397, enabling the recruitment of Src and the initiating the focal adhesion signaling cascade (Hall et al., 2011).

FAK consists of the ezrin-radixin-moesin (FERM) domain located at the $\mathrm{N}$-terminus, a central tyrosine kinase domain and a C-terminal focal adhesion targeting (FAT) domain (Fig. 4) (Parsons, 2003). The FERM domain is made of 3 structural subunits (F1, F2 and F3) and the binding sites for interacting proteins, such as PDGFR (platelet derived growth factor receptor) 
and EGFR (epidermal growth factor receptor) and the cytoplasmic domains of $\beta$-integrins (Schaller et al., 1995; Parsons, 2003; Caccarelli et al., 2006). Within the linker region, which connects the FERM and kinase domain, the tyrosine Y397 is autophosphorylated during the activation of FAK (Hall et al., 2011). This event creates a high-affinity binding site for Src, thereby forming a Src-FAK complex (Parsons, 2003; Bolós et al., 2010; Panera et al., 2017). Src can then phosphorylate Y576 and Y577 located at the activation loop of the kinase domain as well as the tyrosines, Y861 and Y925, located at the C-terminus (Westhoff, et al, 2004; Brami-Cherrier et al., 2014). While the phosphorylation of tyrosines 576 and 577 is known to fully activate the kinase domain, the phosphorylations of Y861 and Y925 regulate binding to interaction partners, such as Grb2, which is involved in RAS/MAPK signaling (Brunton et al., 2005; Ezratty et al., 2005). The C-terminal FAT domain is important for binding and recruitment of other proteins, such as paxillin, to the focal adhesion complex (Lim et al., 2004; Panera et al., 2017).

FAK has also been recognized as a survival kinase in an integrin independent processes and confers protective properties against apoptosis induced by osmotic stress in various cell types as well as against apoptosis induced by ionizing radiation (Kasahara et al., 2002; Lunn et al., 2007). The upregulation of FAK has been detected in several types of cancer, with especially high levels of expression in aggressively infiltrating cancer metastases (Duxbury et al., 2004; Liu et al., 2008; Morgan et al., 2008). An abnormal FAK activation has also been detected in inflammatory joint diseases. Thus, the ADAM15-dependent phosphorylation of FAK at the tyrosines Y576/577 and Y861, which are phosphorylation sites of Src, upon the induction of genotoxic stress in osteoarthritis (OA) chondrocytes has been shown to be antiapoptotic (Fried et al., 2012). An in-depth investigation revealed a direct binding of FAK at the second linker region to the cytoplasmic domain of ADAM15. Accordingly, in RA synovial fibroblasts, receptor-mediated apoptosis induction by Fas ligation led to a phosphorylation of FAK at the same tyrosines (Y576/577 and Y861), however, only in the presence of ADAM15, thereby increasing their capability to resist the execution of the initiated apoptosis program (Böhm et al., 2013). Taken together, both FAK and Src appear to be implicated in the ADAM15-dependent Fas/CD95 elicited pro-survival signaling. 


\section{Focal Adhesion Kinase}

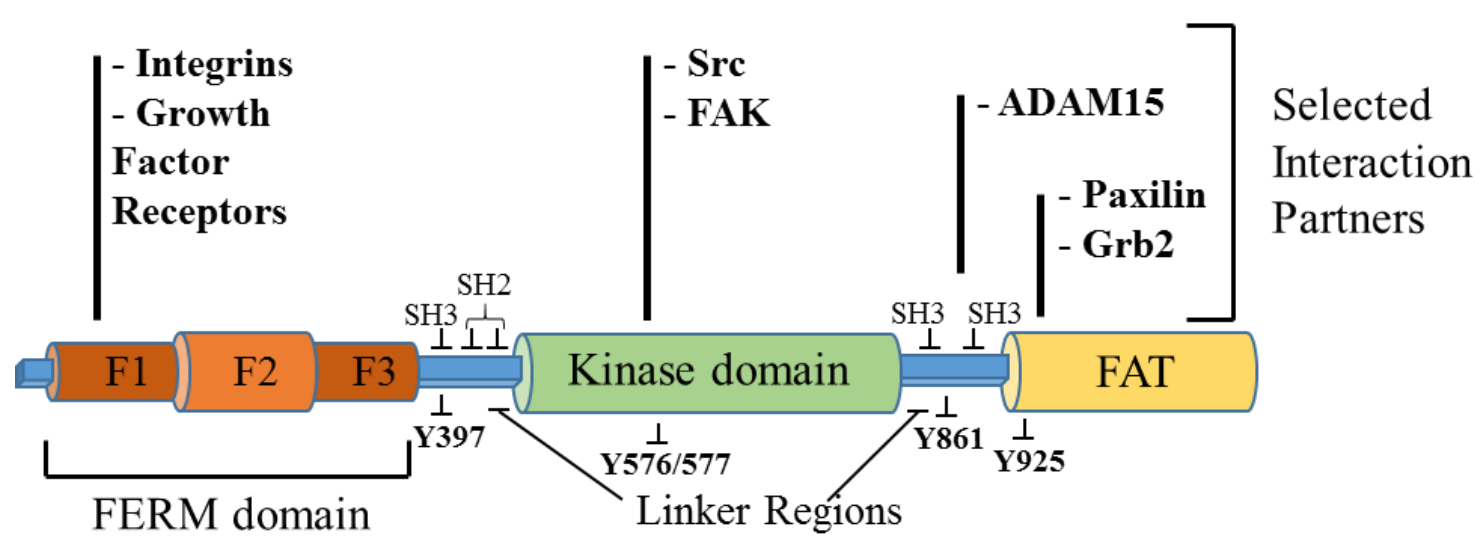

Fig. 4. Structure of Focal Adhesion Kinase (FAK) with chosen interaction partners. FAK consists of 3 major domains and 2 linker regions. From the N-terminus, FAK consists of the FERM domain (containing three sub-domains), the first linker region, the kinase domain, the second linker region and a FAT domain at the C-Terminus. The linker regions contain $\mathrm{SH} 2$ and $\mathrm{SH} 3$ binding domains, which are important for binding of SH/SH3 -domain proteins, e.g. Src. Selected proteins interacting with certain domains of FAK are shown as well as key regulatory tyrosine residues (Y397, Y576/577, Y861 and Y925) (Hall et al., 2011).

\subsection{Calmodulin}

Calmodulin $(\mathrm{CaM})$ is a small $(17 \mathrm{kDa})$, cytosolic, ubiquitous $\mathrm{Ca}^{2+}$ binding protein that is highly conserved in eukaryotes. It is the major $\mathrm{Ca}^{2+}$ sensor in cells and plays a role in the transduction of calcium signals (Kursula, 2014). Calmodulin exists in two different conformations, depending on whether it has incorporated $\mathrm{Ca}^{2+}$ ions $\left(\mathrm{Ca}^{2+}\right.$-calmodulin) or not (apo-calmodulin). The function of calmodulin is exerted via binding and regulating a plethora of enzymes and channels as well as proteins involved in trafficking and structural proteins (Villalobo, 2018). $\mathrm{Ca}^{2+}$-calmodulin can bind to over 2000 proteins in a cell, thereby regulating a myriad of protein kinases and phosphatases (Clapham, 2007). $\mathrm{Ca}^{2+}$-calmodulin is the main conformation associated with protein interactions and will be referred to as calmodulin throughout the text. It has been shown that the rise of cytosolic $\mathrm{Ca}^{2+}$ leads to the formation of $\mathrm{Ca}^{2+}$-calmodulin, which then is translocating to the cell membrane where it can bind protein domains rich in hydrophobic and positively charged residues), effectively "pulling" them of the membrane and activating their enzymatic activity, eg. K-Ras or MARCKS, which are both membrane-bound proteins regulated by binding to calmodulin (Clapham, 2007; Anguita and Villalobo, 2016; Zhou et al., 2017).

Calmodulin consists of an aminoterminal $\mathrm{N}$ domain and a homologous $\mathrm{C}$ domain (Fig. 5). Each domain possesses two EF-hand motifs (Feldkamp et al., 2011). Overall, four EF-hand 
motifs allow calmodulin to bind four $\mathrm{Ca}^{2+}$ ions (Chou et al., 2001). The $\mathrm{N}$ and $\mathrm{C}$ domains are connected by a flexible linker region (Meador et al., 1993). The binding of $\mathrm{Ca}^{2+}$ changes the shape of calmodulin molecule, which results in two different conformations. Without $\mathrm{Ca}^{2+}$ ions bound, calmodulin (apo-calmodulin) has a compact, closed structure and is highly negatively charged (Ahn et al., 2004; Clapham, 2007; Tidow and Nissen, 2013). As opposed to this, the $\mathrm{Ca}^{2+}$-bound form $\left(\mathrm{Ca}^{2+}\right.$-calmodulin) has an open conformation, in which it is shaped like a dumbbell (Fig. 5) (Halling et al., 2016). The conformational transition leads to the exposure of hydrophobic residues located in the pockets between the $\mathrm{N}$ and $\mathrm{C}$ domains and the linker region (Wilson and Brunger, 2000).

Apo-calmodulin and $\mathrm{Ca}^{2+}$-calmodulin can bind to different proteins, with over 2000 interaction partners known for $\mathrm{Ca}^{2+}$-calmodulin (Tidow and Nissen, 2013; Kursula, 2014). Despite the fact that there is no consensus sequence responsible for calmodulin binding, proteins binding to calmodulin often contain sites of basic and bulky amino acid residues, which are surrounded by amino acids containing residues with aromatic rings (Clapham, 2007).
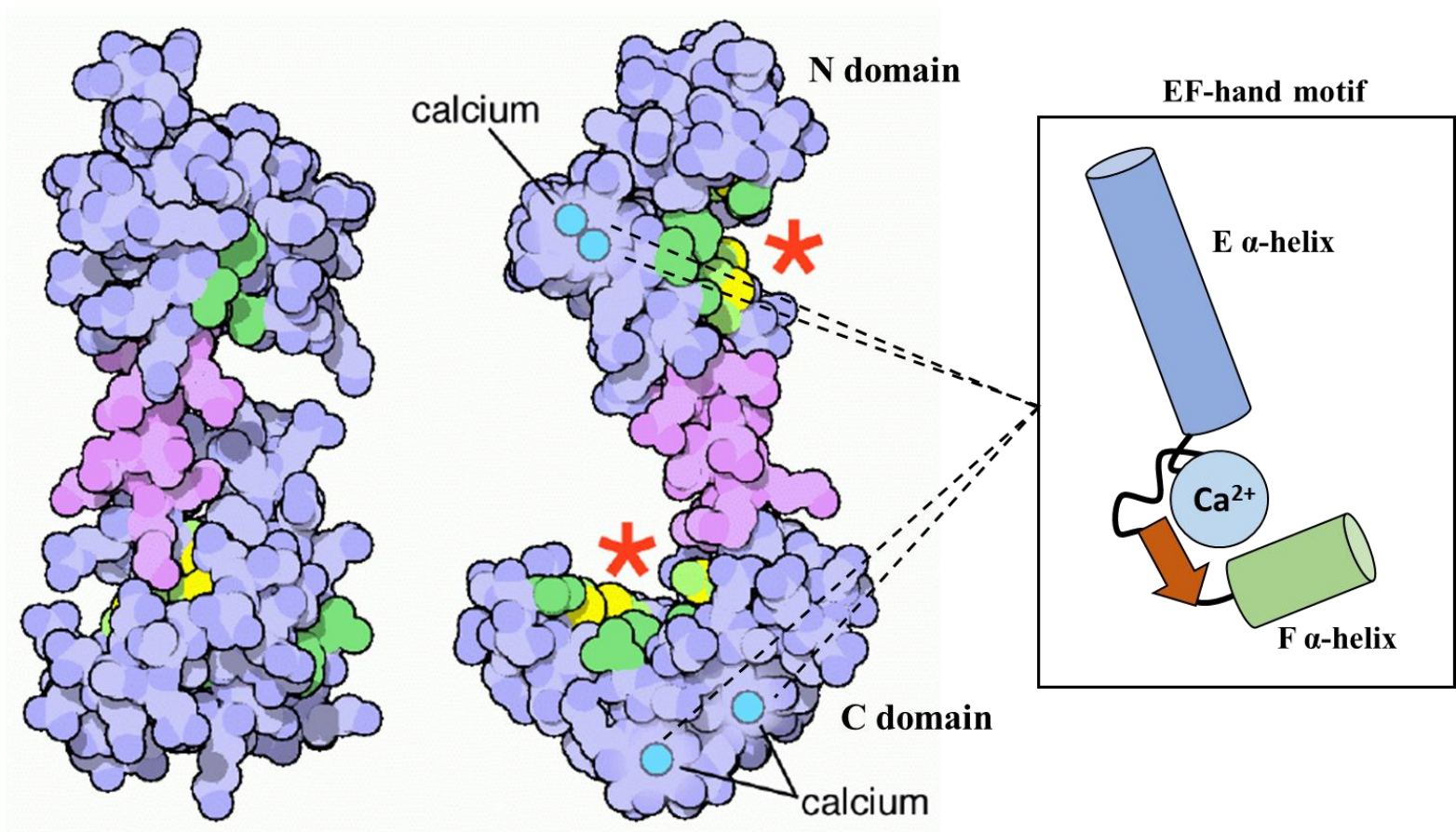

Fig. 5. Changes of the secondary structure of calmodulin in the presence of $\mathrm{Ca}^{2+}$ ions. Calmodulin comprises an $\mathrm{N}$ and $\mathrm{C}$ domain, and each domain contains two EF-hand motifs, which can bind one $\mathrm{Ca}^{2+}$ ion, respectively. In the absence of $\mathrm{Ca}^{2+}$ ions, calmodulin (apo-calmodulin) has a closed conformation and the hydrophobic "pockets" are hidden. The binding of four $\mathrm{Ca}^{2+}$ ions induces a conformational change. $\mathrm{Ca}^{2+}$-calmodulin has an open structure and the newly exposed hydrophobic regions can bind various proteins (indicated by red stars) (PDB entry $1 \mathrm{cfd}$, Goodsell et al., 2015). 


\subsection{Aim of the study}

Previously, it was demonstrated that the expression of ADAM15 conferred antiapoptotic properties to synovial fibroblasts from RA patients upon triggering the death receptor Fas/CD95 by its ligand FasL. This anti-apoptotic response was accompanied by enhanced phosphorylations of the two survival kinases, Src and FAK (Böhm et al., 2013). However, the activation of Src and FAK disappeared upon RNA interference (RNAi) silencing of ADAM15 with a concomitantly increased apoptosis rate. Although a direct interaction between ADAM15 and FAK has been shown, the precise molecular mechanisms responsible for the activation of Src and FAK upon triggering the Fas receptor remained unclear.

The aim of the present study was therefore to investigate the mechanisms underlying the capability of ADAM15 to transform FasL-mediated death-inducing signals into prosurvival activation of Src and focal adhesion kinase (FAK) in rheumatoid arthritis synovial fibroblasts.

Beyond elucidating proteins involved in mediating the cross-talk between ADAM15 and Fas/CD95 (Fig. 6), the study also aimed at the identification of pharmacological means to interfere with the components of ADAM15-dependent signaling as a potentially new strategy to sensitize pathogenic RASFs to FasL-induced apoptosis. 


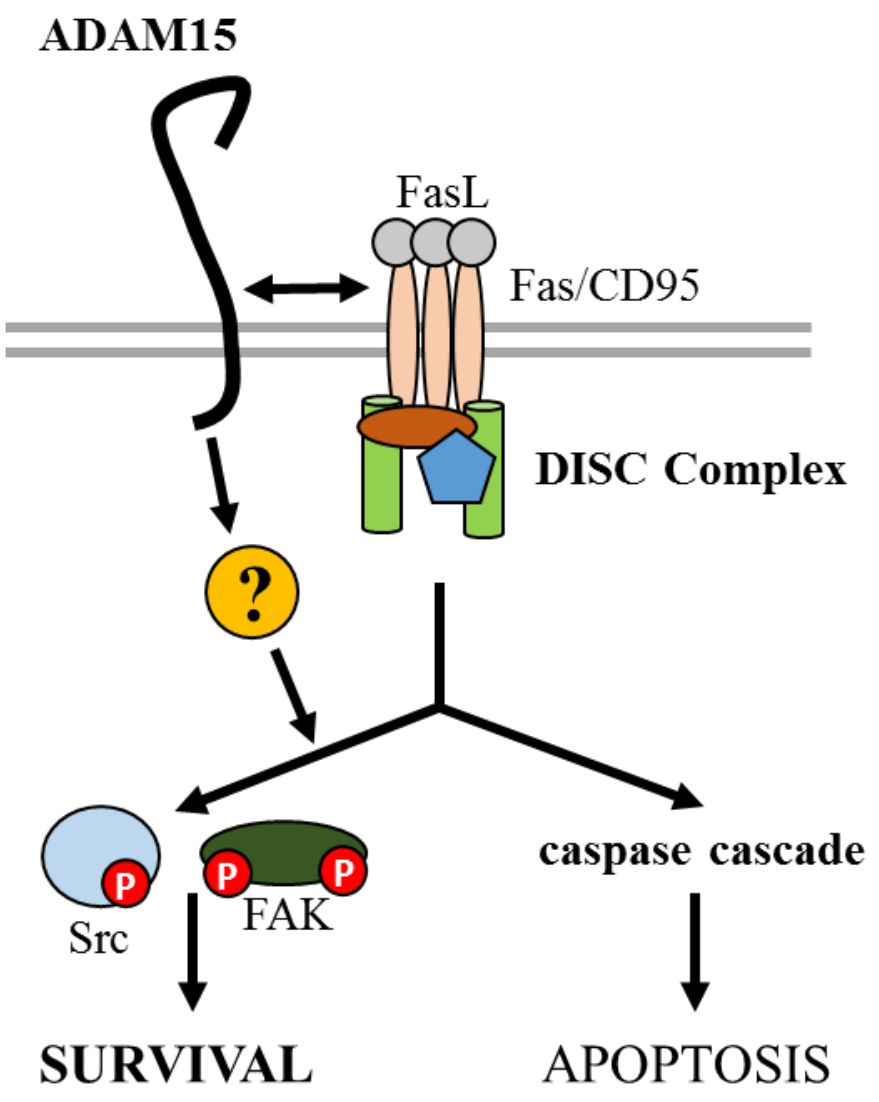

Fig. 6. Working hypothesis for identifying the crosstalk mechanism of Fas receptor triggered and ADAM15-dependent phosphorylations of FAK and Src. Canonically, FasL stimulation leads to the assembly of the death-inducing complex (DISC), thereby activating a caspase cascade to initiate the apoptotic effector pathway. Only in the presence of ADAM15, Fas ligation by FasL results in an enhanced phosphorylation of Src and FAK, leading to cell survival. The identification of the molecular interactions mediating the Fas-induced phosphorylations of FAK and Src in dependency on ADAM15 expression was aim of this present work. 


\section{Materials and Methods}

All consumables and lab equipment used to performed said experiments is listed in the supplemental tables 2 to 11 .

\subsection{Cell biology methods}

\subsubsection{Cell culture}

T/C28a4 cells (chondrocyte cell line generated by immortalizing chondrocytes from non-articular cartilage with SV40 large-T-Antigen (Goldring et al., 1994) and primary synovial fibroblasts were cultured in DMEM (Dulbecco's Modified Eagle Medium, Thermo Fisher Scientific (Gibco), Dreieich, Germany) supplemented with 10\% FCS, $50 \mathrm{U} / \mathrm{ml}$ Penicillin and $50 \mathrm{mg} / \mathrm{ml}$ Streptomycin in $37^{\circ} \mathrm{C}$ and $5 \% \mathrm{CO}_{2}$. The cells were grown in 775 flasks $\left(75 \mathrm{~cm}^{2}\right), 6$ well plates, 24-well plates, 96-well plates or white, half area 96-well plates with transparent bottom (Greiner, Frickenhausen, Germany).

Cells were passaged by first washing in PBS (Dulbecco's Phosphate Buffered Saline without $\mathrm{MgCl}_{2}$ and without $\mathrm{CaCl}_{2}$, Thermo Fisher Scientific (Gibco), Dreieich, Germany) and trypsinization with a T/E solution ( $0.1 \%$ Trypsin, 1 mM EDTA in PBS) for 5 minutes. Trypsin activity was blocked by adding DMEM containing $10 \%$ FCS. For storage, 4 x $10^{6}$ cells were suspended in $1 \mathrm{ml}$ of freezing medium (70\% DMEM, 20\% FCS, 10\% DMSO), aliquoted and stored in $-80^{\circ} \mathrm{C}$ (below 3 months) or liquid nitrogen (above 3 months).

\subsubsection{Cell culture of human RASF}

Primary human RASF were kindly provided by Prof. Dr. Kinne (University Hospital Jena). The cells were derived from synovial tissue obtained during joint replacement/arthroscopic synovectomy surgery at the Clinic of Orthopedics, University Hospital Jena with written informed consent given by the patients prior to the operation procedure (an ethics approval was provided by the Institutional Review Boards of the University Hospital Jena and the University Hospital Frankfurt) The cells were isolated from synovial tissues from donors suffering from RA for at least 3 years. Briefly: the synovial membranes were digested by a sequential digestion with Pronase and collagenase (Roche, Mannheim, Germany) and then cultured for 3 passages in order to eliminate any immune cell 
contamination (Hirth, et al., 2002). All experiments were done on cells ranging from passage 3 to passage 7 .

All of the donors met the criteria for RA established by the American College of Rheumatology in 1987 (Arnett et all., 1988). Rheumatoid factor presence rate was $80 \%$ and the disease was either moderate or severe in all of the donors. All of the donors underwent a joint replacement/arthroscopic synovectomy at the Clinic of Orthopedics, University Hospital Jena.

\subsubsection{Downregulation of ADAM15 by siRNA in primary RASF}

ADAM15 protein expression was knocked down using Silencer Select predesigned and validated small interfering RNAs (siRNAs) for ADAM15 (Ambion/Applied Biosystems). Synovial fibroblasts $\left(3 \times 10^{3}\right)$ from 5 different donors were seeded into 96-well plates (white, half-area, with clear, flat bottom (Greiner, Frickenhausen, Germany)) and treated with $20 \mathrm{nM}$ Silencer Select Predesigned and Validated small interfering RNA (siRNA) for ADAM15 (siRNA ADAM I [5'-GAUCUACUCUGGGAGACAAtt-3'] and siRNA ADAM II [5'CAUUAUUUCGCGAAUCCAAtt-3']) (Ambion/Applied Biosystems) for 48 hours, using $5 \mu 1$ Saint Red transfection reagent in $550 \mu \mathrm{l}$ medium according to the instructions of the supplier (Synvolux, Leiden, Netherlands). The nonsilencing siRNA control \#1 (Ambion) was used as a negative control.

\subsubsection{Stimulation of cells}

\subsubsection{For analysis of phosphorylated proteins}

$5 \times 10^{5}$ cells were seeded into a 6-well plate (Greiner, Frickenhausen, Germany). After 24 hours, the medium was aspirated from the cells. FCS-free DMEM alone or with either TFP $(25 \mu \mathrm{M})$ or BTP-2 $(25 \mu \mathrm{M}, 50 \mu \mathrm{M})$ was placed on the cells. After 30 minutes of pre-incubation, the medium was replaced by FCS-free DMEM containing FasL (100 ng/ml, SuperFasL®, Enzo, Lörrach, Germany) alone or in combination with TFP $(25 \mu \mathrm{M})$ or BTP-2 $(25 \mu \mathrm{M}, 50 \mu \mathrm{M})$. Incubation lasted from 0 to 60 minutes. After the stimulation, the cells were washed with PBS and pelleted by centrifugation for 1 minute in $13000 \mathrm{x} \mathrm{g}$ in $4^{\circ} \mathrm{C}$. The medium was carefully aspirated and the cells were lysed in $100 \mu \mathrm{l}$ of RIPA $(50 \mathrm{mM}$ Tris- $\mathrm{HCl}, \mathrm{pH} 7.2,150 \mathrm{mM} \mathrm{NaCl}$, $1 \%$ Triton X-100, $0.25 \%$ Sodium Deoxycholate) containing $0.1 \%$ Phosphatase Inhibitorcocktail II and III, $0.25 \%$ Protease Inhibitor-cocktail EDTA-free (Sigma-Aldrich) for $30 \mathrm{~min}$ 
on ice. The lysates were centrifuged for 10 minutes, $13000 \mathrm{x}$ g at $4^{\circ} \mathrm{C}$ to remove cell debris and subsequently analyzed for phosphorylatated proteins by Western Blotting.

\subsubsection{For double immunofluorescence stainings}

Cells $\left(3 \times 10^{3}\right)$ were seeded into 8-well chamber slides (Sarstedt, Nümbrecht, Germany) and grown for 3 hours. Cells were fixed with 4\% PFA (in PBS) for 10 minutes and washed twice with PBS for 5 minutes. After blocking with PBS containing $0.1 \%$ TritonX-100 and 1\% BSA for 30 minutes, cells were washed twice with PBS with $0.1 \%$ BSA and incubated with anti-ADAM15, anti-CD95 and anti-calmodulin primary antibodies (diluted in PBS $+0.1 \%$ BSA) overnight in $4^{\circ} \mathrm{C}$. After 2 washes with PBS $+0.1 \%$ BSA for 5 minutes cells were incubated with Alexa Fluor-conjugated secondary antibodies (1:500 diluted in PBS, 0.1\% BSA) for 2 hours in the dark at room temperature and washed twice with PBS $+0.1 \%$ BSA for 5 minutes. Slides were mounted using a ProLong ${ }^{\mathrm{TM}}$ Gold Antifade Mountant with DAPI (Thermo Fisher Scientific, Dreieich, Germany). All primary and secondary antibodies used for the immunostainings are listed in Table. 1. Stained cells were analyzed using a Leica SP8 confocal laser scanning microscope. Images were processed using Imagej Fiji software.

Table 1. Antibodies used for double immunofluorescence stainings.

\begin{tabular}{|c|c|c|c|c|c|}
\hline Primary Antibody & Origin & Dilution & Secondary Antibody & Origin & Dilution \\
\hline $\begin{array}{c}\text { Anti-ADAM15 } \\
\text { (R\&D Systems, } \\
\text { Wiesbaden, Germany) }\end{array}$ & goat & $1: 50$ & $\begin{array}{l}\text { Anti-goat Alexa Fluor } \\
488 \text { or } 594 \text { (Thermo } \\
\text { Fisher Scientific, } \\
\text { Dreieich, Germany) }\end{array}$ & Donkey & $1: 500$ \\
\hline $\begin{array}{c}\text { Anti-Calmodulin (2D1) } \\
\text { (Thermo Fisher Scientific, } \\
\text { Dreieich, Germany) }\end{array}$ & mouse & $1: 50$ & $\begin{array}{c}\text { Anti-mouse Alexa Fluor } \\
488 \text { or } 594 \text { (Thermo } \\
\text { Fisher Scientific, } \\
\text { Dreieich, Germany) }\end{array}$ & Donkey & $1: 500$ \\
\hline $\begin{array}{l}\text { Anti-CD95 C-20 (Santa } \\
\text { Cruz Biotechnology, } \\
\text { Heidelberg, Germany) }\end{array}$ & rabbit & $1: 100$ & $\begin{array}{c}\text { Anti-rabbit Alexa Fluor } \\
488 \text { or } 594 \text { (Thermo } \\
\text { Fisher Scientific, } \\
\text { Dreieich, Germany) }\end{array}$ & Donkey & $1: 500$ \\
\hline
\end{tabular}




\subsubsection{For total apoptosis rate determination}

RASFs $\left(3 \times 10^{3}\right.$ cells) were seeded in 8-Chamber Microscopy Slides (Sarstedt, Nümbrecht, Germany), grown for 24 hours and stimulated with DMEM containing FasL (100 $\mathrm{ng} / \mathrm{ml})$ alone or with DMEM containing either TFP $(25 \mu \mathrm{M})$ or BTP-2 $(25 \mu \mathrm{M})$ for 12 to 24 hours. The total apoptosis rate was determined with the Annexin V FITC Assay Kit from Cayman Chemicals according to the supplier's instructions. Annexin V positive cells were counted using the EVOS fluorescent microscope. At least 200 cells were counted, and the percentage of cells staining positive for annexin $\mathrm{V}$ was determined.

\subsubsection{Caspase 3/7 activity assays}

T/C28a4 chondrocytes transfected with an empty vector, full-length ADAM15 or ADAM15 without the cytoplasmic domain $(\Delta C)\left(5 \times 10^{3}\right)$ or synovial fibroblasts $\left(3 \times 10^{3}\right)$ were seeded in the wells of half-area 96-well white plates with flat, clear bottoms (Greiner, Frickenhausen, Germany). After 24 hours, the medium was replaced with $30 \mu 1$ of DMEM containing 100 ng/ml FasL (SuperFasL®, Enzo, Lörrach, Germany) alone or in combination with TFP $(25 \mu \mathrm{M})$ or BTP-2 $(25 \mu \mathrm{M}, 50 \mu \mathrm{M})$ for 12 to 36 hours. Caspase 3/7 activity of stimulated cells (see 2.1.4.1) was determined using the Caspase-Glo® 3/7 Assay from Promega (Mannheim, Germany) according to the suppliers' instructions. The luciferase-containing assay buffer contains a caspase-3/7 tetrapeptide substrate, which is conjugated to luciferin, serving as a substrate for firefly luciferase. Upon caspase cleavage luciferin is released from the peptide, leading to the generation of luminescence. Light signals were measured using a Mithras LB940 plate reader (Berthold Technologies, Germany).

\subsection{Biochemical and molecular biology methods}

\subsubsection{SDS-PAGE}

The protein concentration of cell lysates was determined using a BCA Assay kit (Thermo Fisher Scientific, Dreieich, Germany) as described in the supplier's protocol, and measured at $560 \mathrm{~nm}$ wavelength (OD 560 ) with LB940 plate reader (Berthold Technologies). Aliquots (20-45 $\mu \mathrm{g})$ of protein samples were heat-treated at $95^{\circ} \mathrm{C}$ for $5 \mathrm{~min}$ with loading buffer $(125 \mathrm{mM}$ Tris- $\mathrm{HCl} \mathrm{pH}$ 6.8, 2\% SDS, 50\% Glycerin, 0.4\% Bromophenol Blue, 5\% $\beta$-Mercaptoethanol) and were 
separated by SDS-polyacrylamide gel electrophoresis (SDS-PAGE) on a 10\% SDS- gel for 90 minutes at a constant voltage of $120 \mathrm{~V}$. Subsequently, the gels were used for Western Blotting.

Gel composition:

separating gel: $10 \%$ Acrylamide, $415 \mathrm{mM}$ Tris-HCl, $\mathrm{pH}$ 8.8, 0.1\% SDS, 0.002\% TEMED, $0.0014 \%$ APS

stacking gel: 4\% Acrylamide, $165 \mathrm{mM}$ Tris-HCl, pH 6.8, 0.1\% SDS, 0.002\% TEMED, $0.0014 \%$ APS

\subsubsection{Western Blot}

Protein transfer was done using a semi-dry method and FastBlot B44 blotters (Biometra, Jena, Germany). The SDS-Page gels were equilibrated for 5 minutes in the transfer buffer (25 $\mathrm{mM}$ Tris-HCl, $\mathrm{pH}$ 8.8, $190 \mathrm{mM}$ Glycin, 20\% Methanol v/v) and next placed on a nitrocellulose membrane (Amersham Protran 0.45 NC nitrocellulose - GE Healthcare, München, Germany) and proteins transfered for 60 minutes at $15 \mathrm{~V}$ and $0.8 \mathrm{~mA} / 1 \mathrm{~cm}^{2}$. After the transfer, the nitrocellulose membrane was stained with Ponceau $\mathrm{S}$ solution $(0.5 \%$ Ponceau $\mathrm{S}$ dissolved in $1 \%$ Acetic acid) was used to visualize the molecular weight markers. Afterwards, membranes were blocked in PBST (137 mM NaCl, 10 mM Na $2 \mathrm{HPO}_{4}, 2.7 \mathrm{mM} \mathrm{KCl}, 2 \mathrm{mM} \mathrm{KH} \mathrm{PO}_{4}, 0.1 \%$ Tween20, $\mathrm{pH}$ 7.4) containing $5 \%$ milk w/v and incubated with primary antibody solutions (1:1000 diluted in PBST containing $1 \%$ milk) overnight at $4^{\circ} \mathrm{C}$. After washing thrice with PBST, nitrocellulose membranes were incubated with secondary antibody conjugated with horseradish peroxidase (HRP) solutions (1:1000) in PBST containing 1\% milk for 2 hours at room temperature. The membranes were developed for 1 minute with ECL reagent (Perkin Elmer, Rodgau, Germany) and analyzed using the PeqLab chemiluminescence imaging system (Vilber Lourmat, Germany).

\subsubsection{Immunoprecipitations}

For analysis of Fas- triggered protein complexes, cells were trypsinized, and suspended cells $(2 \times 106)$ were stimulated with anti- CD95 $(\mathrm{CH}-11 ; 1 \mu \mathrm{g} / \mathrm{ml})$ for various time intervals at $37^{\circ} \mathrm{C}$ and lysed in lysis buffer (10 mM HEPES, pH 7.0, $150 \mathrm{mM} \mathrm{NaCl}, 1 \%$ Triton $\mathrm{X}-100$, containing $0.1 \%$ Phosphatase Inhibitor-cocktail II and III, $0.1 \%$ Phosphatase Inhibitor-cocktail II, $0.25 \%$ Protease Inhibitor-cocktail EDTA-free) for 1 hour on ice. In control cells, $\mathrm{CH}-11$ was added to lysates at a final concentration of $1 \mu \mathrm{g} / \mathrm{ml}$ to immunoprecipitate unstimulated Fas 
receptors. After centrifugation at $15,000 \mathrm{~g}$ for 10 minutes, supernatants were precipitated with $20 \mu \mathrm{l}$ goat anti- mouse IgM-Sepharose overnight at $4{ }^{\circ} \mathrm{C}$. Protein concentration in lysates from stimulated cells was determined using a BCA Assay kit (Thermo Fisher Scientific, Dreieich, Germany) as described in the supplier's protocol, and the Berthold LB940 plate reader. Cell lysates $(500 \mu \mathrm{g})$ were incubated with anti- CD95 (CH- 11), goat anti- ADAM15, anti- Src, and anti- CaM antibodies ( $1 \mu \mathrm{g} / \mathrm{ml}$ each) overnight at $4{ }^{\circ} \mathrm{C}$ and precipitated using IgM-sepharose (Sigma) for $\mathrm{CH}-11$ and protein $\mathrm{G}$-agarose for all other antibodies, washed 3 times in lysis buffer, and analyzed by immunoblotting.

\subsubsection{Calmodulin affinity pull-downs}

Lysates from unstimulated cells were used to perform calmodulin affinity pull-downs. $500 \mu \mathrm{g}$ of protein were incubated with $20 \mu \mathrm{l}$ of sepharose beads conjugated with recombinant calmodulin (calmodulin sepharose 4B, GE Healthcare, München, Germany). All incubations were carried out in a final volume of $500 \mu \mathrm{l}$ for 2 hours in $4^{\circ} \mathrm{C}$. Additionally, either $\mathrm{CaCl}_{2}$ or EDTA was added to the samples to a final concentration of $2.5 \mathrm{mM}$. After the incubation, the sepharose beads were washed two times in $500 \mu \mathrm{l}$ of lysis buffer (10 mM HEPES, pH 7.0, 150 $\mathrm{mM} \mathrm{NaCl}, 1 \%$ Triton X-100, containing $0.1 \%$ Phosphatase Inhibitor-cocktail II and III, $0.1 \%$ Phosphatase Inhibitor-cocktail II, 0.25\% Protease Inhibitor-cocktail EDTA-free). The buffer was supplemented with either $\mathrm{CaCl}_{2}$ (final concentration $=2.5 \mathrm{mM}$ ) or EDTA (final concentration $=2.5 \mathrm{mM}) .10 \mu \mathrm{l}$ of $6 \mathrm{x}$ loading buffer $(125 \mathrm{mM}$ Tris-HCl pH 6.8, 2\% SDS, 50\% Glycerin, $0.4 \%$ Bromophenol Blue, 5\% $\beta$-Mercaptoethanol) was added to the beads. The samples were heat-treated for 5 minutes in $95^{\circ} \mathrm{C}$ and analyzed via Western Blotting. As negative control for the pull-downs, cell lysate was incubated with Cl-Sepharose 4B.

\subsubsection{Production of recombinant cytoplasmic domain of ADAM15 (ADAM15cyto)}

The recombinant human cytoplasmic domain of ADAM15 was expressed as a Cterminal GST fused protein in Escherichia coli strain BL21 Rosetta ${ }^{\mathrm{TM}}(\mathrm{DE} 3)$. The bacteria were grown overnight in $37^{\circ} \mathrm{C}$, while vigorously shaking, in a $5 \mathrm{ml}$ starting culture in LB medium with Ampicillin. This culture was used to inoculate a $500 \mathrm{ml}$ culture, which was grown until $\mathrm{OD}_{600}$ reached 0.6 at $37^{\circ} \mathrm{C}$. IPTG was added to the bacterial culture at the final concentration of $1 \mathrm{mM}$ and incubated at room temperature for 3 hoursRT. IPTG induced lac promoter driven expression of the cytoADAM15-GST protein. The cells were harvestedby centrifugation for 20 minutes at $10000 \mathrm{x}$. The pellet was resuspended in $5 \mathrm{ml}$ of lysis buffer $(50 \mathrm{mM}$ Tris- $\mathrm{HCl} \mathrm{pH}$ 
8, 20\% sucrose, $1 \mathrm{mM}$ EDTA) to which $100 \mu$ l of Complete ${ }^{\circledR}$ Protease Inhibitor cocktail was added along with $75 \mu \mathrm{l}$ of lysozyme stock solution $(10 \mathrm{mg} / \mathrm{ml})$ and $1 \mu 1$ of Benzonase. The lysis was performed on ice for 30 minutes and the soluble and insoluble fractions were separated by centrifugation for $20 \mathrm{~min}$ in $10000 \mathrm{rpm}$. The recombinant protein was purified using affinity purification with glutathione sepharose 4B (GE Healthcare, München, Germany) in a ratio of $200 \mu \mathrm{l}$ of sepharose slurry per $5 \mathrm{ml}$ of lysate. The GST-tag was removed using Precission protease (GE Healthcare, München, Germany) (1U / $100 \mu \mathrm{g}$ of protein).Purified protein was concentrated using centrifuge filters (AMICON, Merck, Darmstadt, Germany) with a 3000 MWCO (molecular weight cut-off). The recombinant cytoplasmic tail of ADAM15 was stored at $4^{\circ} \mathrm{C}$ up to $1-.2$ weeks.

\subsubsection{Protein interaction ELISA (Enzyme Linked Immunosorbent Assay)}

The purified recombinant cytoplasmic domain of ADAM15 (100 ng/100 $\mu \mathrm{l})$ was used to coat the wells of 96-well plate (F8 MAXISORP Loose, NUNC, Roskilde, Denmark) overnight at $4^{\circ} \mathrm{C}$. The wells were then washed with PBS $+0.05 \%$ Tween 20 three times. Recombinant human calmodulin (Enzo, Lörrach, Germany) at various concentrations ( 0.1 - 10 $\mu \mathrm{M})$ in PBS $+0.05 \%$ Tween 20 containing either $2.5 \mathrm{mM} \mathrm{CaCl}_{2}$ or $2.5 \mathrm{mM}$ EDTA was incubated with the cytoADAM coated wells for 2 hours at room temperature. The wells were washed with PBS $+0.05 \%$ Tween 20 three times and subsequently incubated with a primary antibody against calmodulin (\#05-173, Merck, Darmstadt, Germany) in a 1:1000 dilution. The wells were washed twice with PBS $+0.05 \%$ Tween 20 and incubated with an anti-mouse antibody coupled with HRP (Thermo Fisher Scientific, Dreieich, Germany) in a 1: 2000 dilution. After washing the wells twice with PBS $+0.05 \%$ Tween 20 for 5 minutes each, the wells were developed with an ABTS (2,2'-azino-bis (3-ethylbenzothiazoline-6-sulphonic acid, Roche, Mannheim, Germany) solution and measured immediately at $\lambda=405 \mathrm{~nm}$ with the Mithras LB940 plate reader. Wells coated with BSA (100 ng/100 $\mu \mathrm{l})$ and were used as negative controls.

Also, the cytoADAM15 coated wells were incubated with a calmodulin solution $(5 \mu \mathrm{M}$ in PBS, containing $0.05 \%$ Tween $20,2.5 \mathrm{mM} \mathrm{CaCl}_{2}$ ) supplemented with different concentrations of TFP $(1-50 \mu \mathrm{M})$ and bound calmodulin measured, as described above. 


\section{Results}

\subsection{ADAM15 dependent pro-survival signaling induced by FasL}

\subsubsection{ADAM15 transfected chondrocyte cell model}

In the present study an immortalized chondrocyte cell line T/C28a4 (Goldring et al., 1994) served as a cell model for studying the function of ADAM15. Plasmids containing fulllength ADAM15 and an ADAM15 deletion mutant lacking the cytoplasmic domain $(\Delta \mathrm{C})$ were transfected into T/C28a4 chondrocytes and permanent cell lines were established (Böhm et al., 2010). The expression of full-length ADAM15 and the ADAM15 deletion mutant was analyzed by Western Blotting using ADAM15 antibodies directed against the cytoplasmic domain and the prodomain, respectively.

Immunoblots using an antibody against the prodomain of ADAM15 reveal a protein band of approximately $100 \mathrm{kDa}$ in lysates of T/C28a4 chondrocytes transfected with full-length ADAM15. In cells transfected with the ADAM15 deletion mutant $(\Delta C)$, a protein band is detected at approximately $90 \mathrm{kDa}$ (Fig. 7). Cells transfected with an empty vector control do not exhibit any ADAM15 protein expression. 
$(+) \quad(\Delta C)$

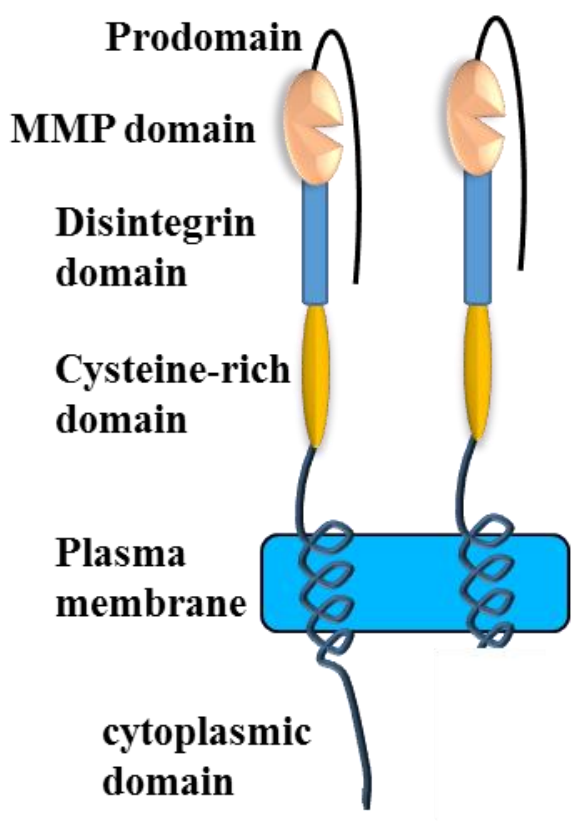

B

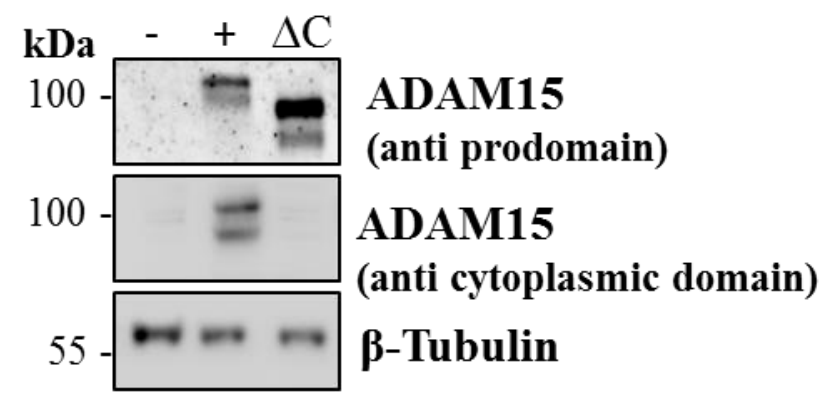

Fig. 7. ADAM15 transfected chondrocyte cell model. (A) schematic representation of full-length ADAM15 (+) and ADAM15 lacking the cytoplasmic domain $(\Delta \mathrm{C})$, showing the prodomain, metalloproteinase (MMP) domain, disintegrin, cysteine-rich domain and the cytoplasmic tail. (B) Chondrocytes transfected with full-length ADAM15 $(+)$ and the ADAM15 deletion mutant $(\Delta \mathrm{C})$ were analyzed by Western Blotting using an antibody directed against the prodomain of ADAM15 (upper panel), and against the cytoplasmic domain (middle panel), showing the molecular weight of full-length ADAM15 at $\sim 100 \mathrm{kDa}$ and ADAM15 $\Delta \mathrm{C}$ at $\sim 90 \mathrm{kDa}$. $\beta$-tubulin served as a loading control (lower panel).

Accordingly, an antibody directed against the cytoplasmic domain of ADAM15 also detects a protein band of approximately $100 \mathrm{kDa}$, but only in chondrocytes transfected with full-length ADAM15. Neither vector control nor $(\Delta \mathrm{C})$ mutant transfected cells show any ADAM15 protein bands in the expected molecular weight (Fig. 7).

\subsubsection{ADAM15-mediated resistance to FasL induced apoptosis.}

In a previous study, it was shown that the upregulated ADAM15 expression in rheumatoid arthritis synovial fibroblasts (RASF) exhibited markedly reduced caspase activity upon Fas ligation, thereby conferring a markedly increased apoptosis resistance in RASFs (Böhm et al, 2013). To analyze, whether ADAM15 possesses protective properties also in chondrocytes, caspase 3/7 activity assays that served as a marker for the assessment of apoptosis 
were performed. T/C28a4 chondrocytes transfected with full-length ADAM15, the ADAM15 deletion mutant $(\Delta \mathrm{C})$ or vector control were stimulated with FasL for 0 - 30 hours and the caspase $3 / 7$ activity was determined.

Full-length ADAM15 transfected cells exhibit a significantly reduced caspase activity of $\sim 2$ 2.5 fold upon FasL stimulation for 24 and 30 hours as compared to vector controls (Fig. 8), revealing that ADAM15 also confers anti-apoptotic properties in chondrocytes. However, the deletion of the cytoplasmic domain of ADAM15 in the ADAM15 $(\Delta \mathrm{C})$ yields caspase activities in the same range as the vector controls (Fig. 8), clearly showing that the expression of fulllength ADAM15 is required for its anti-apoptotic function in chondrocytes.

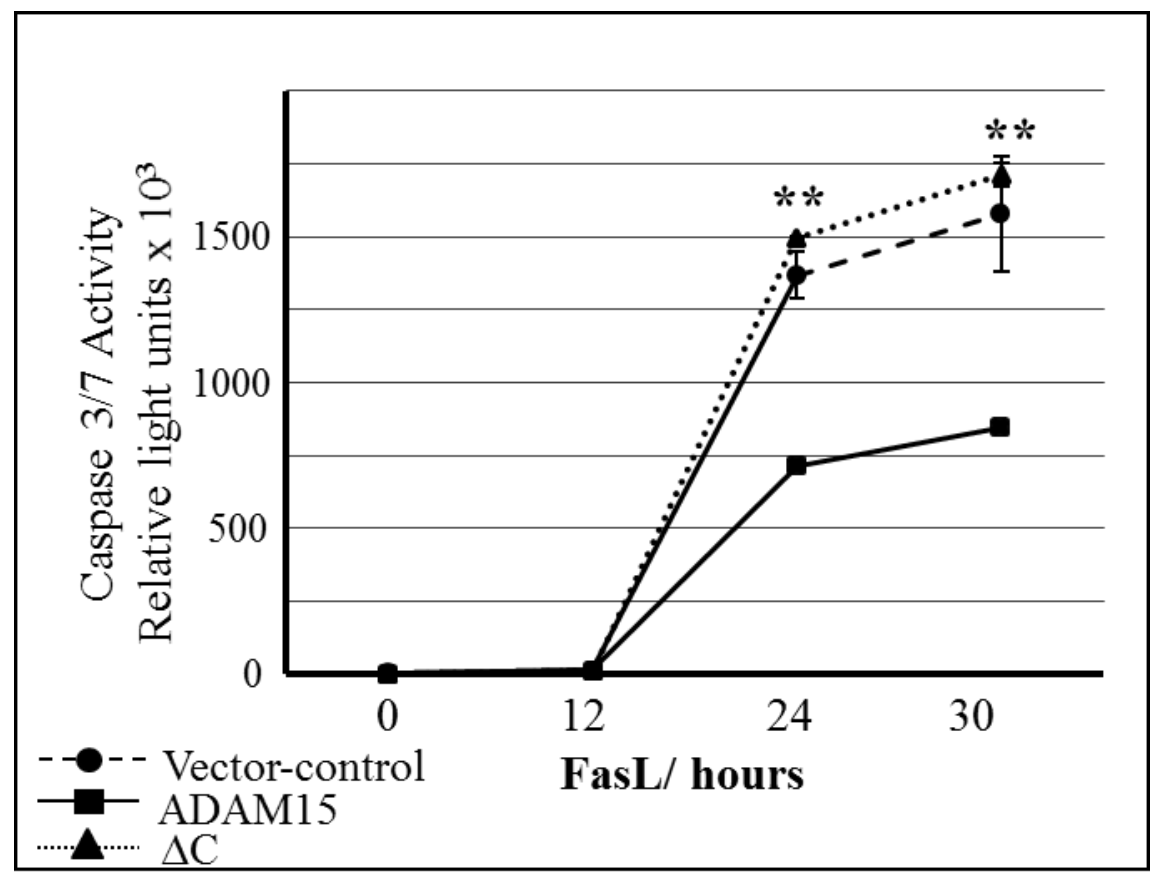

Fig. 8. ADAM15-mediated reduction of FasL-induced caspase 3/7 activity. T/C28a4 chondrocytes transfected with full-length ADAM15, the deletion mutant ADAM15 $(\Delta \mathrm{C})$ or vector control were stimulated with FasL (100 ng/ml) for 0 - 30 hours and caspase $3 / 7$ activity measured in triplicates. The values show the average $\pm \mathrm{SD}$ (standard deviation). ${ }^{* *}=P<0.002$, using Student's t-test, when comparing FasL-stimulated full-length ADAM15 transfected cells versus vector controls.

\subsubsection{ADAM15 dependency of FasL-triggered phosphorylations of Src and FAK}

The significantly increased apoptosis resistance mediated by ADAM15 in RASFs upon Fas ligation was found to be mediated by the induced phosphorylations of the "survival kinases", Focal Adhesion Kinase (FAK) and Src, thereby resulting in enhanced pro-survival 
signaling pathways (Böhm et al., 2013). In order to analyze, whether ADAM15 confers the same effect on the T/C28a4 chondrocytes, full-length ADAM15 transfected and vector control cells were stimulated with FasL and subsequently analyzed by Western Blotting using specific anti-phospho-Src and FAK antibodies.

T/C28a4 chondrocytes transfected with full-length ADAM15 exhibit significantly increased phosphorylation of Src at tyrosine Y416, necessary for full kinase activity (Fajer et al., 2017), upon Fas stimulation for 15 and $30 \mathrm{~min}$. Concomittantly, FAK phosphorylation is detectable at its autophosphorylation site Y397 and at the residues Y576 and Y861, which are both targets of Src-kinase activity (Fig. 9 A). However, cells transfected with the vector control do not exhibit any phosphorylation of Src and FAK induced by FasL above the basal levelsdetectable at unstimulated time points (Fig. 9 A). This clearly shows that Src and FAK phosphorylations are induced in response to FasL stimulation only when the cell expresses ADAM15.

A

B

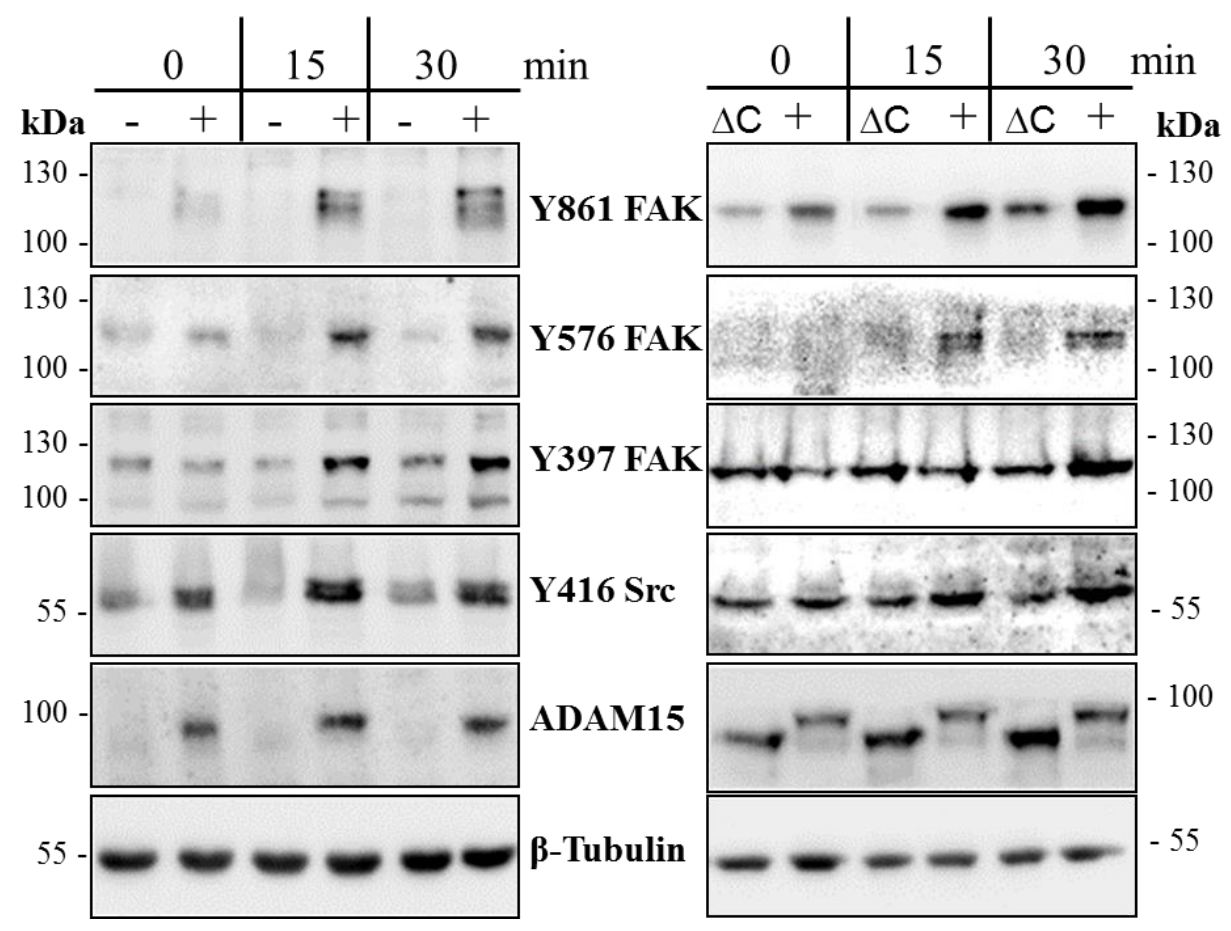

Fig. 9. ADAM15-mediated increase of FasL-induced focal adhesion kinase (FAK) and Src phosphorylations. (A, B) Vector control (-), full-length ADAM15 (+) and the ADAM15 mutant lacking the cytoplasmic tail $(\Delta C)$ transfected chondrocytes were stimulated with FasL $(100 \mathrm{ng} / \mathrm{ml})$ for $0-30$ minutes and analyzed by Western Blot using specific anti-phospho-FAK and Src antibodies, (A) showing FasL-triggered phosphorylations of FAK and Src only in ADAM15 expressing cells. (B) No induction of FAK or Src phosphorylations above the background signals in the ADAM15 $(\Delta \mathrm{C})$ cells is observed. ADAM15 and $\beta$-tubulin served as loading controls. Representative results from 3 independent experiments are shown. 
To further elucidate, whether the cytoplasmic domain of ADAM15 is necessary for the FasL-induced phosphorylation of FAK and Src, full-length ADAM15- and deletion mutant ADAM15 $(\Delta \mathrm{C})$-transfected cells were stimulated with FasL for $0-30$ min and the phosphorylations of FAK and Src analyzed by immunoblotting.

Correspondingly, full-length ADAM15 transfected chondrocytes display a marked induced phosphorylation of FAK at all 3 tyrosines, Y397, Y576 and Y861 and Src at Y416 (Fig. 9 B). However, lysates from the ADAM15 deletion mutant $(\Delta C)$ transfected cells do not reveal any induction of phosphorylated FAK and Src upon Fas receptor stimulation (Fig. 9 B), clearly showing that the cytoplasmic domain of ADAM15 is crucial for FasL-induced phosphorylations of FAK and Src.

Taken together, these results demonstrate that the stimulation of Fas/CD95 leads to an activation of the kinases FAK and Src that is crucially dependent on the expression of fulllength ADAM15.

\subsection{Role of calmodulin in ADAM15-dependent Fas/CD95 signal transduction}

\subsubsection{Calmodulin inhibition of ADAM15-dependent phosphorylations of Src and FAK}

Since Fas/CD95 ligation leads to $\mathrm{Ca}^{2+}$-influx from the extracellular compartment into the cell with a concomitant recruitment of calmodulin to Fas/CD95 (Khadra, et al., 2011), it was analyzed, whether an inhibition of calmodulin might impact ADAM15-dependent phosphorylations of FAK and Src. For that purpose, full-length ADAM15 transfected cells were stimulated with either FasL alone or FasL together with TFP (trifluoperazine) and FAK and Src phosphorylations analyzed by Western Blotting.

As shown above (Fig. 9), FasL stimulation resulted in the phosphorylation of FAK at Y397, Y576, Y861 and Src at Y416 in the ADAM15-transfected cells (Fig 10 A). However, the co-incubation with TFP resulted in an overall markedly reduced phosphorylation of FAK at Y576 and Y861, which are the target sites of Src, as well as of Src at Y416>90\%, as compared to cells stimulated with FasL (Fig. $10 \mathrm{~A}$ ). The phosphorylation of the autophosphorylation site Y397 of FAK, however, was inhibited by 60\% (Fig. 10A). These initial experiments clearly revealed that the specific inhibition of calmodulin by TFP abrogates the Fas receptor-triggered phosphorylations of FAK and Src, thus identifying calmodulin as an important intracellular factor in the ADAM15-mediated Fas/CD95 signal transduction. 


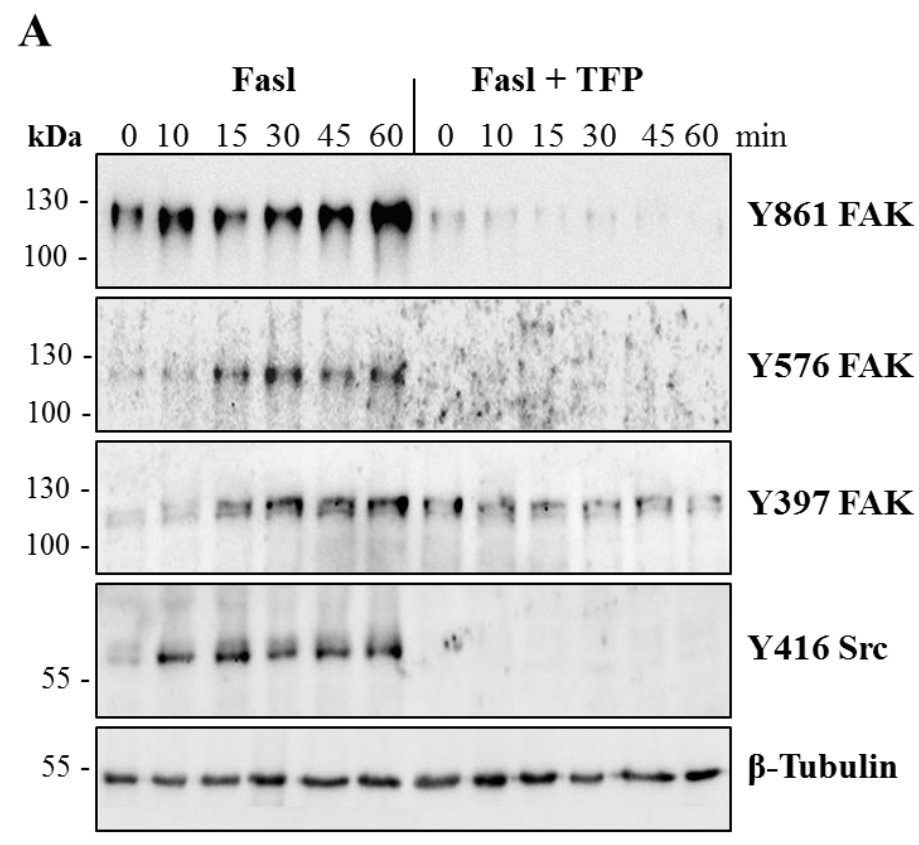

B

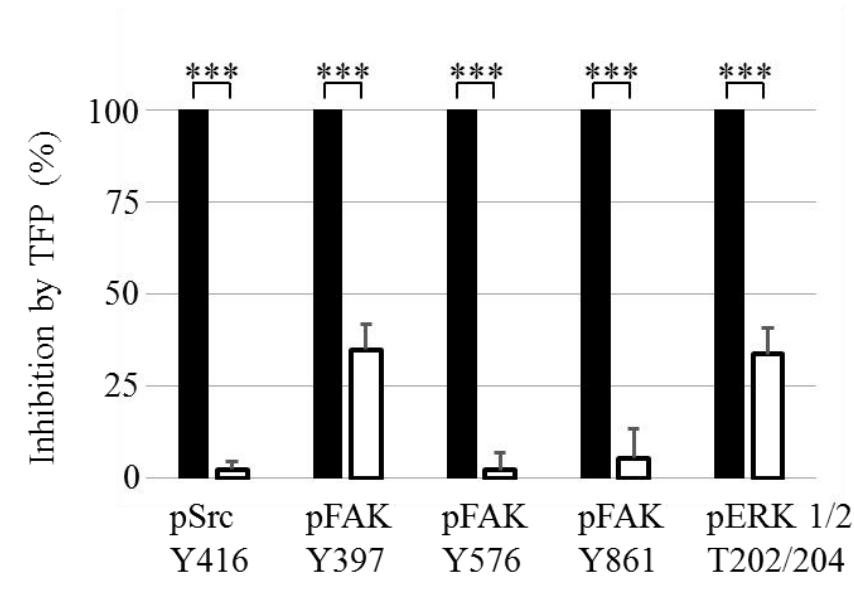

FasL $(100 \mathrm{ng} / \mathrm{ml})$

FasL $(100 \mathrm{ng} / \mathrm{ml})+$ TFP $(25 \mu \mathrm{M})$

Fig. 10. TFP-mediated inhibition of FasL-induced focal adhesion kinase (FAK) and Src phosphorylations. (A) ADAM15-transfected chondrocytes were incubated with FasL $(100 \mathrm{ng} / \mathrm{ml})$ alone or together with TFP $(35 \mu \mathrm{M})$ for 0 - 60 minutes and analyzed by western blotting using specific anti-phospho -Src and -FAK antibodies, showing an efficient inhibition of FasL-induced Src and FAK phosphorylations by BTP-2. $\beta$-tubulin served as loading controls. (B) Densitometric evaluation of immunoblots of cell lysates from rheumatoid arthritis synovial fibroblasts ( $\mathrm{n}=3$ donors) stimulated with FasL and FasL/TFP $(25 \mu \mathrm{M})$ for 0 and 60 minutes shows significant inhibition of phosphorylation of FAK and Src by TFP. Quantification was done using ImageJ Software (https://imagej.nih.gov/ij/). Shown are the average and $S D$ from 3 experiments. $* * *=P<0.0002$, using Student's t-test, when comparing FasL stimulation versus FasL + TFP.

To analyze, whether calmodulin inhibition inhibits FasL-induced Src and FAK phosphorylations also in primary cells, rheumatoid arthritis synovial fibroblasts (RASFs) from 
three different donors $(n=3)$ were stimulated with FasL alone or in combination with TFP and the phosphorylation sites of FAK and Src analyzed by Western Blotting.

Corresponding to the results obtained with ADAM15-transfected chondrocyte cell line, incubation with TFP inhibits the phosphorylations of FAK at Y576 and Y861 as well as Src at Y416 by approximately $90 \%$ (Fig. 10 B). The phosphorylation of FAK at its autophosphorylation site Y397 is inhibited by 70\% (Fig. 10 B).

In summary, the inhibitory effect of TFP on the Fas receptor-triggered FAK and Src activation in synovial fibroblasts is very similar to the one observed in the chondrocyte cells, strongly suggesting that in both cell types calmodulin is necessary for the ADAM15-dependent FasL-induced phosphorylations of FAK and Src.

\subsubsection{Interactions of calmodulin with Src, FAK and CD95}

Since calmodulin might be involved in the the Fas receptor triggered phosphorylations of Src and FAK, a potential protein interaction of calmodulin with the three proteins, Src, FAK and Fas/CD95, was analyzed by pull-down assays using calmodulin-conjugated sepharose beads. Lysates from RASFs as well as full-length ADAM15-, ADAM15 $(\Delta C)$ - and vectortransfected chondrocytes were incubated with calmodulin-conjugated sepharose in the presence of either $\mathrm{CaCl}_{2}$ or EDTA and co-precipitated fractions analyzed by Western Blotting using antiSrc, anti-FAK, and anti-CD95 antibodies.

All cell types revealed binding of calmodulin to $\mathrm{Src}$ in the presence of $\mathrm{Ca}^{2+}$ that was slightly weaker in the presence of EDTA, which suggests that apo-calmodulin as well as the $\mathrm{Ca}^{2+}$-bound conformation of calmodulin binds to Src (Fig. 11 A, B). Moreover, in all independently performed calmodulin pull-down experiments from 5 different donors, the strongest signals of precipitated Src became detectable in the chondrocyte cells transfected with full-length ADAM15, and signals remained considerably weaker in vector control- or ADAM15 $\Delta$ C-transfected cells, strongly indicating the impact of ADAM15 on Src-calmodulin binding.

Analogous to the results from the Src-calmodulin pull-downs, FAK was co-precipitated in all cell types in the presence of both $\mathrm{Ca}^{2+}$ and EDTA (Fig. $11 \mathrm{~A}, \mathrm{~B}$ ). On the other hand, Fas/CD95 bound to calmodulin in all three transfected chondrocytes cell lines and RASFs only in the presence of $2.5 \mathrm{mM} \mathrm{Ca}^{2+}$. The addition of EDTA to the reaction nearly completely abolished the precipitation of Fas/CD95 with calmodulin. 
Overall, the interaction of calmodulin with Src, FAK and Fas/CD95 suggests an involvement of calmodulin in the Fas receptor-triggered downstream signal transduction to the survival kinases FAK and Src in chondrocytes as well as RASFs.

A

\section{T/C28a4 chondrocyte cell lines}

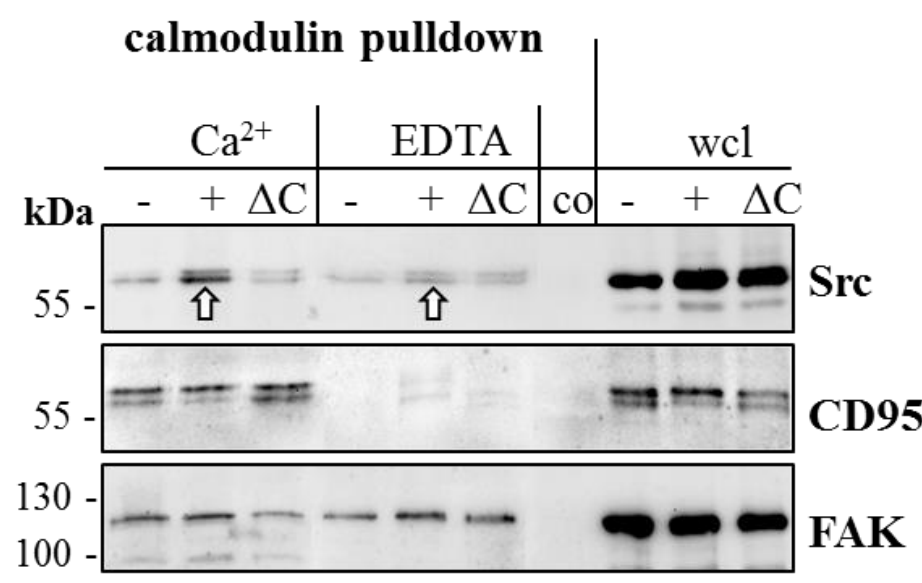

B

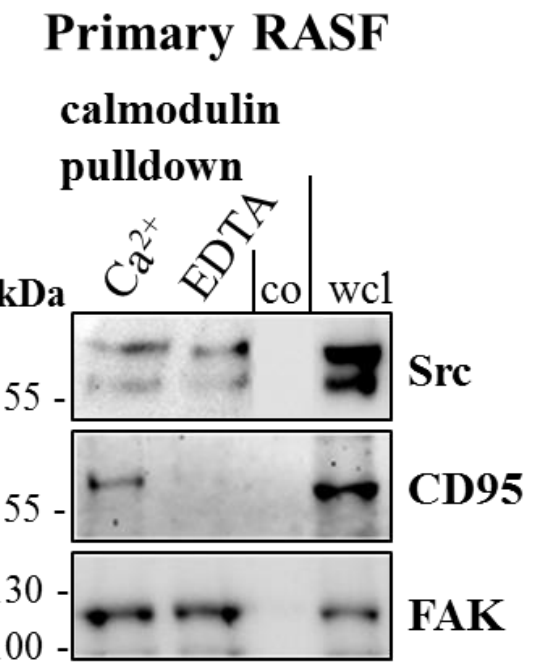

Fig. 11. The interaction of Src, Fas/CD95, focal adhesion kinase (FAK) with calmodulin. (A, B) Pull-down assays on calmodulin-conjugated sepharose of lysates from full-length ADAM15 (+), ADAM15 $(\Delta \mathrm{C})$ and vector transfected chondrocytes (-) (A) and primary RASFs (B). Cell lysates were incubated with calmodulin-conjugated sepharose beads in the presence of either $2.5 \mathrm{mM} \mathrm{CaCl}_{2}$ or 2.5 mM EDTA and analyzed by immunoblotting using specific antibodies, showing binding of Src and FAK to calmodulin regardless of $\mathrm{Ca}^{2+}$ ions and Fas/CD95 only in the presence of $\mathrm{Ca}^{2+}$. As control (co), cell lysates from full-length ADAM15-transfected cells (A) or from synovial fibroblasts (B) were incubated with sepharose CL-4B in the presence of $\mathrm{Ca}^{2+}(2.5 \mathrm{mM})$. wcl $=$ whole cell lysate, $(20 \mu \mathrm{g})$. Arrows indicate the increased amount of Src co-precipitated with calmodulin in lysates of full-length ADAM15transfected cells in the presence of $\mathrm{Ca}^{2+}$.

\subsubsection{Binding of ADAM15 and calmodulin}

\subsubsection{ADAM15 and calmodulin pull-down}

The observed increased binding of calmodulin to Src in the presence of ADAM15 led to the analysis of a potential interaction of ADAM15 itself with calmodulin. For that purpose pull-down assays using calmodulin-conjugated sepharose beads were performed in RASFs and chondrocytes. Lysates from RASFs as well as full-length ADAM15-, ADAM15 ( $\Delta \mathrm{C})$ - and 
vector-transfected chondrocytes in the presence of either $\mathrm{CaCl}_{2}$ or EDTA and analyzed by Western Blotting using anti-ADAM15 antibodies. The calmodulin pull- downs revealed a strong interaction of ADAM15 with calmodulin in the presence of $\mathrm{Ca}^{2+}$ but only minimal binding upon $\mathrm{Ca}^{2+}$ depletion with EDTA both in ADAM15- transfected cells and in RASFs (Fig. 12 A, B).

A

\section{T/C28a4 chondrocyte cell lines}

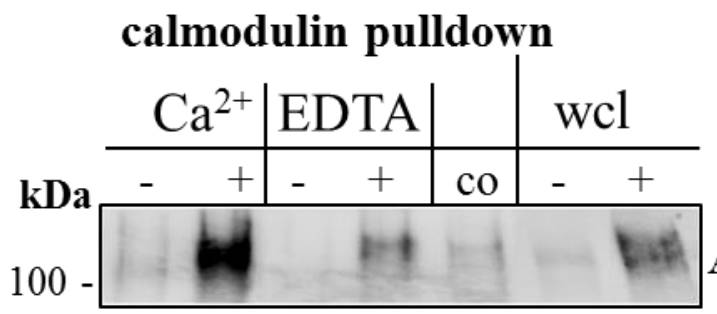

B

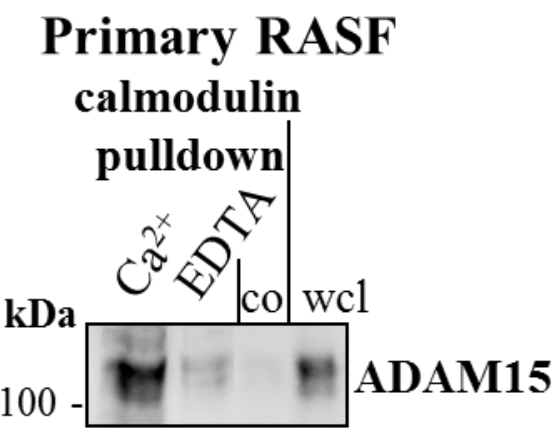

Fig. 12 The interaction of ADAM15 with calmodulin. (A, B) Pull-down assays of (A) vectortransfected (-) and full-length ADAM15-transfected chondrocyte cells (+) and (B) primary synovial fibroblasts using calmodulin-conjugated sepharose beads were performed in the presence of either $\mathrm{Ca}^{2+}$ $(2.5 \mathrm{mM})$ or EDTA $(2.5 \mathrm{mM})$, showing ADAM15-binding to calmodulin in the presence of $\mathrm{Ca}^{2+}$ only. As control (co), cell lysates from full-length ADAM15-transfected cells (A) or from synovial fibroblasts (B) were incubated with sepharose CL-4B in the presence of $\mathrm{Ca}^{2+}$. Representative results from 3 independent experiments are shown. $\mathrm{wcl}=$ whole cell lysate, $(20 \mu \mathrm{g})$.

\subsubsection{ADAM15 and calmodulin protein binding assays}

To confirm the binding of calmodulin to ADAM15, protein binding assays using recombinant proteins in an ELISA format were performed. The cytoplasmic tail of ADAM15 (cytoADAM) was expressed as glutathione S-transferase-tagged fusion (GST) protein, the GST-tag proteolytically removed using PreScission Protease and purified on GST-conjugated sepharose. The GST-tagged and purified cytoADAM without the tag proteins were analyzed by SDS/PAGE (Fig. 13 A).Recombinant cytoADAM immobilized to a 96-well plate was incubated with recombinant calmodulin in increasing concentrations $(0.1$ to $5 \mu \mathrm{M})$ either in the presence of $2.5 \mathrm{mM} \mathrm{CaCl}_{2}$ or $2.5 \mathrm{mM}$ EDTA (Fig.13 B). The bound calmodulin was 
detected using a specific antibody against calmodulin and a HRP-conjugated secondary antibody. The amount of bound calmodulin was proportional to the absorbance at $\lambda=405 \mathrm{~nm}$ (Fig. 13 B).

A concentration- dependent binding of calmodulin to cytoADAM at a low micromolar range could be detected in the presence of $\mathrm{Ca}^{2+}$, which was significantly reduced by EDTA (Fig. 13 B), revealing a direct binding of the cytoplasmic domain of ADAM15 with calmodulin that is clearly dependent on the presence of $\mathrm{Ca}^{2+}$ ions.

To confirm the $\mathrm{Ca}^{2+}$ dependent binding of ADAM15 to calmodulin, protein binding assays using the recombinant proteins in the presence of the calmodulin inhibitor TFP that inhibits the $\mathrm{Ca}^{2+}$ conformation of calmodulin were performed. Recombinant calmodulin $(5 \mu \mathrm{M})$ was bound to cytoADAM immobilized to a 96-well plate with increasing concentrations of TFP $(0-50 \mu \mathrm{M})$ in the presence of $\mathrm{CaCl}_{2}$. The addition of TFP to the cytoADAM/calmodulin binding inhibited the interaction in a concentration-dependent manner, with a half- maximal inhibitory concentration of $\sim 20 \mu \mathrm{M}$ (Fig. $13 \mathrm{C}$ ). Taken together, the results demonstrate the binding of ADAM15 specifically to the $\mathrm{Ca}^{2+}$ conformation of calmodulin. 

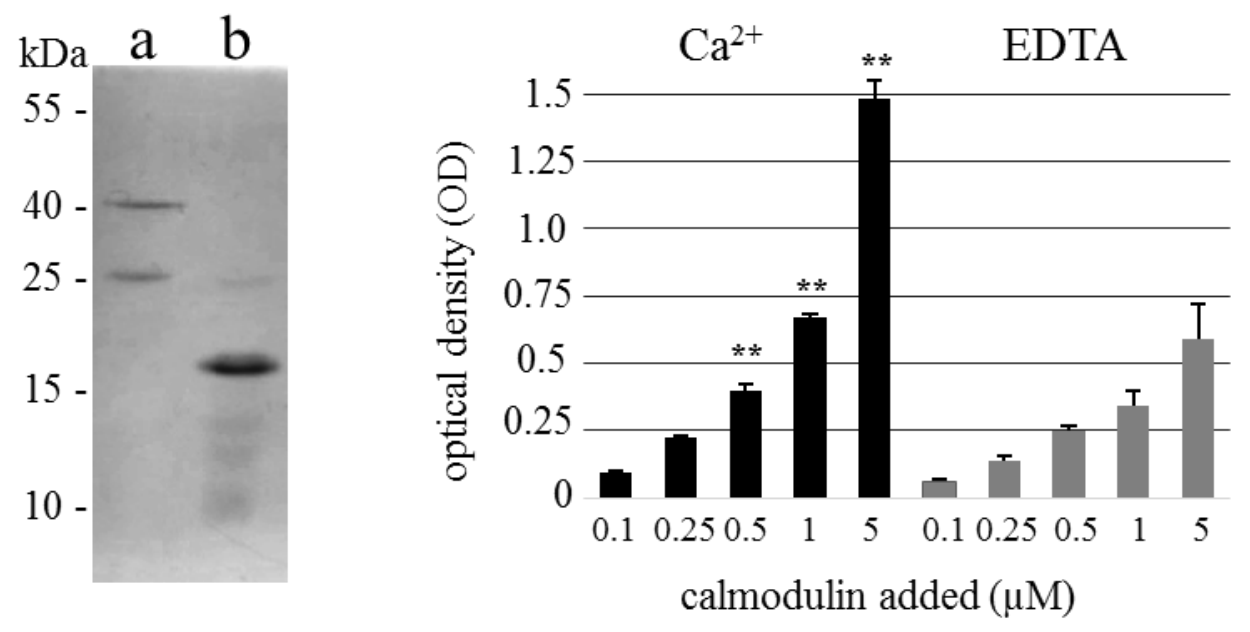

C

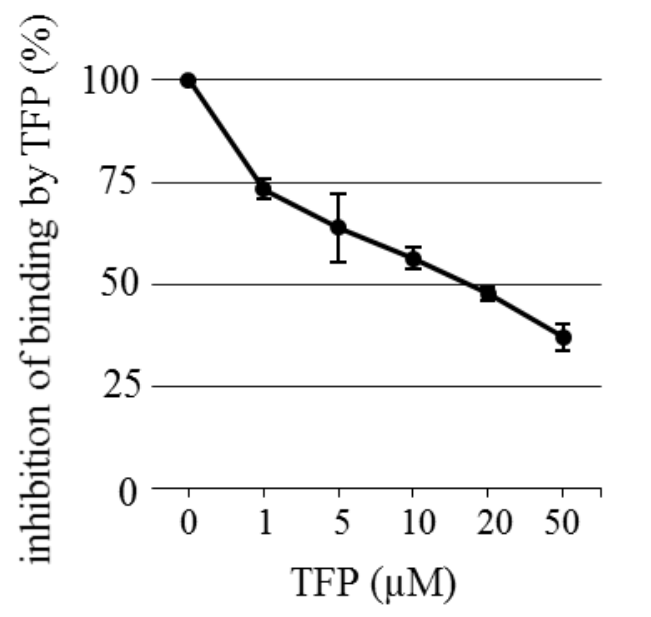

Fig. 13. The interaction of the cytoplasmic domain of ADAM15 with calmodulin. (A) SDS/PAGE of the recombinant GST-tagged cytoplasmic domain of ADAM15 (cytoADAM; lane a), lane b, GSTtag was proteolytically removed. (B) Recombinant calmodulin in increasing concentrations (0.1-5 $\mu \mathrm{M})$ was incubated in triplicates with cytoADAM immobilized to a 96-well plate either with $2.5 \mathrm{mM} \mathrm{Ca}^{2+}$ ions or with $2.5 \mathrm{mM}$ EDTA, showing ADAM15 binding to calmodulin in a $\mathrm{Ca}^{2+}$ dependent manner. (C) cytoADAM coated wells were incubated with recombinant calmodulin $(5 \mu \mathrm{M})$ and increasing concentrations of TFP $(0-50 \mu \mathrm{M})$ in the presence of $\mathrm{CaCl}_{2}$, showing an inhibitory effect of TFP on calmodulin binding to cytoADAM15. The values show the average $\pm S D$. $* *=P<0.002$, versus the respective calmodulin concentration in the presence of EDTA, by Student's t-test (A). All experiments were performed at least three times. 


\subsection{Recruitment of calmodulin to ADAM15 and Fas/CD95 upon Fas ligation}

\subsubsection{Double immunofluorescence staining of calmodulin and ADAM15 in RASFs}

To analyze, whether triggering Fas receptors leads to an association of calmodulin with ADAM15 in vivo, double immunofluorescence stainings of RASFs were performed. The cells were attached to chamber slides for 3 hours, then stimulated with the $\mathrm{CH}-11$ antibody and stained with ADAM15 and calmodulin specific antibodies.

ADAM15 shows a diffuse staining pattern and no detectable co-localization with calmodulin in unstimulated RASFs. The stimulation of Fas/CD95, however, resulted in a staining pattern, in which calmodulin and ADAM15 co-localize in patches at the cell surface. (Fig. 14). This clearly shows that Fas receptor activation leads to a redistribution of calmodulin to ADAM15 at the cell membrane.

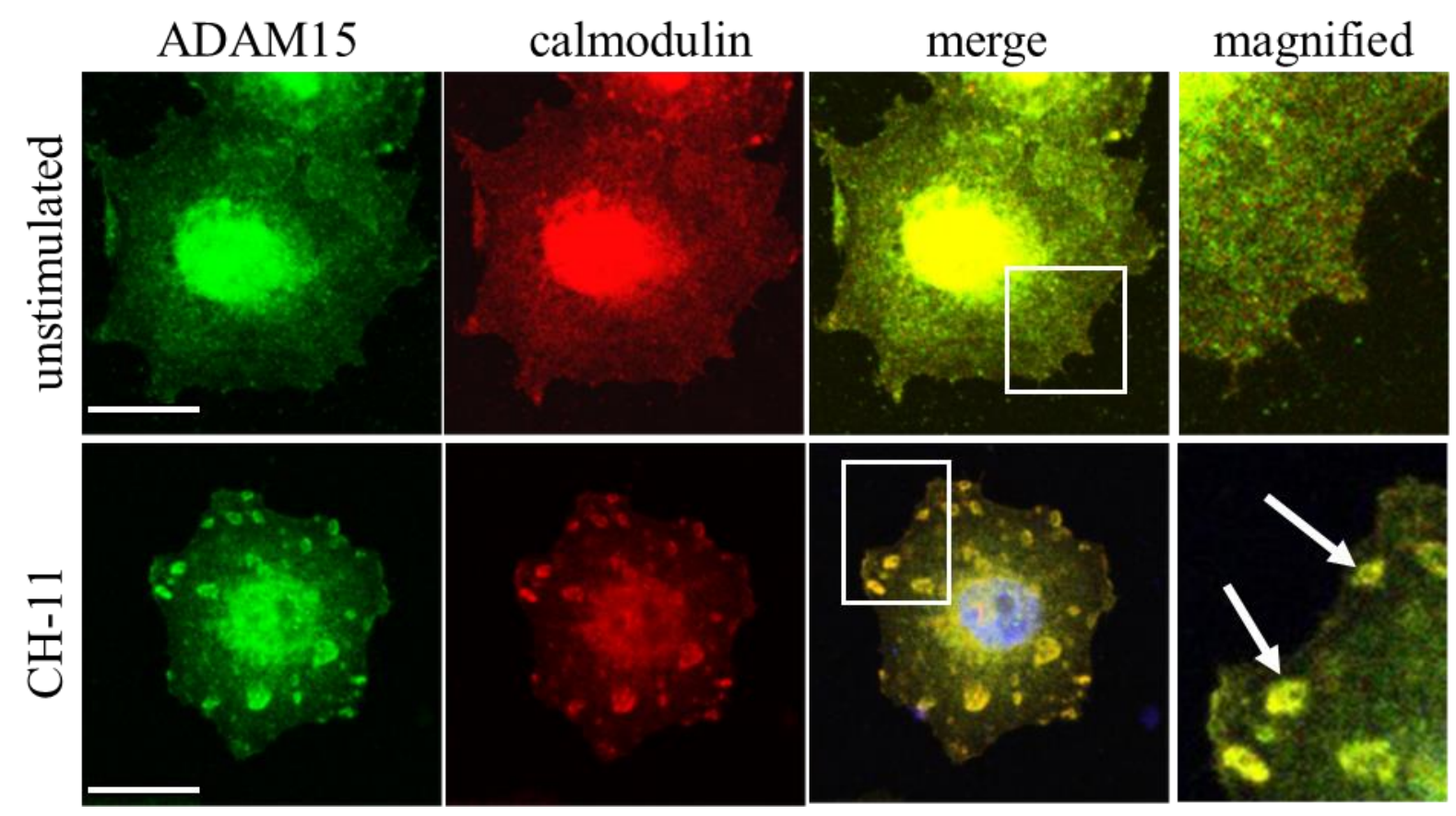

Fig. 14. The recruitment of Src and calmodulin to ADAM15 upon Fas ligation. Confocal microscopy of double immunofluorescence stainings of rheumatoid arthritis synovial fibroblasts (RASFs) either unstimulated or stimulated with the Fas/CD95-activating CH-11 antibody $(2 \mu \mathrm{g} / \mathrm{ml})$ for 10 minutes, using specific anti-ADAM15 and anti-calmodulin antibodies. ADAM15 and calmodulin are visualized with secondary antibodies conjugated with Alexa Fluor 488 (in green) and 594 (in red), respectively. Shown is the association of calmodulin with ADAM15 upon Fas ligation (indicated by white arrows). All pictures were taken with an objective $63 x$, except the last panel that shows a magnified area (indicated by white inset). Size bar $=20 \mu \mathrm{m}$. 


\subsubsection{Co-Immunoprecipitation of calmodulin with ADAM15}

To confirm the results obtained from the double immunofluorescence stainings (Fig. 14), co-immunoprecipitations of lysates from RASFs and full-length ADAM15 transfected chondrocytes using anti-ADAM15 antibodies and immunodetection with calmodulin antibodies were performed.

No co-precipitated calmodulin/ADAM15 complex is detected in both primary RASFs and ADAM15-transfected chondrocytes (Fig. 15 A, B), showing that no interaction between ADAM15 and calmodulin exists in unstimulated cells. However, upon stimulation with the Fasactivating antibody $\mathrm{CH}-11$ calmodulin is co-precipitated with ADAM15 in lysates from RASFs that were stimulated with the $\mathrm{CH}-11$ antibody for 15 minutes as well as in ADAM15-cells, which displayed increasing signal intensities for calmodulin in the precipitates after Fas stimulation for 30 and 60 minutes (Fig. 15 A, B), clearly demonstrating that Fas ligation induces an interaction between calmodulin and ADAM15.

To analyze, whether the inhibition of the $\mathrm{Ca}^{2+}$-conformation of calmodulin can interfere with the Fas receptor-induced binding of calmodulin to ADAM15, co-immunoprecipitations using ADAM15 antibodies of lysates from chondrocytes stimulated with the Fas receptor activating antibody $\mathrm{CH}-11$ antibody in the presence of TFP were performed. No co-precipitates of ADAM15 and calmodulin were detectable in the lysates from ADAM15-cells upon stimulation with $\mathrm{CH}-11$ in the presence of TFP (Fig. $15 \mathrm{~B}$ ), clearly showing that the $\mathrm{Ca}^{2+}$ conformation of calmodulin induced by the ligation of the Fas receptor is required for an efficient binding to ADAM15. 
IP: ADAM15

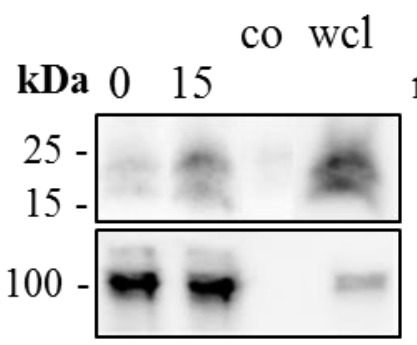

\section{IP: ADAM15}

$\min$

calmodulin

ADAM15

\section{CH-11 | CH-11 + TFP}

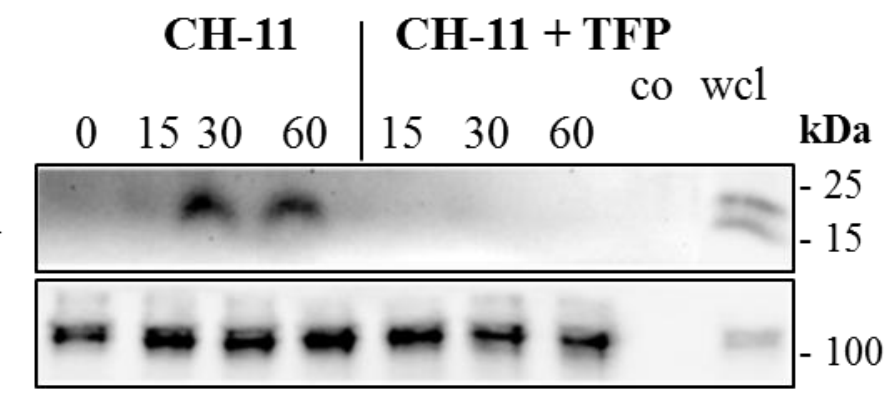

Fig. 15. The recruitment of calmodulin to ADAM15 upon Fas ligation. (A, B) Coimmunoprecipitations (IP) of calmodulin with ADAM15 in RASFs (A) and ADAM15-transfected chondrocytes (B) using ADAM15 antibodies from cells, which were stimulated with the Fas-activating antibody $\mathrm{CH}-11$ for $15-60$ minutes and immunodetection using calmodulin antibodies, showing a Fas receptor-triggered interaction of calmodulin with ADAM15 in RASFs and ADAM15-cells. Parallel coincubation with TFP inhibits these interactions. As control (co), lysates were incubated with Protein $\mathrm{G}$ sepharose beads only, $\mathrm{wcl}=$ whole cell lysate, $(20 \mu \mathrm{g})$. Representative results from 3 independently performed experiments are shown.

\subsection{Fas/CD95 -induced interaction of calmodulin and Fas/CD95}

\subsubsection{Double immunofluorescence staining of calmodulin and Fas/CD95 in RASFs}

To analyze, whether triggering Fas receptors leads to an association of calmodulin with Fas/CD95 in live cells, double immunofluorescence stainings of Fas receptor stimulated and unstimulated RASFs using specific antibodies to calmodulin and CD95 were performed.

The stimulation of Fas/CD95 resulted in a staining pattern, in which calmodulin and CD95 co-localize in patches at the cell surface, which were not detectable in unstimulated RASFs (Fig. 16). This clearly shows that Fas receptor activation in live RASFs leads to a redistribution of calmodulin to Fas/CD95 at the cell membrane. 


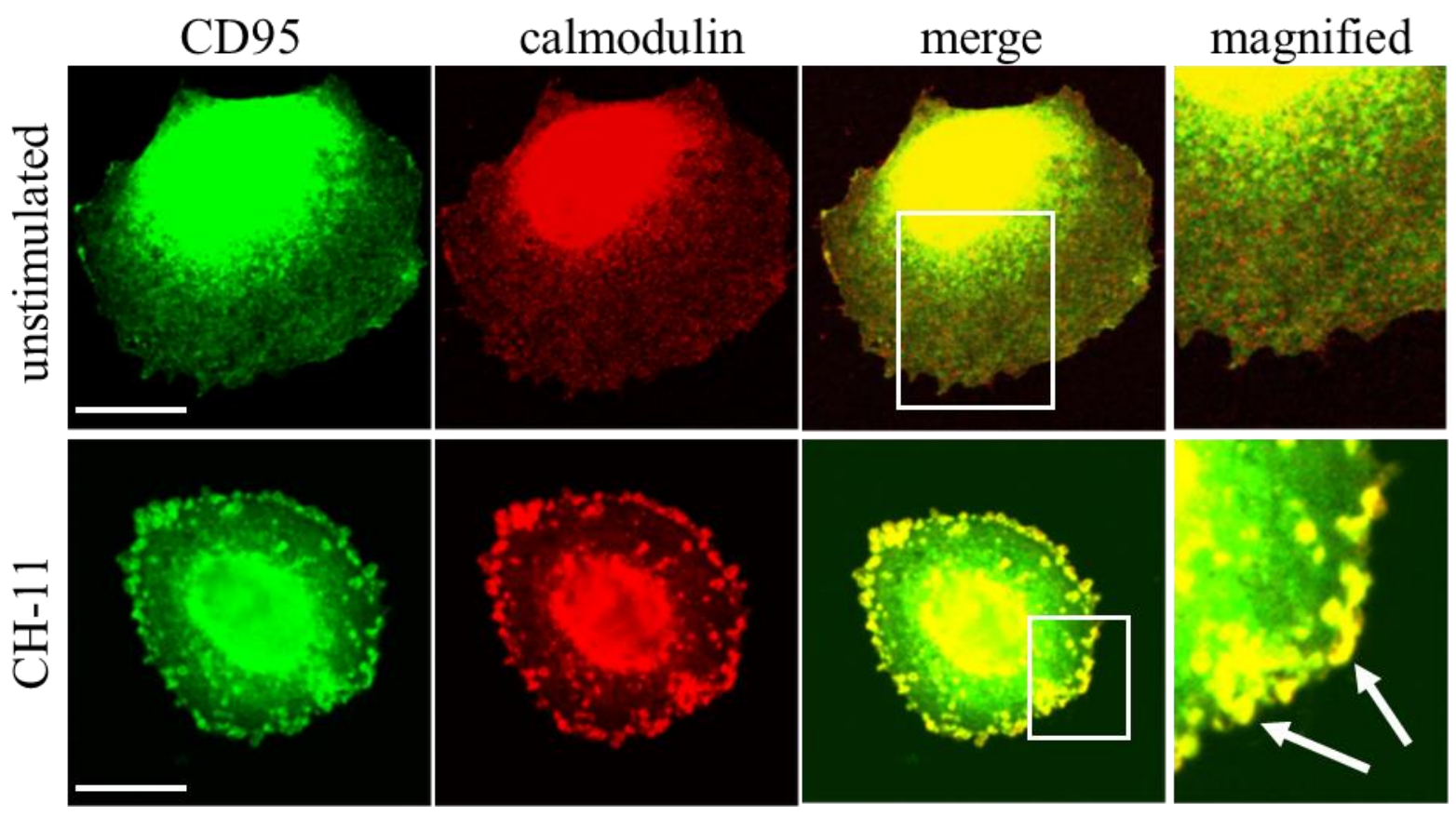

Fig. 16. Recruitment of calmodulin to Fas/CD95 upon Fas ligation. Confocal microscopy of double immunofluorescence stainings of rheumatoid arthritis synovial fibroblasts (RASFs) stimulated with Fasactivating $\mathrm{CH}-11$ antibody $(2 \mu \mathrm{g} / \mathrm{ml})$ for 10 minutes, using specific antibodies to CD95 and calmodulin. Shown is the association of calmodulin with CD95 upon Fas ligation (indicated by white arrows). All images were taken using an objective 63x, except the last panel that shows a magnified area (indicated by white inset). Size bar $=20 \mu \mathrm{m}$.

\subsubsection{Co-Immunoprecipitation of calmodulin with Fas/CD95 in RASFs}

To confirm the results obtained from the double immunofluorescence stainings (Fig. 16), co-immunoprecipitations of lysates from RASFs and full-length ADAM15 transfected chondrocytes using anti-Fas/CD95 antibodies and immunodetection with calmodulin antibodies were performed.

Co-immunoprecipitation studies demonstrate that, calmodulin is not bound to Fas/CD95 in the unstimulated RASFs (Fig. 17 A). Correspondingly, ADAM15-transfected chondrocytes do not exhibit detectable amounts of calmodulin co-precipitated with Fas/CD95 in unstimulated cells (Fig. 17 B). However, calmodulin can be coprecipitated with Fas/CD95 from RASFs following 15 minutes of activation via the Fas receptor. Accordingly, immunoprecipitates of Fas/CD95 derived from ADAM15-transfected cells upon Fas-stimulation for 30 and 60 minutes displayed increasing signal intensities for calmodulin therby providing clear evidence for a Fas activation induced interaction between Fas/CD95 and calmodulin (Fig. 17 A, B). To 
analyze, whether an inhibition the $\mathrm{Ca}^{2+}$-conformation of calmodulin affects the Fas receptorinduced binding of calmodulin to the Fas receptor, co-immunoprecipitations of lysates from chondrocytes stimulated with the Fas receptor activating antibody $\mathrm{CH}-11$ antibody in the presence of TFP were performed using ADAM15 antibodies. No co-precipitates of ADAM15 and calmodulin were detected in the lysates from ADAM15-cells upon stimulation with $\mathrm{CH}-11$ in the presence of TFP (Fig. $17 \mathrm{~B}$ ) thereby providing clear evidence that the $\mathrm{Ca}^{2+}$-conformation of calmodulin induced by stimulation of the Fas receptor is required for an efficient binding to ADAM15.

A

IP: Fas/CD95

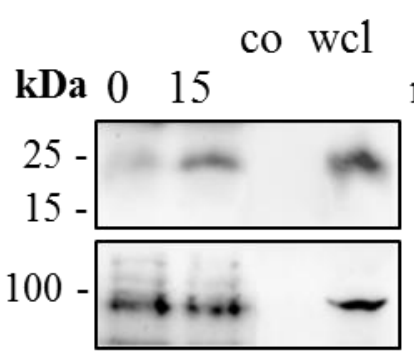

B

IP: Fas/CD95

$\min$

calmodulin

ADAM15
CH-11 $\mid$ CH-11 + TFP

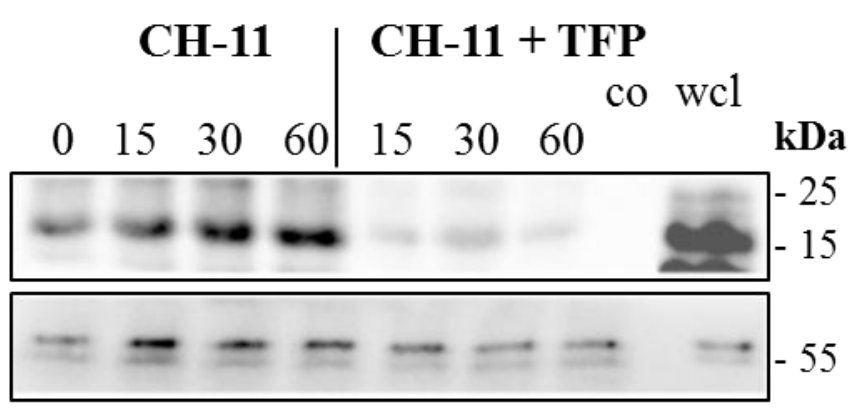

Fig. 17. Recruitment of calmodulin to Fas/CD95 upon Fas ligation in RASFs. (A, B) Coimmunoprecipitations (IP) of calmodulin with Fas/CD95 in RASFs (A) and ADAM15-transfected chondrocytes (B) using Fas/CD95 antibodies from cells, which were stimulated with the Fas-activating antibody $\mathrm{CH}-11$ for $15-60$ minutes and immunodetection using calmodulin antibodies, showing a Fas receptor-triggered interaction of calmodulin with the Fas receptor in RASFs and ADAM15-cells. Parallel coincubation with TFP inhibits these interactions. As control (co), lysates were incubated with Protein Anti-IgM sepharose beads only, wcl = whole cell lysate, $(20 \mu \mathrm{g})$. Representative results from 3 independently performed experiments are shown.

Taken together, the efficient inhibition of Fas receptor-triggered interactions between calmodulin and Fas/CD95 or ADAM15 by a selective pharmacological blockade of calmodulin in its $\mathrm{Ca}^{2+}$-dependent conformation suggests that the $\mathrm{Ca}^{2+}$ influxes induced by Fas ligation promote the conformational changes in calmodulin, crucial for binding to Fas/CD95 as well as ADAM15. 


\subsection{Fas/CD95 activation-induced interaction of Fas/CD95 and ADAM15}

\subsubsection{Double immunofluorescence stainings of Fas/CD95 and ADAM15 in RASFs}

To analyze, whether triggering Fas receptors in RASFs leads to an association of Fas/CD95 with ADAM15 in vivo, double immunofluorescence staining using specific antibodies to ADAM15 and CD95 were performed.

In unstimulated RASFs, both ADAM15 and Fas/CD95 are stained in a diffuse pattern, however, the stimulation of Fas/CD95 resulted in a pattern in which both the Fas receptor and ADAM15 co-localize in patches at the cell surface, which were not detectable in unstimulated RASFs (Fig. 18). This clearly shows that Fas receptor activation leads to the redistribution of ADAM15 into the CD95-cap in living RASFs.

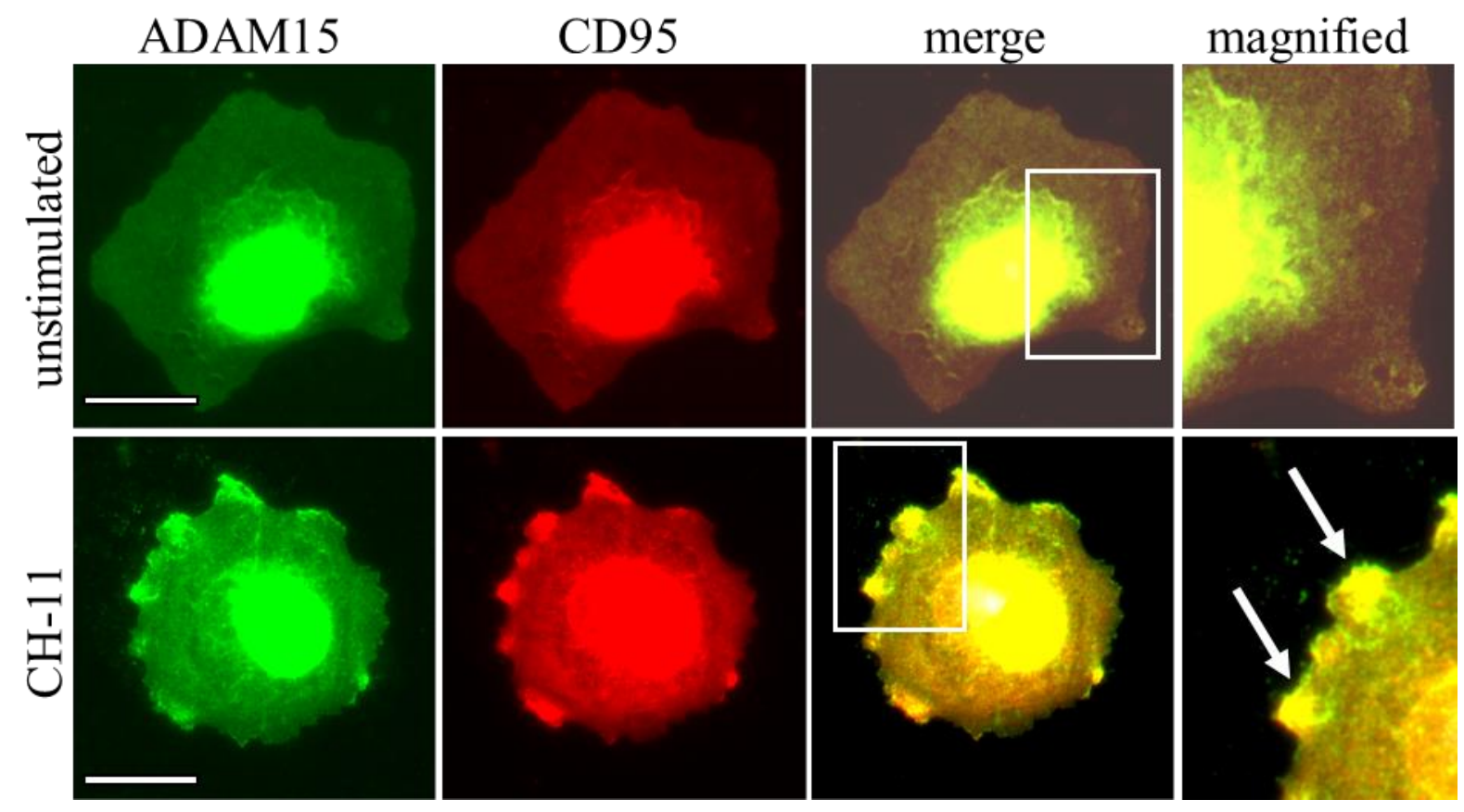

Fig. 18. ADAM15 recruitment to the CD95-cap upon Fas/CD95 ligation. Confocal microscopy of double immunofluorescence stainings of rheumatoid arthritis synovial fibroblasts (RASFs) either unstimulated or stimulated with Fas-activating CH-11 antibody $(2 \mu \mathrm{g} / \mathrm{ml}$, Fas/CD95 activating antibody), using specific anti-CD95 and anti-ADAM15 antibodies. Fas receptor-induced co-localization of ADAM15 and Fas/CD95 in patchy-like areas (indicated by white arrows) located at the cell surface. All pictures were taken with an objective $63 x$, except the last panel that shows a magnified area (indicated by white inset). Size bar $=20 \mu \mathrm{m}$. 


\subsubsection{Co-Immunoprecipitation of ADAM15 with Fas/CD95 in T/C28a4 cells}

To analyze the influence of the $\mathrm{Ca}^{2+}$-dependent calmodulin conformation on Fas receptor-induced interaction of Fas/CD95 and ADAM15, co-immunoprecipitations (co-IPs) using anti-Fas/CD95 antibodies and immunodetection with ADAM15 antibodies and vice versa using anti-ADAM15 antibodies and immunodetection with Fas/CD95 antibodies were performed.

Immunoblots of complexes precipitated with either anti-Fas/CD95 or anti-ADAM15 antibodies revealed that in unstimulated cells, no association between ADAM15 and Fas/CD95 was detectable in ADAM15-transfected chondrocytes. However, the stimulation of Fas/CD95 for 15-60 minutes led to an increase in the signal intensities for ADAM15 or Fas/CD95 in both co-IPs using Fas/CD95 or ADAM15 antibodies (Fig. 19 A, B), clearly showing that Fas receptor triggering leads to an induced interaction between ADAM15 and Fas/CD95.

Parallel co-IPs in cells stimulated with the Fas-activating antibody $\mathrm{CH}-11$ in the presence of TFP were performed to elucidate the effect of calmodulin inhibition by TFP on the ADAM15-Fas/CD95 interaction. These Fas receptor triggered ADAM15/Fas interactions were not inhibited by TFP, as both ADAM15 is co-precipitated with Fas/CD95 and vice versa Fas/CD95 is co-precipitated with ADAM15 in cells stimulated in the presence of TFP, suggesting that calmodulin is not required for the Fas receptor triggered interaction between Fas/CD95 and ADAM15. 
A

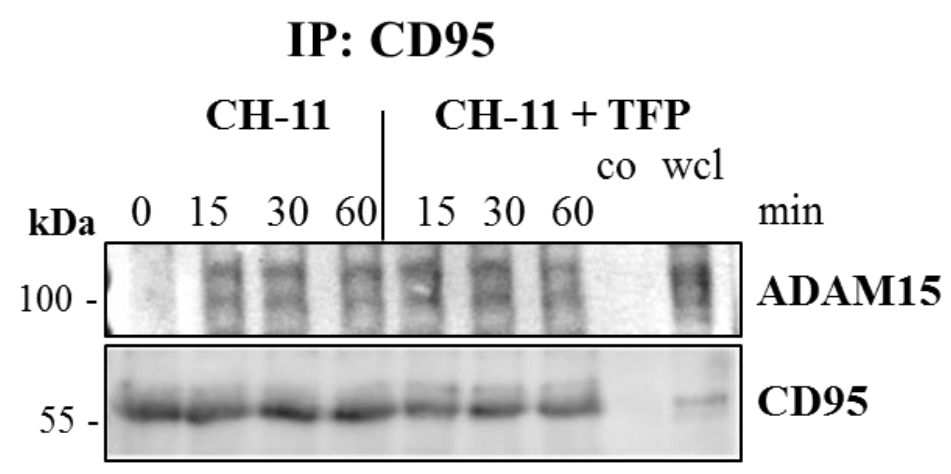

B

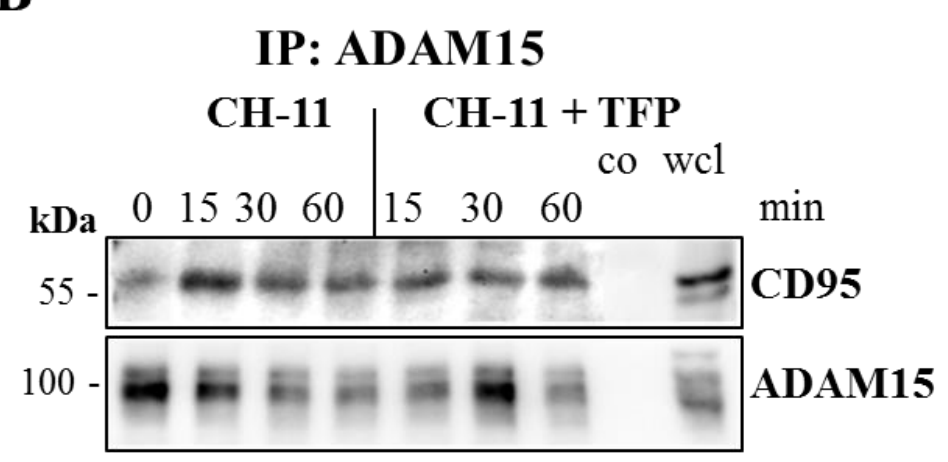

whole cell lysates

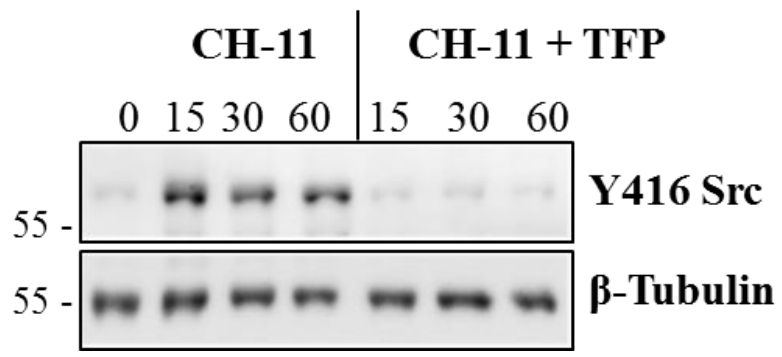

Fig. 19. Induced association of Fas/CD95 and ADAM15 upon Fas receptor ligation. Immunoprecipitations of ADAM15-transfected T/C28a4 chondrocytes stimulated with either Fas receptor agonist or Fas receptor agonist \& trifluoperazine (TFP) using either Fas/CD95 (A) or ADAM15 (B) antibodies were analyzed by immunoblotting, showing a Fas-ligation dependent association of Fas and ADAM15 that is not sensitive to calmodulin inhibition by TFP. Bottom, as a control for functionality of TFP, whole cell lysates (wcl) were stimulated with FasL, which yielded phosphorylation of Src at Y416 and its inhibition by TFP. Tubulin served as a loading control. As control (co), chondrocyte lysates were incubated with Protein G sepharose (B), or with anti-IgM sepharose (A). $\beta$-Tubulin served as loading control. $\mathrm{wcl}=$ whole cell lysate. Representative results from three independent experiments are shown. 


\subsection{Fas/CD95-induced interaction of Src and calmodulin}

Calmodulin was shown to interact with Src markedly stronger in presence of $\mathrm{Ca}^{2+}$ ions (Fig. 11). To analyze, whether Fas ligation has an influence on the interaction between Src and calmodulin, co-IPs using either calmodulin or Src antibodies, followed by immunoblotting using anti-Src or anti-calmodulin antibodies, respectively, were performed. In unstimulated cells, no Src is precipitated with calmodulin and no calmodulin is precipitated with Src (Fig 20 A, B). A marked, time-dependent increase of co-precipitated total Src or calmodulin was observed in both the calmodulin co-IPs using calmodulin or Src antibodies after Fas receptor stimulation for 30 and 60 minutes (Fig. 20 A, B), showing that Fas/CD95 activation leads to an interaction between calmodulin and Src.

Paralell co-IPs in Fas-stimulated cells in the presence of calmodulin inhibitor TFP revealed that neither Src nor calmodulin were co-precipitated with each other (Fig. 20 A, B), strongly indicating that the interaction between Src and calmodulin is strictly dependent on the $\mathrm{Ca}^{2+}$-activated conformation of calmodulin. 

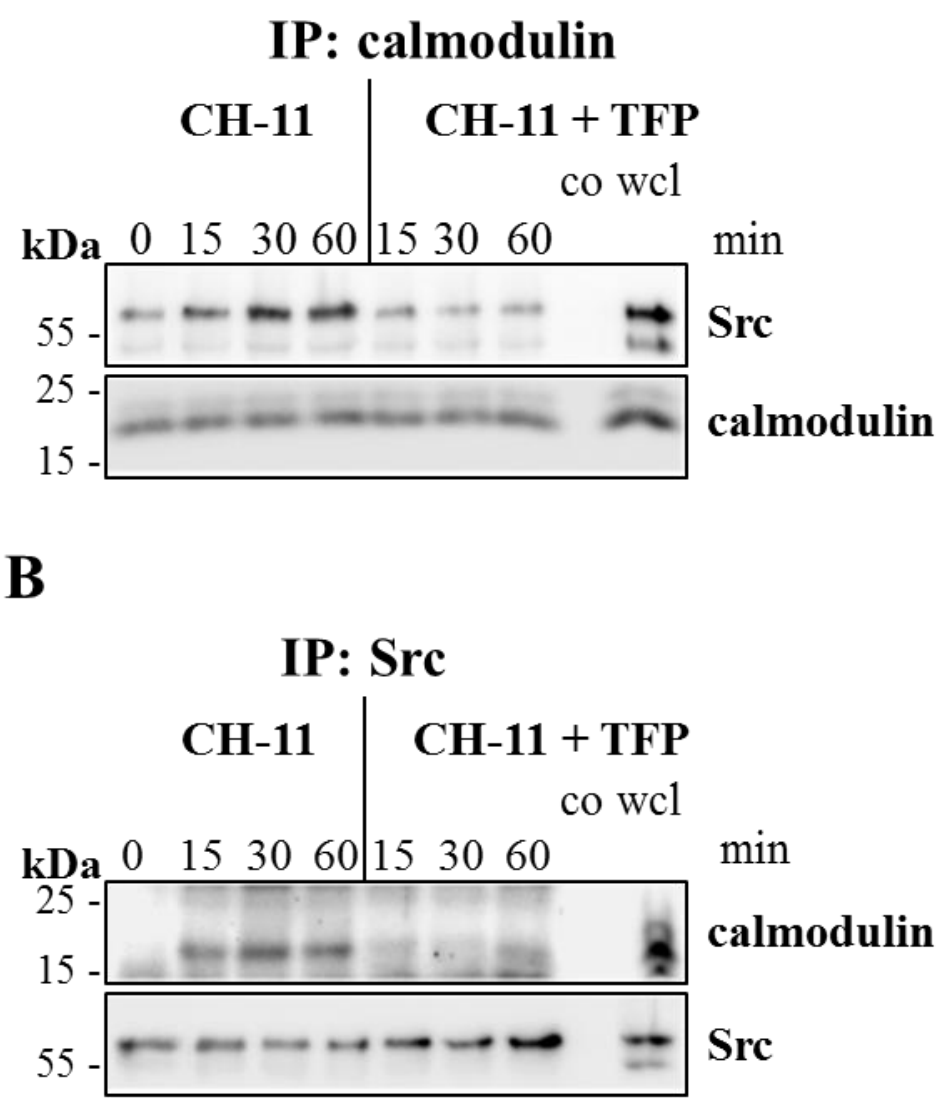

Fig. 20. Enhanced interaction of calmodulin with Src upon Fas ligation. Immunoprecipitations of ADAM15-trancfected T/C28a4 chondrocytes stimulated with a Fas receptor agonist alone or in combination with a calmodulin inhibitor TFP, using either anti-calmodulin (A) or anti-Src (B) antibodies followed by an immunodetection of Src (A) and calmodulin (B) respectively. As control (co), lysates from unstimulated cells were incubated with Protein G sepharose. wcl =whole cell lysate. Representative results from three independently performed experiments are shown.

\subsection{Effect of CRAC channel inhibition on the phosphorylation of Src and} FAK

The demonstrated role of $\mathrm{Ca}^{2+}$ ions in the interactions between calmodulin and ADAM15 (Fig. 12) or Fas receptor (Fig. 11) suggested that $\mathrm{Ca}^{2+}$ ions are a crucial factor leading to signal transduction in cells upon Fas receptor activation. Therefore, it was analyzed, whether inhibition of CRAC/Orai1 channels might influence Fas-mediated phosphorylations of Src and FAK. RASFs were stimulated with FasL or FasL plus the CRAC/Orail channel inhibitor BTP$2(25$ and $50 \mu \mathrm{M})$, and analyzed by immunoblotting using specific anti-phospho-Src and antiphospho-FAK antibodies. 
All FasL-stimulated phosphorylations of Src at Y416 and of FAK at Y576 and Y861 that were detectable after 30 minutes of stimulation were efficiently inhibited $>90 \%$ by BTP- 2 at $25 \mu \mathrm{M}$ and completely blocked by BTP- 2 at $50 \mu \mathrm{M}$. The phosphorylation of FAK at Y397, which was also induced by FasL, was inhibited $~ 70 \%$ by BTP-2 $(25 \mu \mathrm{M}$ and $50 \mu \mathrm{M})$ (Fig.21), indicating that Fas/CD95-elicited $\mathrm{Ca}^{2+}$ influx via the CRAC/Orail channel is necessary for the induction of FAK and Src phosphorylations.

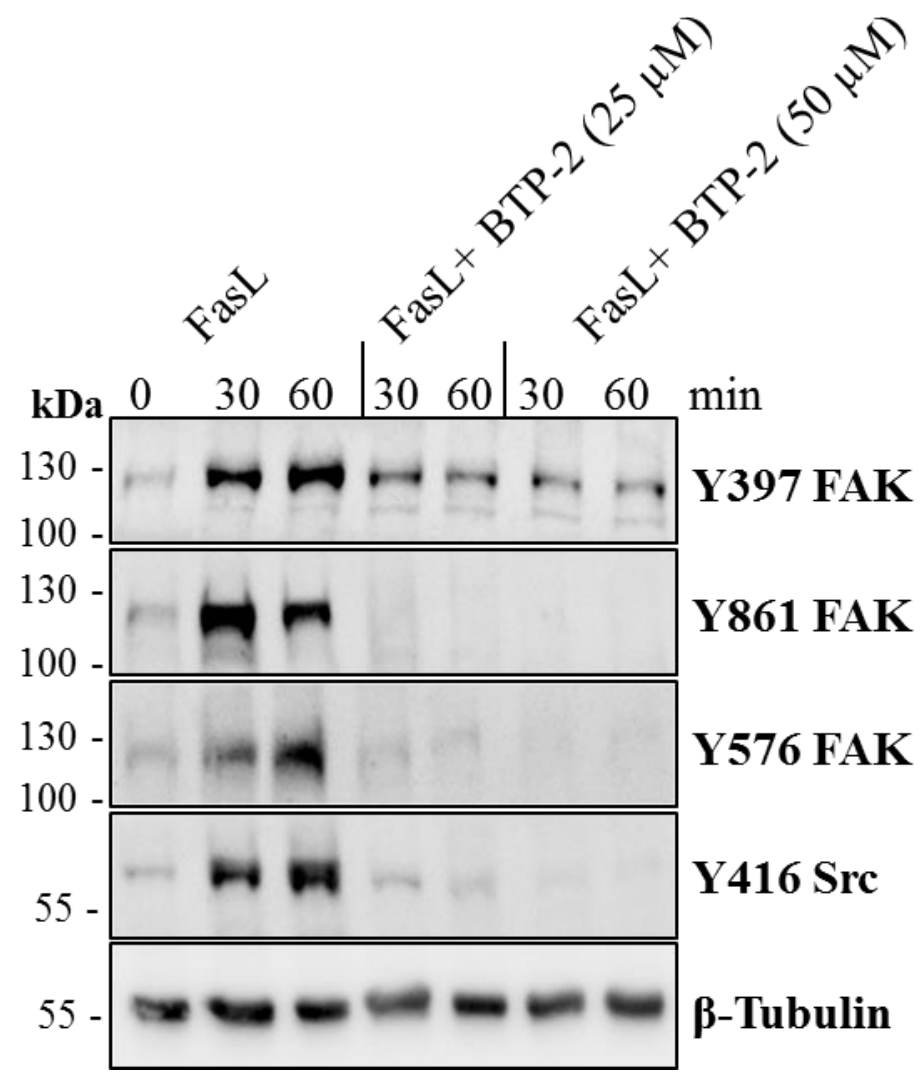

Fig. 21. CRAC mediated calcium influx is crucial for the ADAM15-dependent phosphorylations of Src and FAK. Immunoblots from lysates of RASFs that were stimulated with FasL ( $100 \mathrm{ng} / \mathrm{ml})$ alone or together with the CRAC/Orai1 inhibitor BTP-2 $(25$ and $50 \mu \mathrm{M})$ for 30 and 60 minutes, showing the inhibition of FasL-induced phosphorylations of Src and FAK by BTP-2. $\beta$-tubulin served as loading control. Representative results from 3 independent experiments are shown. 


\subsection{Influence of ADAM15/Src/Calmodulin signaling on the resistance of RASFs to FasL induced apoptosis}

\subsubsection{Influence of calmodulin and CRAC channel inhibition on FasL induced Caspase 3/7 activity in RASFs}

As ADAM15-dependent phosphorylations of Src and FAK have been shown to require the $\mathrm{Ca}^{2+}$ conformation of calmodulin (Fig. 10) as well as $\mathrm{Ca}^{2+}$ ion influx (Fig. 21), it was analyzed, whether calmodulin inhibition by TFP or $\mathrm{Ca}^{2+}$ influx inhibition by BTP-2 could reduce the resistance of RASFs to Fas receptor- mediated apoptosis. RASFs from 10 different donors were treated with TFP, BTP-2, FasL, or FasL in combinations with each inhibitor for 18 hours. Caspase 3/7 measurements are depicted in a dot plot (Fig. 22) with each dot representing the calculated mean of triplicate measurements for 1 donor. RASFs from 8 out of 10 donors responded to FasL stimulation with an increase of their caspase activity, while RASFs from 2 donors remained rather unresponsive (Fig. 22). RASFs from all donors did not show any induction of caspase activity upon incubation with either TFP $(25 \mu \mathrm{M})$ or BTP-2 (25 and $50 \mu \mathrm{M})$ compared to DMEM control. However, coincubation of TFP or BTP- 2 with FasL led to statistically significant increases in caspase activity above the level induced by FasL alone (Fig. 22), indicating their synergistic death-inducing potential in combination with Fas ligation. 


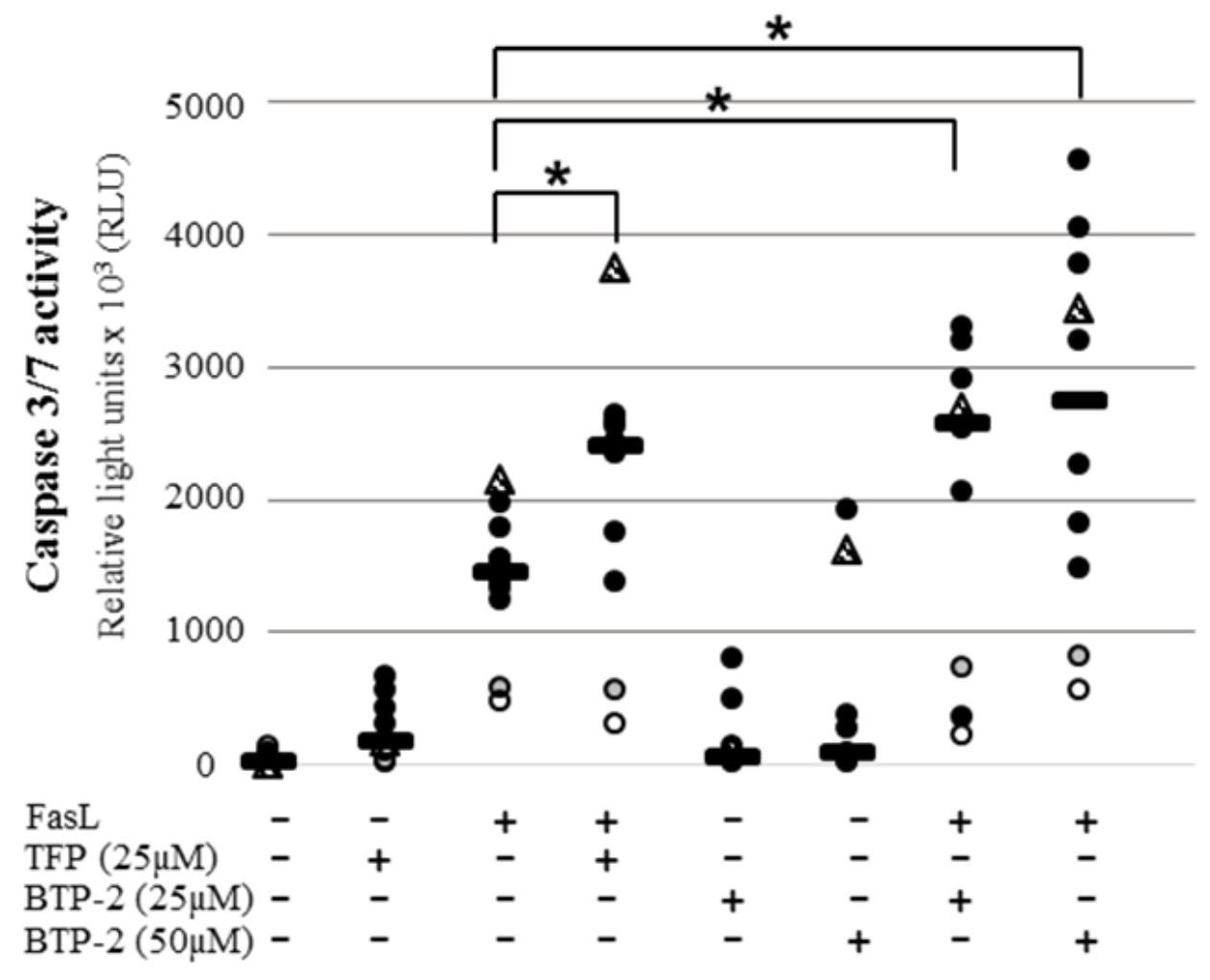

Fig. 22. Increased apoptosis rate of RASFs upon calmodulin inhibition by TFP and by CRAC/Orai1 channel inhibitor BTP-2. FasL-induced apoptosis in RASFs results in significantly and synergistically enhanced caspase 3/7 activity (measured in triplicates) in RASFs upon coincubation with TFP or BTP- 2 for 18 hours. Open circles represent donors whose RASFs did not respond well to any agent. Solid circles represent donors whose RASFs yielded high caspase activities. Each symbol represents the calculated mean of triplicate measurements for 1 donor; horizontal lines indicate the median for 10 different donors. $*=P<0.05$ by Wilcoxon signed rank test.

\subsubsection{Influence of calmodulin and CRAC channel inhibition on the total apoptosis rate of} FasL induced apoptosis

In order to determine the total apoptosis rates, stainings of annexin $\mathrm{V}$, a marker for apoptosis, of synovial fibroblasts from RA donors treated with either FasL, and FasL/TFP or FasL/BTP- 2 cocktails for 18 hours were performed. The RASFs from donor \#2 (Fig. 22, triangle) displayed a $40 \%$ apoptosis rate upon Fasl stimulation, which increased to $\sim 60 \%$ with a cocktail of FasL and BTP-2, with an $90 \%$ apoptosis rate when stimulated with FasL and TFP (Fig. 23), clearly showing a synergistic effect of the FasL/inhibitor cocktails on the total apoptosis rate. However, RASFs from the low responding donor \#1 (Fig, 22, open circle without shading) only displayed apoptosis rates well below $20 \%$ independent of the compound applied 
(Fig. 23). Collectively, pharmacologic inhibition of either CRAC/Orai1 channel or calmodulin can synergistically enhance FasL-induced apoptosis induction in RASFs.

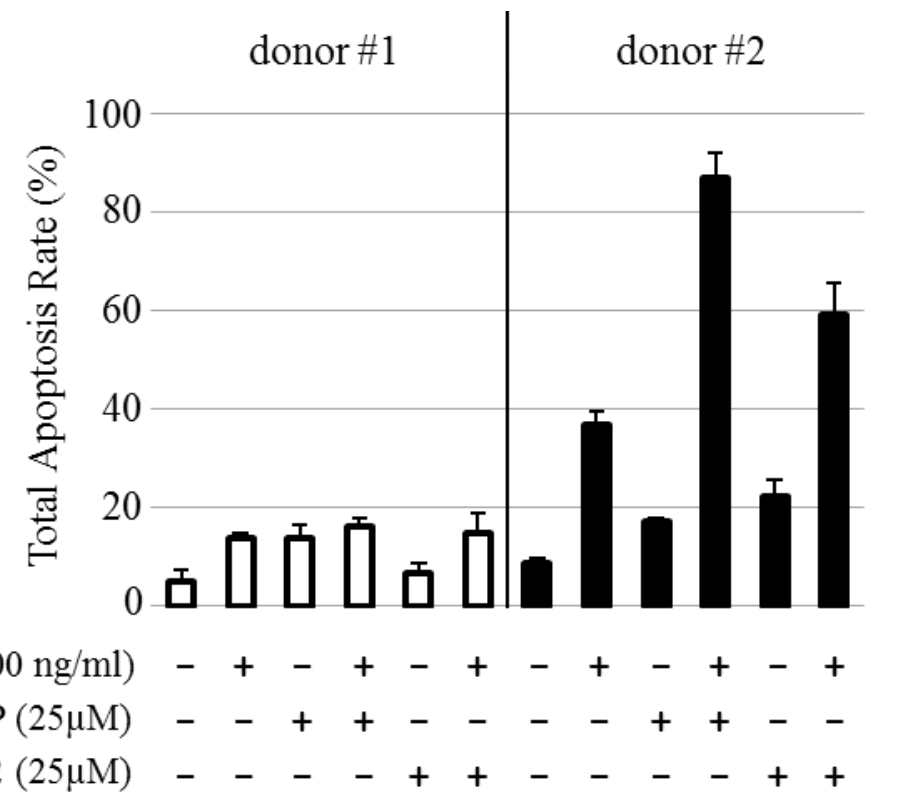

Fig. 23. An increase in the total apoptosis rate induced by FasL upon calmodulin and CRAC/Orai1 channel inhibition. Annexin V (using FITC-conjugated Annexin V) staining of RASFs from two different donors (donor \#1 = open circle without shading, donor \#2 = triangle from Fig. 22) were untreated, incubated with TFP or BTP-2, or treated with either FasL or FasL/inhibitor cocktails for 18 hours, and total apoptosis rate was determined by correlating cells that stained positive for annexin $\mathrm{V}$ to the whole cell population. Results from 3 independent experiments are shown. Values are the mean \pm SD.

\subsubsection{The synergistic effect of ADAM15-knockdown and of calmodulin or CRAC/Orai1} inhibition on FasL induced apoptosis

In order to analyze the influence of ADAM15 on the apoptosis induction by FasL with concomitant CRAC/Orai1 channel or calmodulin inhibition caspase assays of RASFs after silencing of ADAM15 were performed. After ADAM15 silencing, RASFs were stimulated with FasL $(100 \mathrm{ng} / \mathrm{ml})$, TFP $(25 \mu \mathrm{M})$, FasL/TFP, BTP- $2(25 \mu \mathrm{M})$, and FasL/BTP- 2 for 18 hours and caspase $3 / 7$ activity determined.

Immunoblotting revealed that in cell silenced with specific siRNAs I and II ADAM15 was downregulated by $\sim 80 \%$ as compared nonsilencing control or transfection reagent alone (Fig. 24 A) 
RASFs silenced with ADAM15 siRNAs I and II displayed significantly higher caspase activity upon FasL stimulation in comparison to the nonsilencing siRNA and the transfection reagent (fig. $24 \mathrm{~B}$ ).

Neither TFP alone nor BTP- 2 alone elicited any caspase activity in RASFsas compared to DMEM, which served as an incubation control (Fig. 24, B). However, Moreover, apoptosis induction with FasL cocktails containing either inhibitor resulted in significantly and synergistically increased caspase activity in ADAM15-downregulated RASFs compared to nonsilenced cells. Thus, the synergistic effect of ADAM15 knockdown and the inhibition of either calmodulin or CRAC /Orail channels on FasL induced apoptosis shows that ADAM15 is crucially involved in $\mathrm{Ca}^{2+}$-triggered survival signaling elicited by Fas stimulation in RASFs. 
A

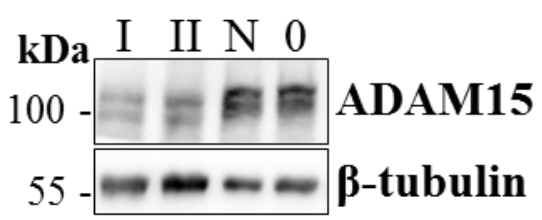

B

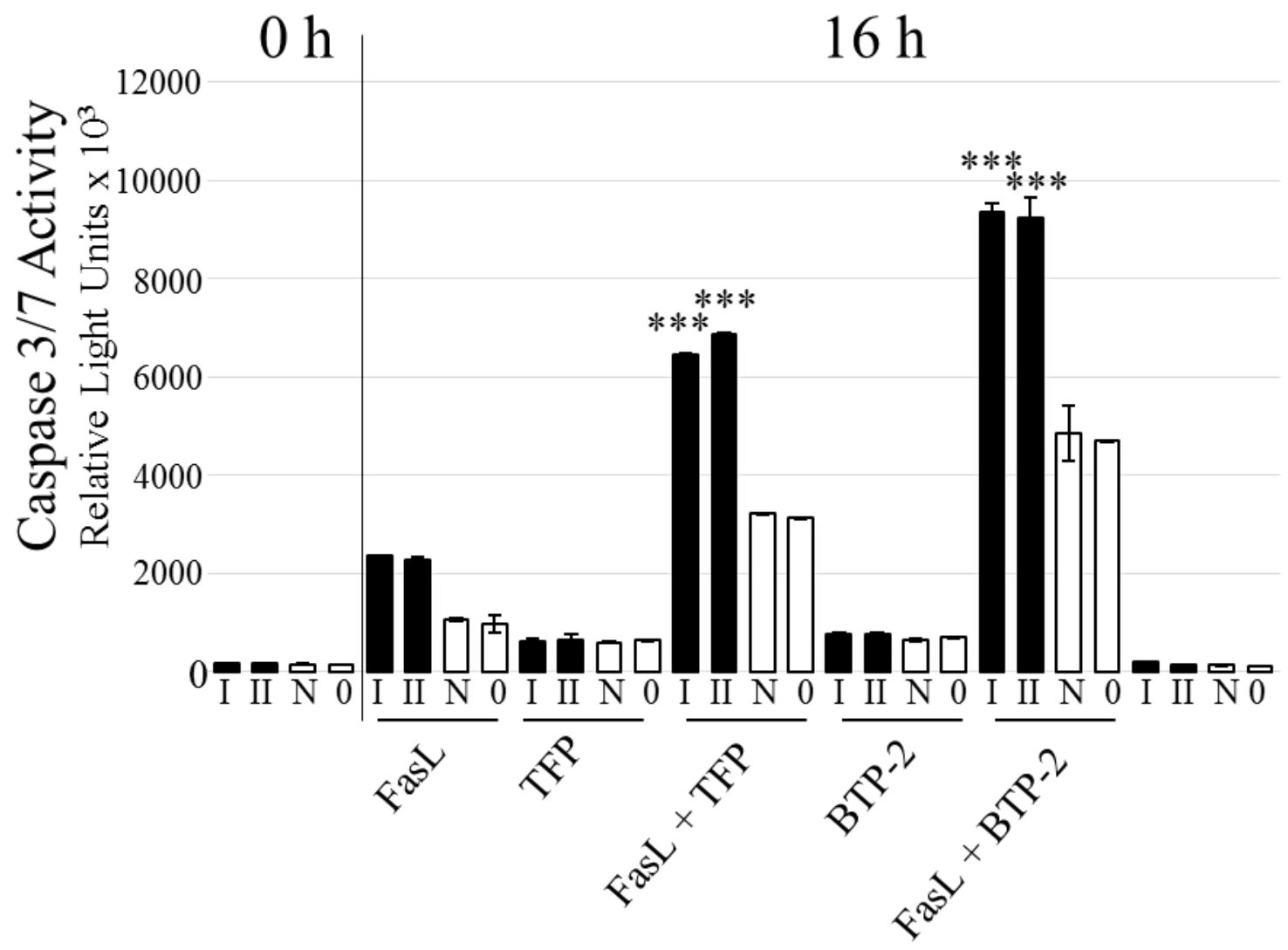

Fig. 24. Higher caspase 3 activity upon apoptosis induction with FasL and inhibition of calmodulin and CRAC/Orai1 channels following ADAM15 silencing in rheumatoid arthritis synovial fibroblasts (RASFs). (A) Immunoblots of ADAM15 downregulated by siRNA I and II, compared to a nonsilencing siRNA control $(\mathrm{N})$ or transfection agent alone (0) using an anti-ADAM15 antibody. (B) After ADAM15 was silenced for 40 hours with specific siRNAs I and II, RASFs were incubated for 16 hours with FasL $(100 \mathrm{ng} / \mathrm{ml})$, TFP $(25 \mu \mathrm{M})$, BTP- $2(25 \mu \mathrm{M})$, and cocktails of FasL with either inhibitor. Apoptosis induction by either FasL/TFP or FasL/BTP-2 resulted in significantly increased caspase 3 activity in ADAM15- silenced RASFs as compared to treatment with a nonsilencing siRNA control (N) or transfection agent alone (0). DMEM served as an incubation control. Results are from RASFs from a representative donor (of 5 donors tested). Values are the mean $\pm \mathrm{SD}$. $* *=\mathrm{P}<0.002$; *** $=\mathrm{P}<0.0002$ versus nonsilencing controls at the same time point, by Student's t- test. 


\section{Discussion}

\subsection{The role of ADAM15 on Fas receptor induced cell signaling}

Resistence of RASF to Fas-mediated apoptosis in chronically inflamed joints significantly contributes to the aggressive phenotype of these clls and their role as important effectors of joint destruction in the pathogenesis of RA. Recently, it was shown that stimulation of the Fas receptor induced Src/FAK-mediated survival signaling in RASFs that was virtually absent upon down-regulation of ADAM15 (Böhm et al., 2013). In the present study we identified calmodulin as a "cross-talk" protein linking death-inducing Fas/CD95 ligation to ADAM15-dependent activation of survival pathways.

Using the chondrocyte T/C28a4 cells transfected with full-length ADAM15 or a mutant lacking the cytoplasmic tail, we could provide unequivocal evidence that Src/FAK activation elicited by Fas ligation is critically dependent on the cytoplasmic domain of ADAM15. Moreover, an ADAM15-dependent activation of Src and FAK is instrumental for triggering cell survival upon Fas ligation. Also, other cell death inducing stimuli have been shown to result in an enhanced phosphorylation of Src and FAK. Thus, an involvement of ADAM15 in modulating apoptotic signaling was demonstrated in osteoarthritis (OA) chondrocytes subjected to genotoxic stress using the DNA topoisomerase inhibitor I camptothecin (Fried et al., 2012). Additionally, an increase in the phosphorylation of FAK at Y576 and Y861, which are common phosphorylation target sites of Src, has already been associated with increased apoptosis resistance induced by various stimuli. For instance, HL-60 leukemic cells, were shown to require FAK kinase activity, which is mainly regulated by the phosphorylation of tyrosine Y576, to resist apoptosis induced by ionizing radiation (Kasahara et al., 2002). Furthermore, colon cancer cells Caco2 display an increased phosphorylation of tyrosines Y397, Y576 and most prominently Y861 upon hyperosmotic stress stimulation, which ultimately renders them highly resistant to apoptosis induced by hyperosmotic stress but also ECM detachment or cytoskeleton disrupment (Lunn et al., 2007).

Interestingly, ADAM15 is not the only member of ADAMs family, which has been implicated in cell signaling. In a myoblast cell line, a binding between the cytoplasmic domain of ADAM12 and Src via the SH3 domain was shown to enforce the open conformation of Src and ultimately cause the activation of the kinase (Kang et al., 2000). It is hypothesized that by activation Src, ADAM12 might contribute to the muscle development because activated Src can phosphorylate myoblast-specific caveolin-3, which is required for myoblast fusion. 
Furthermore, it was discovered recently that in mesangial cells exposed to high glucose, ADAM17 interacts with Src and FAK, leading to an increase in their phosphorylation and their activation. Src can in turn phosphorylate ADAM17 causing its activation, which is generaly thought to promote the accumulation of glomerular matrix and promote the progression of diabetic nephropathy (Li et al., 2018). Also ADAM15 was found to mediate Src and Erk1/2 activation, independently of the metalloproteinase activity, in endothelial cells exposed to thrombin, which increased the permeability of the endothelium and affected neutrophil migration (Sun et al., 2010). A study using recombinant peptides containing SH3 domains revealed that ADAM family members bind to a wide array of SH3-containing peptides, which for ADAM15 included Src family kinases but also unrelated proteins, like sorting-nexin-33 (SNX33), a protein also involved in cell signaling (Kleino et al., 2015).

Taken together, the results of this study supports the emerging role of ADAM15 as a signaling molecule, which markedly enhances the apoptosis resistance of rheumatoid arthritis synovial fibroblasts by activating focal adhesion kinase and Src in response to Fas receptor stimulation.

\subsection{Interactions between ADAM15, Fas/CD95 and calmodulin}

Our data show for the first time $\mathrm{Ca}^{2+-}$ dependent binding of ADAM15 to calmodulin. Pull-down assays using recombinant calmodulin-conjugated sepharose revealed that ADAM15 is precipitated exclusively in the presence of $\mathrm{Ca}^{2+}$ ions. Also, in vitro protein binding assays revealed that the binding of the recombinant cytoplasmic domain of ADAM15 to calmodulin was efficiently blocked by EDTA and by the calmodulin inhibitor TFP in a concentrationdependent manner. TFP, a highly specific calmodulin antagonist binding to the $\mathrm{Ca}^{2+}$-activated calmodulin conformation in 2 hydrophobic pockets adjacent to the $\mathrm{Ca}^{2+}$-coordinating residues, efficiently inhibits protein interactions at these sites, further supporting the notion that the interaction between ADAM15 and calmodulin requires the $\mathrm{Ca}^{2+}$-bound conformation of calmodulin (Vandonselaar et al., 1994; Halling et al., 2016).

Our results revealed that in in-vitro protein binding assays the interaction of ADAM15 with calmodulin was in the low micromolar range with a dissociation constant $\mathrm{K}_{\mathrm{d}} \sim 2 \mu \mathrm{M}$. Calmodulin binds to a plethora of over 2000 proteins with $\mathrm{K}_{\mathrm{d}}$ ranging from $40 \mathrm{nM}$ for CamKII to $18-22 \mu \mathrm{M}$ for Rab3a protein (Kajo et al., 2001). Interestingly, the interaction of the Fas receptor with calmodulin has previously been analyzed by surface plasmon resonance (SPR), which revealed that calmodulin binds to Fas with a $\mathrm{K}_{\mathrm{d}} \sim 2 \mu \mathrm{M}$ in the presence of calcium ions, showing a similar $\mathrm{K}_{\mathrm{d}}$ value to the $\mathrm{K}_{\mathrm{d}}$ calculated for the binding of calmodulin to ADAM15 
(Fernandez et al., 2013), showing the same affinity of calmodulin binding to both ADAM15 and the Fas receptor.

Moreover, the present work provides clear evidence for the interaction of calmodulin with ADAM15 in the living cell, however, this interaction requires a preceding Fas ligation, which in turn triggers the recruitment of $\mathrm{Ca}^{2+}$-calmodulin to ADAM15. According to the results obtained from the pull-down- and protein binding- assays, TFP efficiently blocked the interaction in living cells, demonstrating that $\mathrm{Ca}^{2+}$-bound form of calmodulin is required for binding to ADAM15. It remained unclear, how an interaction between $\mathrm{Ca}^{2+}$-bound form of calmodulin and ADAM15 contributes to the triggering of Src/FAK pro-survival pathways by FasL, which otherwise elicits death signals. The previously demonstrated enhancing effect of ADAM15 on the FAK/Src phosphorylation in response to apoptosis-inducing genotoxic stress was shown to be dependent on the direct binding of ADAM15 to the C-terminus of FAK (Fried et al., 2012). The said interaction was, thereby reinforcing counter-regulatory survival pathways suggesting that ADAM15 provides a scaffold for the binding of FAK and Src.

Taken together with the discovery of a novel calmodulin-ADAM15 interaction, this indicated that apart from scaffolding Src and FAK, the cytoplasmic tail of ADAM15 assists the engagement of calmodulin to the complex following its coactivation in the context of the apoptotic signal.

Our data clearly show association of ADAM15 with Fas/CD95 upon Fas receptor stimulation, providing unequivocal evidence for recruitment of ADAM15 into the CD95-Cap at the cell membrane. Fas/CD95 was previously shown to interact with Src via a direct binding to calmodulin in pancreatic cancer cells stimulated with a Fas receptor agonist (Yuan et al., 2011). Efficient inhibition of Src and Fas receptor binding by the calmodulin inhibitor TFP demonstrated that the interaction between Src and CD95 is mediated by calmodulin. As compared to that, our results revealed that TFP has no effect on the novel Fas ligation-induced interaction between ADAM15 and Fas/CD95.

Concomitantly, cytosolic calmodulin is recruited to both membrane proteins (ADAM15 and Fas/CD95) upon Fas receptor triggering. Thus, binding of calmodulin to the cytoplasmic death domain of Fas has been reported previously to occur at a 2:1 ratio in a $\mathrm{Ca}^{2+}$ - dependent manner sensitive to TFP inhibition and was hypothesized to antagonize apoptosis execution by blocking FADD binding to Fas in DISC formation (Wu et al., 2005; Chen et al., 2008; Pawar et al., 2008; Fernandez et al., 2013).

The Fas receptor activation-dependent binding of the receptor and calmodulin is initiated by a CRAC/Orai1-dependent $\mathrm{Ca}^{2+}$ fluxes elicited by Fas receptor ligation, which might delay the execution of apoptosis by abrogating the death signals but might also promote the 
assembly of signaling complexes comprised of calmodulin and Src associated to ADAM15 scaffold already angaging cytoplasmic FAK (Cahalan et al., 2009). The immediate formation of such ADAM15-dependent pro-survival complexes into the CD95-Cap enables a quick activation of various anti-apoptotic pathways, for instance leading to the activation of FAK, which in turn leads to the upregulation of NF- $\kappa B$ and subsequent increase in the expression of XIAP which is an inhibitor of activated caspase 3, thereby enhancing the probability that the cell survives despite the induction of Fas/CD95-mediated apoptotic signaling (Böhm et al., 2010).

\subsection{Interactions of calmodulin and either Src or focal adhesion kinase (FAK)}

To fulfill the criteria necessary for an assembly of an ADAM15-dependent pro-survival complex, a physical interaction of calmodulin with other components of this complex, such as Src and FAK, is required. In this study, pull-downs using immobilized calmodulin revealed that indeed calmodulin binds not only to Src, the Fas receptor and the cytoplasmic domain of ADAM15 but also to FAK in chondrocyte cells transfected with ADAM15. Contrary to the interactions between calmodulin with either Fas/CD95 or ADAM15, which were strictly dependent on the presence of $\mathrm{Ca}^{2+}$ ions, the binding to Src and FAK was $\mathrm{Ca}^{2+}$-independent. This was consistent with the previously published data that show binding of calmodulin to of Src (Stateva et al., 2015). Furthermore, the $\mathrm{Ca}^{2+}$-independent binding of calmodulin to FAK has also been shown using pull-downs on calmodulin sepharose (Kohno et al., 2008).

Interestingly, pull-down assays using immobilized calmodulin revealed that in lysates from cells expressing full-length ADAM15, more Src was pulled-down as compared to vector control and ADAM15 $(\Delta \mathrm{C})$, which demonstrated that in the presence of full-length ADAM15 the interaction between Src and calmodulin is stronger, suggesting a scaffolding role of the cytoplasmic domain of ADAM15 for the Src/calmodulin binding.

\subsection{The ADAM15-dependent pro-survival signaling pathway upon Fas/CD95 stimulation.}

Our results can be summarized in a description of a potential scenario for Fas-mediated induction of survival signaling (Fig. 25). Upon binding of FasL (or agonistic antibodies), Fas receptors undergo homotrimerization and/or subsequent trimer clustering accompanied by localized $\mathrm{Ca}^{2+}$ fluxes into the cell via CRAC/Orail channels that lead to attenuation of DISC 
formation (Khadra et al., 2011). In parallel, ADAM15 is redistributed into the forming CD95Cap. The influx of $\mathrm{Ca}^{2+}$ ions leads to a conformational change of calmodulin, which binds calcium ions and is subsequently relocated, together with Src to the cytoplasmic domains of ADAM15 and the Fas receptor. Subsequently, FAK associated with cytoplasmic domain of ADAM15 (Fried et al., 2012) and capable of interacting with calmodulin gets phosphorylated at its tyrosine residues Y576 and Y861 by activated Src. The Fas receptor activation-induced assembly of this ADAM15-containing pro-survival signaling complex can be efficiently blocked by either antagonizing the $\mathrm{Ca}^{2+}$ influx using the CRAC/Orail channel inhibitor BTP-2 or by inhibiting calmodulin using TFP, which leads to an abrogation of Src and FAK phsosphorylations. 


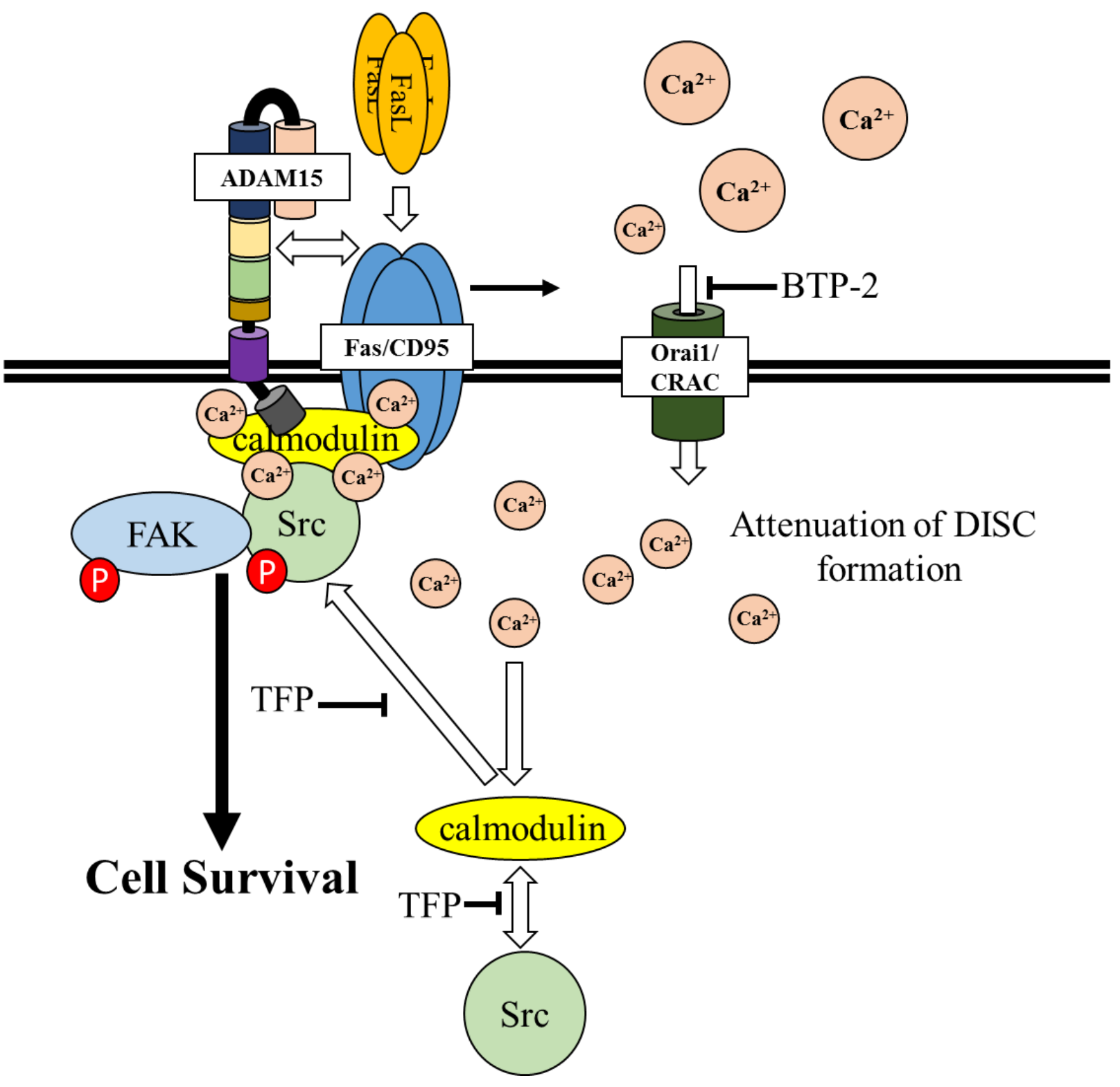

Fig. 25. The ADAM15-dependent pro-survival signaling pathway induced by Fas/CD95 activation. Ligation of FasL to Fas/CD95 leads to homo-oligomerization of the receptor. ADAM15 is recruited into the forming CD95-cap and Orai1/CRAC channel is activated, which leads to $\mathrm{Ca}^{2+}$ ion influx. Calmodulin binds to $\mathrm{Ca}^{2+}$ ions and changes conformation. Together with $\mathrm{Src}$ it is redistributed and binds to the cytoplasmic domains of ADAM15 and Fas/CD95 where it contributes to Src activation. FAK, bound to the cytoplasmic domain of ADAM15, interacts with active Src and is phosphorylated at tyrosines Y576 and Y861 resulting in the activation of FAK. Active Src and FAK promote cell survival. The pathway can be antagonized by using TFP, which inhibits binding of calmodulin to Src, ADAM15 and Fas/CD95 or by using BTP-2, which inhibits CRAC /Orai1 channel mediated influx of $\mathrm{Ca}^{2+}$ ions necessary for calmodulin to bind to ADAM15 and Fas/CD95. 


\subsection{The role of ADAM15-Fas-calmodulin complex signaling in apoptosis resistance of RASFs}

ADAM15 expression has been demonstrated to be significantly upregulated in the synovial membrane of RA patients. It is expressed in fibroblast-like synoviocytes but also by infilatrating macrophages (Böhm et al., 2001). The present work clearly demonstrates that ADAM15 is contributing to the apoptosis resistance of RASFs stimulated with FasL. Therefore, the newly identified mechanism described above is likely to add an interesting facet to the spectrum of already uncovered pathways of apoptosis resistance, since it opens potential new avenues for pharmacological interference.

Besides ADAM15, several other anti-apoptotic molecules have already been implicated as constituents of the apoptosis resistant phenotype of RASFs, including FLIP, which was found to be expressed in RASFs and protect them from Fas activation-induced apoptosis (Palao et al., 2004). Interestingly, TNF- $\alpha$ signaling leads to the upregulation of FLIP in RASFs, thereby inducing apoptosis resistance against Fas. Another example includes $\mathrm{POSH}$, which is a $\mathrm{SH} 3$ domain-containing protein involved in Jnk activation, which is thought to mediate its prosurvival effects mainly via the inhibition of caspase activation (Tsuda et al., 2010). Also, small ubiquitin-like modifier 1 (SUMO-1/sentrin) expression is highly upregulated in the synovial lining of RA patients (Franz et al., 2001). SUMO-1 protects the RASF by binding to the cytoplasmic domain of the Fas receptor that interferes with the Fas-activation triggered recruitment of pro-apoptotic DISC components to Fas (Mainecke et al., 2007).

Previously, it was shown that pharmacological targeting of FAK, using FAK inhibitor 14 or Src, using dasatinib, sensitize RASFs to the induction of apoptosis. In the present study, it is demonstrated for the first time that the simultaneous application of either the calmodulin inhibitor TFP or the CRAC/Orai1 channel inhibitor BTP-2 with a Fas receptor agonist synergistically enhances Fas-mediated apoptosis in RASFs. The death-promoting effect of both compounds is critically dependent on a synergistic Fas ligation, which is provided under pathophysiologic conditions in RA by high membrane-bound as well as soluble FasL concentrations, which are secreted by immune cells in the synovial fluid of inflamed joints (Hashimoto et al., 1998). While TFP, applied in our study for its calmodulin-blocking effects, is a Food and Drug Administration-approved antipsychotic drug with preferred therapeutic use for schizophrenia, it was recently shown to significantly reduce the metastatic potential of cancer cells by affecting Akt survival signaling pathways. It was shown that in prostate cancer cells incubated with TFP, inactivation of Akt led to a decrease in $\beta$-catenin phosphorylation and its translocation to the nucleus resulting in reduced vascular endothelial growth factor (VEGF) 
expression and cell migration (Pulkoski-Gross et al., 2015). Also, CRAC channel antagonists have recently already been tested for their anti-arthritic potential in the murine model of collagen-induced arthritis resulting in ameliorated disease development, relief from pain, and a $50 \%$ reduction of structural joint damage (Gao et al., 2015; Blair et al., 2016). In this context, the newly discovered role of calmodulin and CRAC/Orai 1 channels as pharmacological targets to break the resistance to Fas-mediated apoptosis in RASFs might encourage further studies aiming at new treatment options in RA. 


\section{References}

Agochiya M, Brunton VG, Owens DW, Parkinson EK, Paraskeva C, Keith WN, et al. Increased dosage and amplification of the focal adhesion kinase gene in human cancer cells. Oncogene 1999;18:5646-5653.

Ahn EY, Lim ST, Cook WJ, Mcdonald JM. Calmodulin binding to the Fas death domain. Regulation by Fas receptor activation. J Biol Chem. 2004;279(7):5661-6.

Algeciras-Schimnich A, Shen L, Barnhart BC, Murmann AE, Burkhardt JK, Peter ME. Molecular ordering of the initial signaling events of CD95. Mol Cell Biol. 2002;22(1):207-20.

Alers JC, Krijtenburg PJ, Vis AN, Hoedemaeker RF, Wildhagen MF, Hop WCJ, et al. Molecular cytogenetic analysis of prostatic adenocarcinomas from screening studies: Early cancers may contain aggressive genetic features. Am J Pathol 2001;158:399-406.

Andreini C, Banci L, Bertini I, Elmi S, Rosato A. Comparative analysis of the ADAM and ADAMTS families. J Proteome Res 2005;4:881-888.

Anguita E, Villalobo A. Src-family tyrosine kinases and the Ca signal. Biochim Biophys Acta Mol Cell Res. 2016;1864(6):915-932.

Anguita E, Villalobo A. Ca signaling and Src-kinases-controlled cellular functions. Arch Biochem Biophys. 2018;650:59-74.

Bartok B, Firestein GS. Fibroblast-like synoviocytes: key effector cells in rheumatoid arthritis. Immunol Rev. 2010;233(1):233-55.

Baum B, Georgiou M. Dynamics of adherens junctions in epithelial establishment, maintenance, and remodeling. J Cell Biol. 2011;192(6):907-17.

Bivona TG, Hieronymus $\mathrm{H}$, Parker J, et al. FAS and NF- $\kappa \mathrm{B}$ signalling modulate dependence of lung cancers on mutant EGFR. Nature. 2011;471(7339):523-6.

Blair HC, Soboloff J, Robinson LJ, Tourkova IL, Larrouture QC, Witt MR, et al. Suppression of arthritis- induced bone erosion by a CRAC channel antagonist. RMD Open 2016;2:e00093.

Blobel CP, White JM. Structure, function and evolutionary relationship of proteins containing a disintegrin domain. Curr Opin Cell Biol. 1992;4(5):760-5.

Blobel CP. ADAMs: key components in EGFR signalling and development. Nat Rev Mol Cell Biol. 2005;6(1):32-43. 
Blume-Jensen P, Hunter T. Oncogenic kinase signalling. Nature. 2001;411(6835):355-65.

Bolós V, Gasent JM, López-tarruella S, Grande E. The dual kinase complex FAK-Src as a promising therapeutic target in cancer. Onco Targets Ther. 2010;3:83-97.

Böhm BB, Aigner T, Blobel CP, Kalden JR, Burkhardt H. Highly enhanced expression of the disintegrin metalloproteinase MDC15 (metargidin) in rheumatoid synovial tissue. Arthritis Rheum. 2001;44(9):2046-54.

Böhm BB, Aigner T, Roy B, Brodie TA, Blobel CP, Burkhardt H. Homeostatic effects of the metalloproteinase disintegrin ADAM15 in degenerative cartilage remodeling. Arthritis Rheum. 2005;52(4):1100-9.

Böhm BB, Fehrl Y, Janczi T, Schneider N, Burkhardt H. Cell adhesion-induced transient interaction of ADAM15 with poly(A) binding protein at the cell membrane colocalizes with mRNA translation. PLoS ONE. 2018;13(9):e0203847.

Böhm B, Hess S, Krause K, Schirner A, Ewald W, Aigner T, et al. ADAM15 exerts an antiapoptotic effect on osteoarthritic chondrocytes via up-regulation of the X-linked inhibitor of apoptosis. Arthritis Rheum 2010;62:1372-1382.

Böhm BB, Schirner A, Burkhardt H. ADAM15 modulates outside-in signalling in chondrocytematrix interactions. J Cell Mol Med. 2009;13(8B):2634-44.

Böhm BB, Freund I, Krause K, Kinne RW, Burkhardt H. ADAM15 adds to apoptosis resistance of synovial fibroblasts by modulating focal adhesion kinase signaling. Arthritis Rheum. 2013;65(11):2826-34.

Brami-Cherrier K, Gervasi N, Arsenieva D, Walkiewicz K, Boutterin M-C, Ortega A, et al. FAK dimerization controls its kinase-dependent functions at focal adhesions. EMBO $J$ 2014;33:356-370.

Brunton VG, Avizienyte E, Fincham VJ, Serrels B, Metcalf CA, Sawyer TK, et al. Identification of Src-specific phosphorylation site on focal adhesion kinase: Dissection of the role of Src SH2 and catalytic functions and their consequences for tumor cell behavior. Cancer Res 2005;65:1335-1342.

Burdelski C, Fitzner M, Hube-Magg C, Kluth M, Heumann A, Simon R, et al. Overexpression of the A Disintegrin and Metalloproteinase ADAM15 is linked to a Small but Highly Aggressive Subset of Prostate Cancers. Neoplasia (United States) 2017;19:279-287.

Cahalan MD. STIMulating store-operated Ca(2+) entry. Nat Cell Biol. 2009;11(6):669-77. 
Calalb MB, Polte TR, Hanks SK. Tyrosine phosphorylation of focal adhesion kinase at sites in the catalytic domain regulates kinase activity: a role for Src family kinases. Mol Cell Biol. 1995;15(2):954-63.

Calalb MB, Zhang X, Polte TR, Hanks SK. Focal adhesion kinase tyrosine-861 is a major site of phosphorylation by Src. Biochem Biophys Res Commun. 1996;228(3):662-8.

Chang BJ, Samal AB, Vlach J, Fernandez TF, Brooke D, Jr PEP, et al. Identification of the calmodulin-binding domains of Fas death receptor. PLoS One 2016;11:1-23.

Charrier L, Yan Y, Nguyen HTT, Dalmasso G, Laboisse CL, Gewirtz AT, et al. ADAM15/Metargidin Mediates Homotypic Aggregation of Human T Lymphocytes and Heterotypic Interactions of T Lymphocytes with Intestinal Epithelial Cells. J Biol Chem 2007;282:1694816958.

Charrier-Hisamuddin L, Laboisse CL, Merlin D. ADAM-15: a metalloprotease that mediates inflammation. FASEB J. 2008;22(3):641-53.

Chen Y, Pawar P, Pan G, Ma L, Liu H, McDonald JM. Calmodulin binding to the Fas- mediated death- inducing signaling complex in cholangiocarcinoma cells. J Cell Biochem 2008;103:78899.

Chou JJ, Li S, Klee CB, Bax A. Solution structure of $\mathrm{Ca}(2+)$-calmodulin reveals flexible handlike properties of its domains. Nat Struct Biol. 2001;8(11):990-7.

Clapham DE. Calcium signaling. Cell. 2007;131(6):1047-58.

Dara L. The Receptor Interacting Protein Kinases in the Liver. Semin Liver Dis. 2018;38(1):7386.

Dickens LS, Boyd RS, Jukes-Jones R, Hughes MA, Robinson GL, Fairall L, et al. A Death Effector Domain Chain DISC Model Reveals a Crucial Role for Caspase-8 Chain Assembly in Mediating Apoptotic Cell Death. Mol Cell 2012;47:291-305.

Dreymueller D, Uhlig S, Ludwig A. ADAM-family metalloproteinases in lung inflammation: potential therapeutic targets. Am J Physiol Lung Cell Mol Physiol. 2015;308(4):L325-43.

Duffy MJ, Lynn DJ, Lloyd AT, O'Shea CM. The ADAMs family of proteins: from basic studies to potential clinical applications. Thromb Haemost. 2003;89(4):622-31.

Duffy MJ, Mckiernan E, O'donovan N, Mcgowan PM. Role of ADAMs in cancer formation and progression. Clin Cancer Res. 2009;15(4):1140-4. 
Duxbury MS, Ito H, Zinner MJ, Ashley SW, Whang EE. Focal adhesion kinase gene silencing promotes anoikis and suppresses metastasis of human pancreatic adenocarcinoma cells. Surgery. 2004;135(5):555-62.

Edwards DR, Handsley MM, Pennington CJ. The ADAM metalloproteinases. Mol Aspects Med. 2008;29(5):258-89.

Elmore S. Apoptosis: a review of programmed cell death. Toxicol Pathol. 2007;35(4):495-516.

Ezratty EJ, Partridge MA, Gundersen GG. Microtubule-induced focal adhesion disassembly is mediated by dynamin and focal adhesion kinase. Nat Cell Biol. 2005;7(6):581-90.

Fedida-Metula S, Feldman B, Koshelev V, Levin-gromiko U, Voronov E, Fishman D. Lipid rafts couple store-operated $\mathrm{Ca} 2+$ entry to constitutive activation of $\mathrm{PKB} / \mathrm{Akt}$ in a Ca2+/calmodulin-, Src- and PP2A-mediated pathway and promote melanoma tumor growth. Carcinogenesis. 2012;33(4):740-50.

Feldkamp MD, O'Donnell SE, Yu L, Shea MA. Allosteric effects of the antipsychotic drug trifluoperazine on the energetics of calcium binding by calmodulin. Proteins. 2010;78(10):2265-82.

Fernandez TF, Samal AB, Bedwell GJ, Chen Y, Saad JS. Structural and biophysical characterization of the interactions between the death domain of Fas receptor and calmodulin. J Biol Chem. 2013;288(30):21898-908.

Firestein GS, Nguyen K, Aupperle KR, Yeo M, Boyle DL, Zvaifler NJ. Apoptosis in rheumatoid arthritis: p53 overexpression in rheumatoid arthritis synovium. Am J Pathol. 1996;149(6):2143-51.

Firestein GS, Echeverri F, Yeo M, Zvaifler NJ, Green DR. Somatic mutations in the p53 tumor suppressor gene in rheumatoid arthritis synovium. Proc Natl Acad Sci U S A 1997;94:10895900.

Franz JK, Pap T, Hummel KM, Nawrath M, Aicher WK, Shigeyama Y, et al. Expression of sentrin, a novel anti-apoptotic molecule, at sites of synovial invasion in rheumatoid arthritis. Arthritis Rheum 2000;43:599-607.

Fried D, Böhm BB, Krause K, Burkhardt H. ADAM15 protein amplifies focal adhesion kinase phosphorylation under genotoxic stress conditions. J Biol Chem. 2012;287(25):21214-23. 
Fricker N, Beaudouin J, Richter P, Eils R, Krammer PH, Lavrik IN. Model-based dissection of CD95 signaling dynamics reveals both a pro- and anti-apoptotic role of c-FLIPL. J Cell Biol. 2010;190(3):377-89.

Friedrich BM, Murray JL, Li G, Sheng J, Hodge TW, Rubin DH, et al. A Functional Role for ADAM10 in Human Immunodeficiency Virus Type-1 Replication. Retrovirology 2011;8:32.

Gaidos G, Panaitiu AE, Guo B, Pellegrini M, Mierke DF. Identification and Characterization of the Interaction Site between cFLIPL and Calmodulin. PLoS ONE. 2015;10(11):e0141692.

Gao J, Zheng W, Wang L, Song B. A disintegrin and metallproteinase 15 knockout decreases migration of fibroblast-like synoviocytes and inflammation in rheumatoid arthritis. Mol Med Rep. 2015;11(6):4389-96.

Gao XH, Gao R, Tian YZ, McGonigle P, Barrett JE, Dai Y, et al. A store-operated calcium channel inhibitor attenuates collagen- induced arthritis. Br J Pharmacol 2015;172:2991-3002.

Gerhardt S, Hassall G, Hawtin P, McCall E, Flavell L, Minshull C, et al. Crystal Structures of Human ADAMTS-1 Reveal a Conserved Catalytic Domain and a Disintegrin-like Domain with a Fold Homologous to Cysteine-Rich Domains. J Mol Biol 2007;373:891-902.

Giebeler N, Zigrino P. A Disintegrin and Metalloprotease (ADAM): Historical Overview of Their Functions. Toxins (Basel). 2016;8(4):122.

Glassey B, Civetta A. Positive selection at reproductive ADAM genes with potential intercellular binding activity. Mol Biol Evol. 2004;21(5):851-9.

Goldring MB, Birkhead JR, Suen L, Yamin R, Mizuno S, Glowacki J, et al. Human Chondrocytes. 1994;94:2307-2316.

Gomis-Rüth FX. Structural aspects of the metzincin clan of metalloendopeptidases. Mol Biotechnol. 2003;24(2):157-202.

Gomis-Rüth FX. Catalytic domain architecture of metzincin metalloproteases. J Biol Chem. 2009;284(23):15353-7.

Goodsell DS, Dutta S, Zardecki C, Voigt M, Berman HM, Burley SK. The RCSB PDB "Molecule of the Month": Inspiring a Molecular View of Biology. PLoS Biol. 2015;13(5):e1002140.

Gould R.J., Polokoff M.A., Friedman P.A., Huang T.F., Holt J.C., Cook J.J., Niewiarowski S. Disintegrins: a family of integrin inhibitory proteins from viper venoms. Proc. Soc. Exp. Biol. Med. 1990;195:168-171. 
Grams F, Huber R, Kress LF, Moroder L, Bode W. Activation of snake venom metalloproteinases by a cysteine switch-like mechanism. FEBS Lett. 1993;335(1):76-80.

Guicciardi ME, Gores GJ. Life and death by death receptors. FASEB J. 2009;23(6):1625-37.

Haas C, Aicher WK, Dinkel A, Peter HH, Eibel H. Characterization of SV40T antigen immortalized human synovial fibroblasts: maintained expression patterns of EGR-1, HLA-DR and some surface receptors. Rheumatol Int. 1997;16(6):241-7.

Hall JE, Fu W, Schaller MD. Focal adhesion kinase: exploring Fak structure to gain insight into function. Int Rev Cell Mol Biol. 2011;288:185-225.

Halling DB, Liebeskind BJ, Hall AW, Aldrich RW. Conserved properties of individual Ca2+binding sites in calmodulin. Proc Natl Acad Sci USA. 2016;113(9):E1216-25.

Ham C, Levkau B, Raines EW, Herren B. ADAM15 is an adherens junction molecule whose surface expression can be driven by VE-cadherin. Exp Cell Res. 2002;279(2):239-47.

Hashimoto H, Tanaka M, Suda T, Tomita T, Hayashida K, Takeuchi E, et al. Soluble Fas ligand in the joints of patients with rheumatoid arthritis and osteoarthritis. Arthritis Rheum $1998 ; 41: 657-62$.

Huang D, Khoe M, Befekadu M, Chung S, Takata Y, Ilic D, et al. Focal adhesion kinase mediates cell survival via NF-kB and ERK signaling pathways. Am J Physiol Physiol 2006;292:C1339-C1352

Hynes RO. Integrins: bidirectional, allosteric signaling machines. Cell. 2002;110(6):673-87.

Ikari Y, Yee KO, Schwartz SM. Role of alpha5beta1 and alphavbeta3 integrins on smooth muscle cell spreading and migration in fibrin gels. Thromb Haemost. 2000;84(4):701-5.

Ingley E. Src family kinases: regulation of their activities, levels and identification of new pathways. Biochim Biophys Acta. 2008;1784(1):56-65.

Janczi T, Böhm BB, Fehrl Y, Degiacomo P, Kinne RW, Burkhardt H. ADAM15 in Apoptosis Resistance of Synovial Fibroblasts: Converting Fas/CD95 Death Signals Into the Activation of Pro-survival Pathways by Calmodulin Recruitment. Arthritis Rheumatol. 2018.

Jiao Y, Ding H, Huang S, Liu Y, Sun X, Wei W, et al. Bcl-XL and Mcl-1 upregulation by calreticulin promotes apoptosis resistance of fibroblast-like synoviocytes via activation of PI3K/Akt and STAT3 pathways in rheumatoid arthritis. Clin Exp Rheumatol 36:841-849. 
Kang Q, Cao Y, Zolkiewska A. Metalloprotease-disintegrin ADAM 12 binds to the SH3 domain of Src and activates Src tyrosine kinase in C2C12 cells. Biochem J. 2000;352 Pt 3:88392

Karouzakis E, Trenkmann M, Gay RE, Michel BA, Gay S, Neidhart M. Epigenome Analysis Reveals TBX5 as a Novel Transcription Factor Involved in the Activation of Rheumatoid Arthritis Synovial Fibroblasts. J Immunol 2014;193:4945-4951.

Kasahara, T., Koguchi, E., Funakoshi, M., Aizu-Yokota, E., and Sonoda, Y. (2002) Antiapoptotic action of focal adhesion kinase (FAK) against ioniz- ing radiation. Antioxid Redox Signal 4, 491-499

Kavurma MM, Tan NY, Bennett MR. Death receptors and their ligands in atherosclerosis. Arterioscler Thromb Vasc Biol. 2008;28(10):1694-702.

Kelwick R, Desanlis I, Wheeler GN, Edwards DR. The ADAMTS (A Disintegrin and Metalloproteinase with Thrombospondin motifs) family. Genome Biol. 2015;16:113.

Khadra N, Bresson-Bepoldin L, Penna A, Chaigne-Delalande B, Ségui B. regulates recruitment of protein kinase $\mathrm{C}$ ( $\mathrm{PKC}$ ) $\beta 2$, and prevents death-inducing signaling complex formation. PNAS;108(47):19072-7.

Khokha R, Murthy A, Weiss A. Metalloproteinases and their natural inhibitors in inflammation and immunity. Nat Rev Immunol. 2013;13(9):649-65.

Kiaei M, Kipiani K, Calingasan NY, Wille E, Chen J, Heissig B, et al. Matrix metalloproteinase-9 regulates TNF- $\alpha$ and FasL expression in neuronal, glial cells and its absence extends life in a transgenic mouse model of amyotrophic lateral sclerosis. Exp Neurol 2007;205:74-81.

Kim LC, Song L, Haura EB. Src kinases as therapeutic targets for cancer. Nat Rev Clin Oncol. 2009;6(10):587-95.

Kleino I, Ortiz RM, Yritys M, Huovila APJ, Saksela K. Alternative splicing of ADAM15 regulates its interactions with cellular SH3 proteins. J Cell Biochem 2009;108:877-885.

Kleino I, Järviluoma A, Hepojoki J, Huovila AP, Saksela K. Preferred SH3 domain partners of ADAM metalloproteases include shared and ADAM-specific SH3 interactions. PLoS One 2015;10:1-19.

Kobayashi T, Okamoto K, Kobata T, Hasunuma T, Kato T, Hamada H, et al. Differential regulation of Fas-mediated apoptosis of rheumatoid synoviocytes by tumor necrosis factor 
alpha and basic fibroblast growth factor is associated with the expression of apoptosis-related mole- cules. Arthritis Rheum 2000;43:1106-14.

Kober AMM, Legewie S, Pforr C, Fricker N, Eils R, Krammer PH, et al. Caspase-8 activity has an essential role in CD95/Fas-mediated MAPK activation. Cell Death Dis 2011;2:e212-e212.

Kohno T, Matsuda E, Sasaki H, Sasaki T. Protein-tyrosine kinase CAKbeta/PYK2 is activated by binding $\mathrm{Ca} 2+/$ calmodulin to FERM F2 alpha2 helix and thus forming its dimer. Biochem $\mathrm{J}$. 2008;410(3):513-23.

Korb A, Pavenstädt H, Pap T. Cell death in rheumatoid arthritis. Apoptosis. 2009;14(4):44754.

Krammer PH, Arnold R, Lavrik IN. Life and death in peripheral T cells. Nat Rev Immunol. 2007;7(7):532-42.

Kuefer R, Day KC, Kleer CG, Sabel MS, Hofer MD, Varambally S, et al. ADAM15 disintegrin is associated with aggressive prostate and breast cancer disease. Neoplasia 2006;8:319-29.

Kurenova E, Xu L, Yang X, Baldwin AS, Craven RJ, Hanks SK, et al. Focal adhesion kinase suppresses apoptosis by binding to the death domain of receptor-interacting protein. Mol Cell Biol 2004;24:4361-71.

Kursula P. The many structural faces of calmodulin: a multitasking molecular jackknife. Amino Acids. 2014;46(10):2295-304.

Langer H, May AE, Bültmann A, Gawaz M. ADAM 15 is an adhesion receptor for platelet GPIIb-IIIa and induces platelet activation. Thromb Haemost. 2005;94(3):555-61.

Lavrik IN, Krammer PH. Regulation of CD95/Fas signaling at the DISC. Cell Death Differ. 2012;19(1):36-41.

Lavrik IN. Systems biology of death receptor networks: live and let die. Cell Death Dis. 2014;5:e1259.

Lefevre S, Meier FM, Neumann E, Muller-Ladner U. Role of synovial fibroblasts in rheumatoid arthritis. Curr Pharm Des. 2015;21(2):130-41.

Le Gallo M, Poissonnier A, Blanco P, Legembre P. CD95/Fas, Non-Apoptotic Signaling Pathways, and Kinases. Front Immunol. 2017;8:1216.

Li X, Zhang Z, Peng A, et al. Effect of CD95 on inflammatory response in rheumatoid arthritis fibroblast-like synoviocytes. Cell Immunol. 2014;290(2):209-16. 
Lim Y, Han I, Jeon J, Park H, Bahk YY, Oh ES. Phosphorylation of focal adhesion kinase at tyrosine 861 is crucial for Ras transformation of fibroblasts. J Biol Chem. 2004;279(28):290605.

Liu G, Meng X, Jin Y, Bai J, Zhao Y, Cui X, et al. Inhibitory role of focal adhesion kinase on anoikis in the lung cancer cell A549. Cell Biol Int 2008;32:663-670.

Lorenzatti Hiles G, Bucheit A, Rubin JR, et al. ADAM15 Is Functionally Associated with the Metastatic Progression of Human Bladder Cancer. PLoS ONE. 2016;11(3):e0150138.

Lorenzen I, Lokau J, Düsterhöft S, et al. The membrane-proximal domain of A Disintegrin and Metalloprotease 17 (ADAM17) is responsible for recognition of the interleukin-6 receptor and interleukin-1 receptor II. FEBS Lett. 2012;586(8):1093-100.

Lorenzen I, Lokau J, Düsterhöft S, Trad A, Garbers C, Scheller J, et al. The membrane-proximal domain of A Disintegrin and Metalloprotease 17 (ADAM17) is responsible for recognition of the interleukin-6 receptor and interleukin-1 receptor II. FEBS Lett 2012;586:1093-1100.

Lu D, Chung KF, Xia M, Lu X, Scully M, Kakkar V. Integrin binding characteristics of the disintegrin-like domain of ADAM-15. Thromb Haemost. 2006;96(5):642-51.

Lu D, Scully M, Kakkar V, Lu X. ADAM-15 disintegrin-like domain structure and function. Toxins (Basel). 2010;2(10):2411-27.

Lucas N, Day ML. The role of the disintegrin metalloproteinase ADAM15 in prostate cancer progression. J Cell Biochem 2009;106:967-74

Lum L, Reid MS, Blobel CP. Intracellular maturation of the mouse metalloprotease disintegrin MDC15. J Biol Chem. 1998;273(40):26236-47.

Lunn, J. A., Jacamo, R., and Rozengurt, E. (2007) Preferential phosphorylation of focal adhesion kinase tyrosine 861 is critical for mediating an anti-apoptotic response to hyperosmotic stress. J. Biol. Chem. 282, 10370-10379

Luo JL, Kamata H, Karin M. IKK/NF-kappaB signaling: balancing life and death--a new approach to cancer therapy. J Clin Invest. 2005;115(10):2625-32.

Meinecke I, Cinski A, Baier A, Peters MA, Dankbar B, Wille A, et al. Modification of nuclear PML protein by SUMO- 1 regulates Fas- induced apoptosis in rheumatoid arthritis synovial fibroblasts. Proc Natl Acad Sci U S A 2007;104:5073-8.

Malhi H, Guicciardi ME, Gores GJ. Hepatocyte death: a clear and present danger. Physiol Rev. 2010;90(3):1165-94. 
Maretzky T, Reiss K, Ludwig A, Buchholz J, Scholz F, Proksch E, et al. ADAM10 mediates E-cadherin shedding and regulates epithelial cell-cell adhesion, migration, and -catenin translocation. Proc Natl Acad Sci 2005;102:9182-9187.

Maretzky T, Yang G, Ouerfelli O, Overall CM, Worpenberg S, Hassiepen U, et al. Characterization of the catalytic activity of the membrane-anchored metalloproteinase ADAM15 in cell-based assays. Biochem J 2009;420:105-113.

Maretzky T, Gall SM Le, Worpenberg-Pietruk S, Eder J, Overall CM, Huang XY, et al. Src stimulates fibroblast growth factor receptor-2 shedding by an ADAM15 splice variant linked to breast cancer. Cancer Res 2009;69:4573-4576.

Maretzky T, Zhou W, Huang X-Y, Blobel CP. A transforming Src mutant increases the bioavailability of EGFR ligands via stimulation of the cell-surface metalloproteinase ADAM17. Oncogene 2011;30:611-618.

Martin J, Eynstone LV, Davies M, Williams JD, Steadman R. The role of ADAM 15 in glomerular mesangial cell migration. J Biol Chem. 2002;277(37):33683-9.

Matsumoto S, Muller-Ladner U, Gay RE, Nishioka K, Gay S. Ultrastructural demonstration of apoptosis, Fas and Bcl-2 expression of rheumatoid synovial fibroblasts. J Rheumatol 1996;23: $1345-52$.

Matsuno H, Yudoh K, Watanabe Y, Nakazawa F, Aono H, Kimura T. Stromelysin-1 (MMP-3) in synovial fluid of patients with rheumatoid arthritis has potential to cleave membrane bound Fas ligand. J Rheumatol. 2001;28(1):22-8.

McIlwain DR, Berger T, Mak TW. Caspase functions in cell death and disease. Cold Spring Harb Perspect Biol. 2013;5(4):a008656.

McInnes IB, Schett G. Cytokines in the pathogenesis of rheumatoid arthritis. Nat Rev Immunol. 2007;7(6):429-42.

McInnes IB, Schett G. The pathogenesis of rheumatoid arthritis. $N$ Engl J Med. 2011;365(23):2205-19.

Meador WE, Means AR, Quiocho FA. Modulation of calmodulin plasticity in molecular recognition on the basis of X-ray structures. Science. 1993;262(5140):1718-21.

Milla ME, Leesnitzer M a, Moss ML, Clay WC, Carter HL, Miller a B, et al. Specific sequence elements are required for the expression of functional tumor necrosis factor-alpha-converting enzyme (TACE). J Biol Chem 1999;274:30563-30570. 
Mitra SK, Schlaepfer DD. Integrin-regulated FAK-Src signaling in normal and cancer cells. Curr Opin Cell Biol. 2006;18(5):516-23.

Moiseeva EP. Adhesion receptors of vascular smooth muscle cells and their functions. Cardiovasc Res. 2001;52(3):372-86.

Morgan L, Nicholson RI, Hiscox S. SRC as a therapeutic target in breast cancer. Endocr Metab Immune Disord Drug Targets. 2008;8(4):273-8.

Mosnier JF, Jarry A, Bou-hanna C, Denis MG, Merlin D, Laboisse CL. ADAM15 upregulation and interaction with multiple binding partners in inflammatory bowel disease. Lab Invest. 2006;86(10):1064-73.

Mow VC, Ratcliffe A, Poole AR. Cartilage and diarthrodial joints as paradigms for hierarchical materials and structures. Biomaterials. 1992;13(2):67-97.

Müller-Ladner U, Pap T, Gay RE, Neidhart M, Gay S. Mechanisms of disease: the molecular and cellular basis of joint destruction in rheumatoid arthritis. Nat Clin Pract Rheumatol. 2005;1(2):102-10.

Müller-Ladner U, Ospelt C, Gay S, Distler O, Pap T. Cells of the synovium in rheumatoid arthritis. Synovial fibroblasts. Arthritis Res Ther. 2007;9(6):223.

Mullins FM, Park CY, Dolmetsch RE, Lewis RS. STIM1 and calmodulin interact with Orai1 to induce Ca2+-dependent inactivation of CRAC channels. Proc Natl Acad Sci USA. 2009;106(36):15495-500.

Najy AJ, Day KC, Day ML. The ectodomain shedding of E-cadherin by ADAM15 supports ErbB receptor activation. J Biol Chem. 2008;283(26):18393-401.

Najy AJ, Day KC, Day ML. ADAM15 supports prostate cancer metastasis by modulating tumor cell-endothelial cell interaction. Cancer Res 2008;68:1092-1099.

Nagata S. Fas ligand-induced apoptosis. Annu Rev Genet. 1999;33:29-55.

Nath D, Slocombe PM, Stephens PE, Warn a, Hutchinson GR, Yamada KM, et al. Interaction of metargidin (ADAM-15) with alphavbeta3 and alpha5beta1 integrins on different haemopoietic cells. J Cell Sci 1999;112 ( Pt 4:579-587.

Nozawa K, Kayagaki N, Tokano Y, Yagita H, Okumura K, Hasimoto H. Soluble Fas (APO-1, CD95) and soluble Fas ligand in rheumatic diseases. Arthritis Rheum. 1997;40(6):1126-9. 
Oeckinghaus A, Hayden MS, Ghosh S. Crosstalk in NF-кB signaling pathways. Nat Immunol. 2011;12(8):695-708.

OpenStax College. (2013). Anatomy \& physiology. Houston, TX: OpenStax CNX. Retrieved from http://cnx.org/content/col11496/latest/

Palao G, Santiago B, Galindo M, Payá M, Ramirez JC, Pablos JL. Down-regulation of FLIP sensitizes rheumatoid synovial fibroblasts to Fas-mediated apoptosis. Arthritis Rheum. 2004;50(9):2803-10.

Panera N, Crudele A, Romito I, Gnani D, Alisi A. Focal Adhesion Kinase: Insight into Molecular Roles and Functions in Hepatocellular Carcinoma. Int J Mol Sci. 2017;18(1)

Pap T, Franz JK, Hummel KM, Jeisy E, Gay R, Gay S. Activation of synovial fibroblasts in rheumatoid arthritis: lack of expression of the tumour suppressor PTEN at sites of invasive growth and destruction. Arthritis Res 2000;2:59-64.

Parsons JT. Focal adhesion kinase: the first ten years. J Cell Sci. 2003;116(Pt 8):1409-16.

Parsons SJ, Parsons JT. Src family kinases, key regulators of signal transduction. Oncogene. 2004;23(48):7906-9.

Pawar PS, Micoli KJ, Ding H, Cook WJ, Kappes JC, Chen Y, et al. Calmodulin binding to cellular FLICE- like inhibitory protein modulates Fas- induced signaling. Biochem $J$ 2008;412:459-68.27.

Perutelli P. Disintegrins: potent inhibitors of platelet aggregation. Recenti Prog Med. 1995;86(4):168-74.

Peter ME, Krammer PH. The CD95(APO- 1/Fas) DISC and beyond. Cell Death Differ 2003;10:26-35.

Peter ME, Budd RC, Desbarats J, et al. The CD95 receptor: apoptosis revisited. Cell. 2007;129(3):447-50.

Peter ME, Hadji A, Murmann AE, et al. The role of CD95 and CD95 ligand in cancer. Cell Death Differ. 2015;22(5):885-6.

Pistritto G, Trisciuoglio D, Ceci C, Garufi A, D'orazi G. Apoptosis as anticancer mechanism: function and dysfunction of its modulators and targeted therapeutic strategies. Aging (Albany $N Y$ ). 2016;8(4):603-19. 
Poghosyan Z, Robbins SM, Houslay MD, Webster A, Murphy G, Edwards DR. Phosphorylation-dependent interactions between ADAM15 cytoplasmic domain and Src family protein-tyrosine kinases. J Biol Chem. 2002;277(7):4999-5007.

Poissonnier A, Sanséau D, Gallo M Le, Malleter M, Levoin N, Viel R, et al. CD95-Mediated Calcium Signaling Promotes T Helper 17 Trafficking to Inflamed Organs in Lupus-Prone Mice. Immunity 2016;45:209-223.

Pulkoski-Gross A, Li J, Zheng C, Li Y, Ouyang N, Rigas B, et al. Repurposing the antipsychotic trifluoperazine as an antimetastasis agent. Molecular pharmacology 2015;87:501-12.

Pundt N, Peters M a, Wunrau C, Strietholt S, Fehrmann C, Neugebauer K, et al. Susceptibility of rheumatoid arthritis synovial fibroblasts to FasL- and TRAIL-induced apoptosis is cell cycledependent. Arthritis Res Ther 2009;11:R16.

Ramiro S, Sepriano A, Chatzidionysiou K, et al. Safety of synthetic and biological DMARDs: a systematic literature review informing the 2016 update of the EULAR recommendations for management of rheumatoid arthritis. Ann Rheum Dis. 2017;76(6):1101-1136.

Rawlings ND, Morton FR, Kok CY, Kong J, Barrett AJ. MEROPS: the peptidase database. Nucleic Acids Res. 2008;36(Database issue):D320-5.

Rehm M, Huber HJ, Dussmann H, Prehn JH. Systems analysis of effector caspase activation and its control by X-linked inhibitor of apoptosis protein. EMBO J. 2006;25(18):4338-49.

Roskoski R. Src protein-tyrosine kinase structure and regulation. Biochem Biophys Res Commun. 2004;324(4):1155-64.

Roskoski R. ERK1/2 MAP kinases: Structure, function, and regulation. Pharmacological Research 2012;66:105-143. dx.doi.org/10.1016/j.phrs.2012.04.005.

Salas V, Sánchez-Torres J, Cusidó-Hita DM, García-Marchan Y, Sojo F, Benaim G, et al. Characterisation of tyrosine-phosphorylation-defective calmodulin mutants. Protein Expr Purif 2005;41:384-392.

Salomoni P, Khelifi AF. Daxx: death or survival protein?. Trends Cell Biol. 2006;16(2):97-104.

Sen B, Johnson FM. Regulation of Src Family Kinases in Human Cancers. Journal of Signal Transduction 2011;2011:1-14.

Schaller MD, Otey CA, Hildebrand JD, Parsons JT. Focal adhesion kinase and paxillin bind to peptides mimicking beta integrin cytoplasmic domains. J Cell Biol. 1995;130(5):1181-7. 
Schäfer B, Marg B, Gschwind A, Ullrich A. Distinct ADAM metalloproteinases regulate G protein-coupled receptor-induced cell proliferation and survival. $J$ Biol Chem. 2004;279(46):47929-38.

Schett G, Gravallese E. Bone erosion in rheumatoid arthritis: mechanisms, diagnosis and treatment. Nat Rev Rheumatol. 2012;8(11):656-64.

Schleich K, Warnken U, Fricker N, Öztürk S, Richter P, Kammerer K, et al. Stoichiometry of the CD95 Death-Inducing Signaling Complex: Experimental and Modeling Evidence for a Death Effector Domain Chain Model. Mol Cell 2012;47:306-319.

Schulte M, Reiss K, Lettau M, Maretzky T, Ludwig A, Hartmann D, et al. ADAM10 regulates FasL cell surface expression and modulates FasL-induced cytotoxicity and activation-induced cell death. Cell Death Differ 2007;14:1040-9.

Scrivo R, Di franco M, Spadaro A, Valesini G. The immunology of rheumatoid arthritis. Ann N Y Acad Sci. 2007;1108:312-22.

Siegmund D, Lang I, Wajant H. Cell death-independent activities of the death receptors CD95, TRAILR1, and TRAILR2. FEBS J. 2017;284(8):1131-1159.

Smolen JS, Aletaha D, Mcinnes IB. Rheumatoid arthritis. Lancet. 2016;388(10055):2023-2038.

Smolen JS, Aletaha D, Barton A, Burmester GR, Emery P, Firestein GS, et al. Rheumatoid arthritis. Something with Nat 2018;4:53-79.

Stateva SR, Salas V, Anguita E, Benaim G, Villalobo A. Ca2+/Calmodulin and ApoCalmodulin Both Bind to and Enhance the Tyrosine Kinase Activity of c-Src. PLoS ONE. 2015;10(6):e0128783.

Stennicke HR, Jürgensmeier JM, Shin H, Deveraux Q, Wolf BB, Yang X, et al. Pro-caspase-3 is a major physiologic target of caspase-8. J Biol Chem 1998;273:27084-90.

Stewart SE, Ashkenazi A, Williamson A, Rubinsztein DC, Moreau K. Phospholipid flipping facilitates annexin translocation across membranes. bioRxiv 2018:241976.

Strasser A, Jost PJ, Nagata S. The many roles of FAS receptor signaling in the immune system. Immunity. 2009;30(2):180-92.

Sun C, Wu MH, Guo M, Day ML, Lee ES, Yuan SY. ADAM15 regulates endothelial permeability and neutrophil migration via Src/ERK1/2 signalling. Cardiovasc Res 2010;87:348-355. 
Quistad SD, Traylor-Knowles N. Precambrian origins of the TNFR superfamily. Cell Death Discov. 2016;2:16058.

Takada Y, Ye X, Simon S. The integrins. Genome Biol. 2007;8(5):215.

Takeda S, Igarashi T, Mori H, Araki S. Crystal structures of VAP1 reveal ADAMs' MDC domain architecture and its unique C-shaped scaffold. EMBO J. 2006;25(11):2388-96.

Takeda S. ADAM and ADAMTS Family Proteins and Snake Venom Metalloproteinases: A Structural Overview. Toxins (Basel). 2016;8(5)

Tauzin S, Chaigne-Delalande B, Selva E, Khadra N, Daburon S, Contin-Bordes C, et al. The naturally processed CD95L Elicits a c-yes/Calcium/PI3K-driven cell migration pathway. PLoS Biol 2011;9.

Thodeti CK, Albrechtsen R, Grauslund M, et al. ADAM12/syndecan-4 signaling promotes beta 1 integrin-dependent cell spreading through protein kinase Calpha and RhoA. J Biol Chem. 2003;278(11):9576-84.

Tidow H, Nissen P. Structural diversity of calmodulin binding to its target sites. FEBS J. 2013;280(21):5551-65.

Tousseyn T, Thathiah A, Jorissen E, Raemaekers T, Konietzko U, Reiss K, et al. ADAM10, the Rate-limiting Protease of Regulated Intramembrane Proteolysis of Notch and Other Proteins, Is Processed by ADAMS-9, ADAMS-15, and the $\gamma$-Secretase. J Biol Chem 2009;284:1173811747.

Trochon-Joseph V, Martel-Renoir D, Mir LM, et al. Evidence of antiangiogenic and antimetastatic activities of the recombinant disintegrin domain of metargidin. Cancer Res. 2004;64(6):2062-9.

Tsuda M, Kawaida R, Kobayashi K, Shinagawa A, Sawada T, Yama- da R, et al. POSH promotes cell survival in Drosophila and in human RASF cells. FEBS Lett 2010;584:4689-94.

Ungerer C, Doberstein K, Bürger C, Hardt K, Boehncke WH, Böhm B, et al. ADAM15 expression is downregulated in melanoma metastasis compared to primary melanoma. Biochem Biophys Res Commun 2010;401:363-369.

Van Wart HE, Birkedal-Hansen H. The cysteine switch: a principle of regulation of metalloproteinase activity with potential applicability to the entire matrix metalloproteinase gene family. Proc Natl Acad Sci USA. 1990;87(14):5578-82. 
Vandonselaar M, Hickie RA, Quail JW, Delbaere LT. Trifluoperazine-induced conformational change in Ca(2+)-calmodulin. Nat Struct Biol. 1994;1(11):795-801.

van Roy F, Berx G. The cell-cell adhesion molecule E-cadherin. Cell Mol Life Sci. 2008;65(23):3756-88.

Vargo-Gogola T, Crawford HC, Fingleton B, Matrisian LM. Identification of novel matrix metalloproteinase-7 (matrilysin) cleavage sites in murine and human Fas ligand. Arch Biochem Biophys. 2002;408(2):155-61.

Villalobo A. The multifunctional role of phospho-calmodulin in pathophysiological processes. Biochem J. 2018;475(24):4011-4023.

Wang L, Yang JK, Kabaleeswaran V, Rice AJ, Cruz AC, Pak AY, et al. The Fas-FADD death domain complex structure reveals the basis of DISC assembly and disease mutations. Nat Struct Mol Biol 2010;November ;1324-1329.

Ward-Kavanagh LK, Lin WW, Šedý JR, Ware CF. The TNF Receptor Superfamily in Costimulating and Co-inhibitory Responses. Immunity. 2016;44(5):1005-19.

Weber S, Saftig P. Ectodomain shedding and ADAMs in development. Development. 2012;139(20):3693-709.

Westhoff MA, Serrels B, Fincham VJ, Frame MC, Carragher NO. SRC-mediated phosphorylation of focal adhesion kinase couples actin and adhesion dynamics to survival signaling. Mol Cell Biol. 2004;24(18):8113-33.

Wheeler DL, Iida M, Dunn EF. The Role of Src in Solid Tumors. Oncologist 2009;14:667-678. Wilson MA, Brunger AT. The 1.0 A crystal structure of $\mathrm{Ca}(2+)$-bound calmodulin: an analysis of disorder and implications for functionally relevant plasticity. J Mol Biol. 2000;301(5):123756.

White JM. ADAMs: modulators of cell-cell and cell-matrix interactions. Curr Opin Cell Biol. 2003;15(5):598-606.

Wu J, Zhang L, Ma X, Zhang X, Jin J. Screening cellular proteins involved in the antiproliferative effect of the ADAM15 disintegrin domain in murine melanoma cells. Oncol Rep. 2008;20(3):669-75.

Wu X, Ahn EY, McKenna MA, Yeo H, McDonald JM. Fas binding to calmodulin regulates apoptosis in osteoclasts. J Biol Chem 2005;280:29964-70. 
Yang W, Wang X, Duan C, Lu L, Yang H. Alpha-synuclein overexpression increases phosphoprotein phosphatase 2A levels via formation of calmodulin/Src complex. Neurochem Int. 2013;63(3):180-94.

Yamada D, Ohuchida K, Mizumoto K, Ohhashi S, Yu J, Egami T, et al. Increased expression of ADAM 9 and ADAM 15 mRNA in pancreatic cancer. Anticancer Res 2007;27:793-799.

Yuan K, Jing G, Chen J, Liu H, Zhang K, Li Y, et al. Calmodulin mediates Fas receptor-induced FADD-independent survival signaling in pancreatic cancer cells via activation of SrcExtracellular Signal-regulated Kinase (ERK). J Biol Chem 2011;286:24776-24784.

Yuan K, Yong S, Xu F, Zhou T, Mcdonald JM, Chen Y. Calmodulin antagonists promote TRA8 therapy of resistant pancreatic cancer. Oncotarget. 2015;6(28):25308-19.

Zhang D, Lin J, Han J. Receptor-interacting protein (RIP) kinase family. Cellular \& molecular immunology 2010;7:243-9. dx.doi.org/10.1038/cmi.2010.10

Zhong JL, Poghosyan Z, Pennington CJ, et al. Distinct functions of natural ADAM-15 cytoplasmic domain variants in human mammary carcinoma. Mol Cancer Res. 2008;6(3):38394.

Zhou Y, Prakash P, Liang H, Cho KJ, Gorfe AA, Hancock JF. Lipid-Sorting Specificity Encoded in K-Ras Membrane Anchor Regulates Signal Output. Cell 2017;168:239-251.e16.

\section{Abbreviations}

ADAM - A Disintegrin And Metalloproteinase

ADAMTS - ADAM with thrombospondin motifs

BSA - Bovine serum albumin

cytoADAM15 - Recombinant cytoplasmic domain of ADAM15

CRAC - Calcium release activated channel

DISC - Death Inducing Signaling Complex

DMEM - Dulbecco's Modified Eagle Medium

ECM - Extracellular matrix

EGF - Epidermal growth factor

EGFR - Epidermal growth factor receptor

ELISA - Enzyme Linked Immunosorbent Assay

EMT transition - Epithelial to mesenchymal transition 
ER - Endoplasmic reticulum

ERK - Extracellular signal regulated kinase

FasL - Fas ligand

FAK -Focal Adhesion Kinase

GST - Glutathione-S-Transferase

IP - Immunoprecipitation

$\mathrm{kDa}$ - Kilodalton

MAPK - mitogen-activated protein kinase

MMP - Matrix metalloproteinase

OA - Osteoarthritis

OD - optical density

RA - Rheumatoid Arthritis

RASF - Rheumatoid arthritis synovial fibroblast

RTK - Receptor tyrosine kinase

SH2 - Src homology 2

SH3 - Src homology 3

siRNA - small interfering RNA

wcl - whole cell lysate 


\section{Supplement}

\section{List of figures}

Fig. 1. Schematic diagram of an articular synovial joint.. ................................................ 9

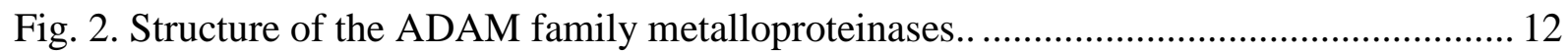

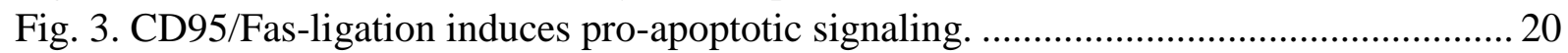

Fig. 4. Structure of Focal Adhesion Kinase (FAK) with chosen interaction partners.. ............ 26

Fig. 5. Changes of the secondary structure of calmodulin in the presence of $\mathrm{Ca}^{2+}$ ions.......... 27

Fig. 6. Working hypothesis for identifying the crosstalk mechanism of Fas receptor triggered

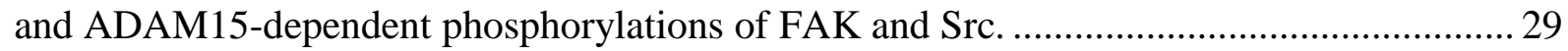

Fig. 7. ADAM15 transfected chondrocyte cell model.. …..................................................... 38

Fig. 8. ADAM15-mediated reduction of FasL-induced caspase 3/7 activity.......................... 39

Fig. 9. ADAM15-mediated increase of FasL-induced focal adhesion kinase (FAK) and Src phosphorylations.

Fig. 10. TFP-mediated inhibition of FasL-induced focal adhesion kinase (FAK) and Src phosphorylations.

Fig. 11. The interaction of Src, Fas/CD95, focal adhesion kinase (FAK) with calmodulin. ... 44

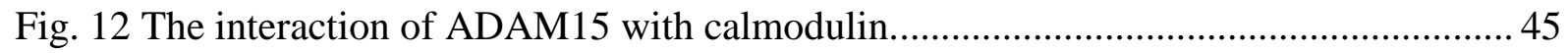

Fig. 13. The interaction of the cytoplasmic domain of ADAM15 with calmodulin................ 47

Fig. 14. The recruitment of Src and calmodulin to ADAM15 upon Fas ligation. .................... 48

Fig. 15. The recruitment of calmodulin to ADAM15 upon Fas ligation. ................................50

Fig. 16. Recruitment of calmodulin to Fas/CD95 upon Fas ligation. ...................................... 51

Fig. 17. Recruitment of calmodulin to Fas/CD95 upon Fas ligation in RASFs...................... 52

Fig. 18. ADAM15 recruitment to the CD95-cap upon Fas/CD95 ligation.............................. 53

Fig. 19. Induced association of Fas/CD95 and ADAM15 upon Fas receptor ligation. ........... 55

Fig. 20. Enhanced interaction of calmodulin with Src upon Fas ligation. .............................. 57

Fig. 21. CRAC mediated calcium influx is crucial for the ADAM15-dependent

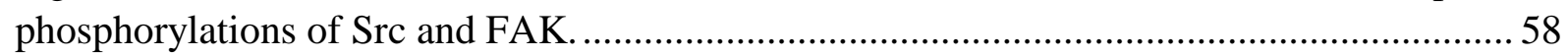

Fig. 22. Increased apoptosis rate of RASFs upon calmodulin inhibition by TFP and by

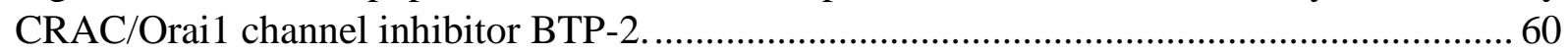

Fig. 23. An increase in the total apoptosis rate induced by FasL upon calmodulin and CRAC/Orail channel inhibition.

Fig. 24. Higher caspase 3 activity upon apoptosis induction with FasL and inhibition of calmodulin and CRAC/Orai1 channels following ADAM15 silencing in rheumatoid arthritis synovial fibroblasts (RASFs).

Fig. 25. The ADAM15-dependent pro-survival signaling pathway induced by Fas/CD95 activation.

\section{List of Tables}

Table 1. Table of antibodies used for double immunofluorescence stainings. ....................... 32

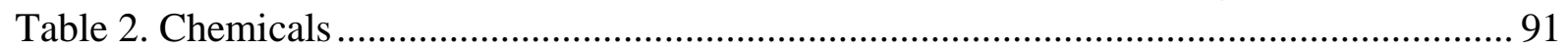

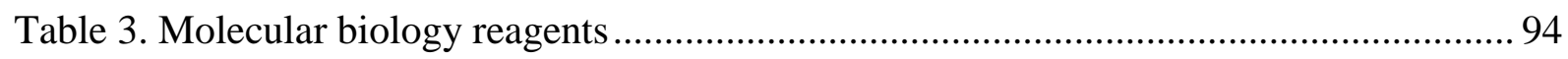

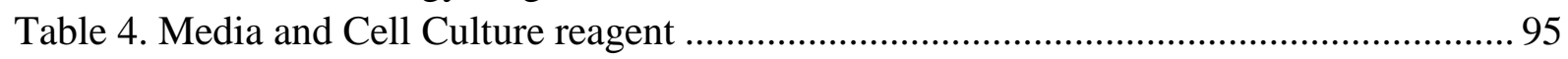

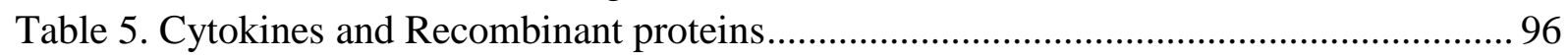

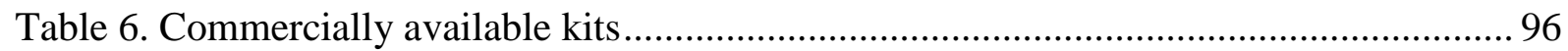

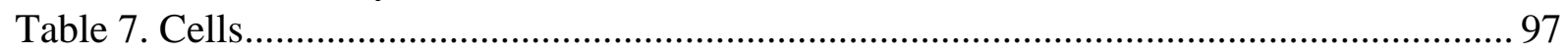


Table 8. Antibodies 97

Table 9. Bacteria strains .99

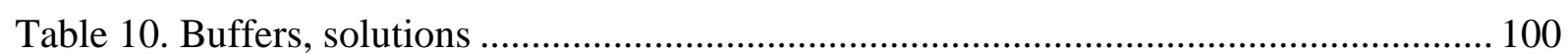

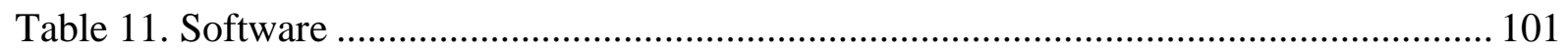

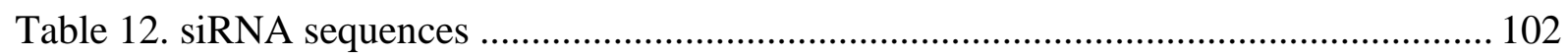

\subsection{Lab equipment and consumables}

\section{Table 2. Chemicals}

Blot Transfer System

Biometra, Göttigen, DE

Butane/Propane Gas-Cartridge C206 Campingaz, Hattersheim, DE

Chamberslides

Sarstedt, Nümbrecht, DE

$\mathrm{CO}_{2}-$ Incubator HeraCell 240 Thermo Fisher Scientific, Dreieich, DE

Cover glasses, 24x66 mm Menzel, Braunschweig, DE

FACS-Fortessa Becton \& Dickinson, Heidelberg, DE FACS-tubes BD Bioscience, Heidelberg, DE

Falcon tubes $15 / 50 \mathrm{ml}$ Greiner, Frickenhausen, DE Fine weight XS205 Mettler Toledo, Giessen, DE

Filter tips 10/100/200/1000 $\mu 1$ Starlab, Hamburg, DE

Gel electrophoresis chamber Peqlab, Erlangen, DE

Heat block Eppendorf, Hamburg, DE

Cryotube $(0,5 / 2 \mathrm{ml})$ Starlab, Hamburg, DE

Fridge/Freezer Liebherr, DE

MaxiSorp F8 Loose Nunc ELISA strips Thermo Fisher Scientific, Dreieich, DE

Microscope EVOS FL Cell imaging system Thermo Fisher Scientific, Dreieich, DE

Microscope Leica SP8 Confocal Leica, Wetzlar, DE

Microscope Axiovert 25 Zeiss, München, DE 
PCR-Cycler PeqStar

Peqlab, Erlangen, DE

PCR-Tubes 0,2/0,5 ml Biozym, Oldendorf, DE

Petri dishes, $10 \mathrm{~cm}$

Greiner, Frickenhausen, DE

pH-Meter

Schott, Mainz, DE

Photometer

Eppendorf, Hamburg, DE

Pipetboy Cell Mate II

Thermo Fisher Scientific (Matrix Tec),

Dreieich, DE

Pipettes

Eppendorf, Hamburg, DE

Plate reader Mithras LB940

Berthold Technologies, DE

Roller (SRT9)

Stuart (Vertrieb: VWR), Darmstadt, DE

Power Supply EPS 601

GE Healthcare, München, DE

Shuttler unimax 2010

Heidolph, Schwabach, DE

Stripettes (Costar ) 5,10,25 ml

Sarstedt, Nümbrecht, DE

UV-lightbox $302 \mathrm{~nm}$

Bachofer, Reutlingen, DE

Vortexer

Scientific Industries, Karlsruhe, DE

Weight Kern 470

Kern, Balingen, DE

Cell culture plates 6 / 24-well

Greiner, Frickenhausen, DE

Cell culture plates 96well, clear

Greiner, Frickenhausen, DE

Cell culture plates 96well, half area, white, transparent bottom

Greiner, Frickenhausen, DE

Cell culture flasks $75 \mathrm{~cm}^{2}$

Greiner, Frickenhausen, DE

Nitrocellulose membrane (Amersham Protran

$0,45 \mu \mathrm{m}$ NC Nitrocellulose)

GE Healthcare, München, DE

Whatman Blotting filter paper

Neolab, Heidelberg, DE 
Centrifuges (Minifuge, Multifuge,

Tablecentrifuge)

Thermo Fisher Scientific, Dreieich, DE

Cell Scrapers

Greiner, Frickenhausen, DE

Amicon® Ultra $0.5 \mathrm{~mL}$ Centrifugal Filters

Merck, Darmstadt, DE

Cell Counting Chamber

Marienfeld-Superior, Marienfeld, DE

Acrylamide $40 \%$

Roth, Karlsruhe, DE

Agar

Life Technologies, Darmstadt, DE

Agarose

Sigma, Hamburg, DE

Ammonium persulfate (APS)

Roth, Karlsruhe, DE

Bacto Yeast Extract

Roth, Karlsruhe, DE

Boric acid

Applichem, Darmstadt, DE

Bromophenol blue

Applichem, Darmstadt, DE

DAPI

Sigma, Hamburg, DE

Di-Sodium Hydrogen Phosphate $\left(\mathrm{Na}_{2} \mathrm{HPO}_{4} \mathrm{X}\right.$

Riedel-de Haen, Seelze, DE

$\mathrm{H}_{2} \mathrm{O}$ )

EDTA-Tricomplex III

Roth, Karlsruhe, DE

Acetic Acid 100\%

Applichem, Darmstadt, DE

Ethanol (EtOH) 96\%

Sigma, Hamburg, DE

Ethidium Bromide

Roth, Karlsruhe, DE

Glucose solution

Roth, Karlsruhe, DE

Glycin p.A.

Applichem, Darmstadt, DE

Hydrogen Peroxide $\left(\mathrm{H}_{2} \mathrm{O}_{2}\right)$

Sigma, Hamburg, DE

Potassium Chloride (KCl)

Merck, Darmstadt, DE

Potassium Di-hydrogen Phosphate $\left(\mathrm{KH}_{2} \mathrm{PO}_{4}\right)$

Merck, Darmstadt, DE 


\begin{tabular}{|c|c|}
\hline Methanol (MeOH) & Sigma, Hamburg, DE \\
\hline Milk powder, defatted & Roth, Karlsruhe, DE \\
\hline Magnesium Chloride $\left(\mathrm{MgCl}_{2}\right)$ & Sigma, Hamburg, DE \\
\hline Sodium Chloride $(\mathrm{NaCl})$ & Sigma, Hamburg, DE \\
\hline Sodium Dodecyl Sulfate (SDS) & Sigma, Hamburg, DE \\
\hline Sodium Hydroxide $(\mathrm{NaOH})$ & Merck, Darmstadt, DE \\
\hline Paraformaldehyde & Roth, Karlsruhe, DE \\
\hline Pepton & Roth, Karlsruhe, DE \\
\hline Ponceau S & Applichem, Darmstadt, DE \\
\hline TEMED 99\% & Roth, Karlsruhe, DE \\
\hline Tris- $\mathrm{HCl}$ & Sigma, Hamburg, DE \\
\hline TritonX-100 & Sigma, Hamburg, DE \\
\hline Tween20 & Roth, Karlsruhe, DE \\
\hline Calcium Chloride $\left(\mathrm{CaCl}_{2}\right)$ & Roth, Karlsruhe, DE \\
\hline 2-Mercaptoethanol, BME & Roth, Karlsruhe, DE \\
\hline HEPES, dry powder & Sigma, Hamburg, DE \\
\hline Hydrochloric Acid, concentrated & Roth, Karlsruhe, DE \\
\hline Ethanol $70 \%$ & \\
\hline
\end{tabular}

\section{Table 3. Molecular biology reagents}

ABTS 2,2'-Azino-di-(3-ethylbenzthiazolin-6-

Roche, Mannheim, DE sulfonsäure) 
Roti-Blue, 5x Concentrated Roth, Karlsruhe, DE

DNA-Loading buffer Roth, Karlsruhe, DE

Protein Marker (prestained/unstained) Thermo Fisher Scientific, Dreieich, DE

Pierce Protein G Agarose Thermo Fisher Scientific, Dreieich, DE

Pierce Protein A Agarose Thermo Fisher Scientific, Dreieich, DE

Anti-Mouse IgM ( $\mu$-chain specific)-Agarose Sigma, Hamburg, DE GE Healthcare, München, DE

Glutathione Sepharose 4B GE Healthcare, München, DE

cOmplete $^{\mathrm{TM}}$, EDTA-free Protease Inhibitor Cocktail Sigma, Hamburg, DE

Phosphatase Inhibitor Cocktail 2 Sigma, Hamburg, DE

Phosphatase Inhibitor Cocktail 3 Sigma, Hamburg, DE

TFP, Trifluoperazine Hydrochloride Santa Cruz Biotechnology, Heidelberg,

DE

BTP-2

Santa Cruz Biotechnology, Heidelberg, DE PP2 Sigma, Hamburg, DE EZ-Link® Sulfo-NHS-LC-LC-Biotin Thermo Fisher Scientific, Dreieich, DE LodeStars $2.7 \mu \mathrm{m}$ Streptavidin Agilent, Santa Clara, USA

Table 4. Media and Cell Culture reagent 


\section{Table 5. Cytokines and Recombinant proteins}

\section{Table 6. Commercially available kits}


Table 7. Cells

\begin{tabular}{|c|c|c|}
\hline Name & Description & Source/Company \\
\hline $\begin{array}{l}\text { T/C28a4 } \\
\text { Chondrocytes }\end{array}$ & $\begin{array}{l}\text { Human Chondrocytes from } \\
\text { non-articular cartilage } \\
\text { immortalized with SV40T }\end{array}$ & $\begin{array}{l}\text { Cell line, Dr. M. B. Goldring (Hospital } \\
\text { for Special Surgery, New York, NY) } \\
\text { (Goldring et al., 1994) }\end{array}$ \\
\hline K4IM & $\begin{array}{l}\text { Human RASF fibroblasts } \\
\text { immortalized with SV40T }\end{array}$ & $\begin{array}{l}\text { Cell Line, Prof. Dr. C. Haas (Clinical } \\
\text { Research Unit for Rheumatology, } \\
\text { University Hospital, Freiburg, } \\
\text { Germany) (Haas et al., 1997) }\end{array}$ \\
\hline RASF & $\begin{array}{l}\text { Primary human Synovial } \\
\text { Fibroblasts from RA patients }\end{array}$ & $\begin{array}{l}\text { Primary cells, Prof. Dr. Raimund Kinne } \\
\text { (Clinic of Orthopedics, University } \\
\text { Hospital Jena) }\end{array}$ \\
\hline
\end{tabular}

Table 8. Antibodies

\begin{tabular}{|l|l|l|l|l|}
\hline & Name & Species & Source/Firma & Application \\
\hline \multirow{4}{*}{$\begin{array}{c}\text { Primary } \\
\text { Antibodies }\end{array}$} & Anti FAK 4,47 & Mouse & Merck, Darmstadt, DE & WB, IP \\
\cline { 2 - 6 } & Anti pFAK Y397 & Mouse & $\begin{array}{l}\text { BD Biosciences, } \\
\text { Heidelberg, DE }\end{array}$ & WB \\
\cline { 2 - 6 } & Anti pFAK Y576 & Rabbit & Abcam (Cambridge, UK) & WB \\
\cline { 2 - 6 } & Anti Src (32G6) & Rabbit & $\begin{array}{l}\text { Abcam (Cambridge, UK) } \\
\text { USA) }\end{array}$ & WB \\
\hline
\end{tabular}




\begin{tabular}{|c|c|c|c|c|}
\hline & Anti Src (L4A1) & Mouse & $\begin{array}{l}\text { Cell Signaling (Danvers, } \\
\text { USA) }\end{array}$ & $\mathrm{WB}, \mathrm{IP}$ \\
\hline & Anti pSrc Y416 & Rabbit & $\begin{array}{l}\text { Cell Signaling (Danvers, } \\
\text { USA) }\end{array}$ & WB \\
\hline & $\begin{array}{ll}\text { Anti } & \text { pJnk } \\
\text { T183/Y185 } & \end{array}$ & Rabbit & $\begin{array}{l}\text { Cell Signaling (Danvers, } \\
\text { USA) }\end{array}$ & WB \\
\hline & Anti pAkt S473 & Rabbit & $\begin{array}{l}\text { Cell Signaling (Danvers, } \\
\text { USA) }\end{array}$ & WB \\
\hline & $\begin{array}{l}\text { Anti pErk 1/2 } \\
\text { T202/Y204 }\end{array}$ & Rabbit & $\begin{array}{l}\text { Cell Signaling (Danvers, } \\
\text { USA) }\end{array}$ & WB \\
\hline & Anti CD95 (B-10) & Mouse & $\begin{array}{l}\text { Santa Cruz (Heidelberg, } \\
\text { DE) }\end{array}$ & WB \\
\hline & Anti CD95 (C-20) & Rabbit & $\begin{array}{l}\text { Santa Cruz (Heidelberg, } \\
\text { DE) }\end{array}$ & IP, FACS, IF \\
\hline & Anti CD95 (CH-11) & Mouse & Merck (Darmstadt, DE) & $\begin{array}{l}\text { IP, Cell } \\
\text { Stimulation }\end{array}$ \\
\hline & $\begin{array}{l}\text { Anti Calmodulin } \\
(05-173)\end{array}$ & Mouse & Merck (Darmstadt, DE) & WB, IP \\
\hline & $\begin{array}{ll}\text { Anti } & \text { Calmodulin } \\
\text { (2D1) } & \\
\end{array}$ & Mouse & $\begin{array}{l}\text { Thermo Fisher Scientific, } \\
\text { (Dreieich, DE) }\end{array}$ & IF \\
\hline & $\begin{array}{l}\text { Anti ADAM15 } \\
\text { prodomain (AF935) }\end{array}$ & Goat & $\begin{array}{l}\text { RD Systems (Wiesbaden, } \\
\text { DE) }\end{array}$ & IP, WB \\
\hline & $\begin{array}{l}\text { Anti ADAM15 } \\
\text { prodomain } \\
\text { [EPR5619] }\end{array}$ & Rabbit & Abcam (Cambridge, UK) & WB \\
\hline & $\begin{array}{l}\text { Anti ADAM15 } \\
\text { cytoplasmic domain }\end{array}$ & Rabbit & Absam (Cambridge, UK) & WB \\
\hline & Anti GAPDH & Rabbit & Abcam (Cambridge, UK) & WB \\
\hline & Anti-Tubulin & Rabbit & Abcam (Cambridge, UK) & WB \\
\hline Secondary & Anti-Mouse-HRP & Goat & $\begin{array}{l}\text { Thermo Fisher Scientific, } \\
\text { (Dreieich, DE) }\end{array}$ & WB, ELISA \\
\hline Antıbodies & Anti-Rabbit-HRP & Goat & $\begin{array}{l}\text { Thermo Fisher Scientific, } \\
\text { (Dreieich, DE) }\end{array}$ & WB \\
\hline
\end{tabular}




\begin{tabular}{|l|l|l|l|}
\hline Anti-Goat-HRP & Donkey & Dako (Hamburg, DE) & WB \\
\cline { 2 - 5 } Anti-Mouse-HRP & Goat & Abcam(Cambridge, UK) & WB \\
\hline $\begin{array}{llll}\text { Anti-Goat-Alexa- } \\
488\end{array}$ & Donkey & $\begin{array}{l}\text { Thermo Fisher Scientific, } \\
\text { Dreieich, DE }\end{array}$ & IF \\
\hline $\begin{array}{l}\text { Anti-Rabbit-Alexa- } \\
488\end{array}$ & Mouse & $\begin{array}{l}\text { Thermo Fisher Scientific, } \\
\text { Dreieich, DE }\end{array}$ & IF \\
\hline $\begin{array}{l}\text { Anti-Rabbit- Alexa- } \\
594\end{array}$ & Maus & $\begin{array}{l}\text { Thermo Fisher Scientific, } \\
\text { Dreieich, DE }\end{array}$ & IF \\
\hline $\begin{array}{l}\text { Anti-Mouse- Alexa- } \\
594\end{array}$ & Goat & $\begin{array}{l}\text { Thermo Fisher Scientific, } \\
\text { Dreieich, DE }\end{array}$ & IF \\
\hline $\begin{array}{l}\text { Anti-Mouse- Alexa- } \\
594\end{array}$ & Chicken & $\begin{array}{l}\text { Thermo Fisher Scientific, } \\
\text { Dreieich, DE }\end{array}$ & IF \\
\hline
\end{tabular}

ELISA (Enzyme-linked-immunosorbent-assay), FACS (Fluorescence-Activated cell sorting), IHC (Immunhistochemistry), IF (Immunofluorescence), IP (Immunoprecipitation), WB (Western Blot)

\section{Table 9. Bacteria strains}

\begin{tabular}{|c|c|}
\hline Name & Genotype \\
\hline $\begin{array}{l}\text { DH5 } \alpha \\
\text { (Stratagene, Zuidoost, NE) }\end{array}$ & $\begin{array}{l}\text { F } \not 80 \text { dlacZ } \Delta \text { M15 } \Delta \text { (lacZYA-argF) U169 deoR } \\
\text { recA1 endA1 hsdR17(rk-, mk+) PhoA supE44 } \\
\lambda \text { - thi-1 gyrA96 relA1 }\end{array}$ \\
\hline $\begin{array}{l}\text { XL1-Blue } \\
\text { (Stratagene, Zuidoost, NE) }\end{array}$ & $\begin{array}{l}\text { recA1 endA1 gyrA96 thi-1 hsdR17 supE44 } \\
\text { relA1 lac [F' proAB lacIqZ } \Delta \text { M15 Tn10 (Tetr)] }\end{array}$ \\
\hline $\begin{array}{l}\text { BL21, Rosetta }{ }^{\mathrm{TM}}(\mathrm{DE} 3) \\
\text { (Merck, Darmstadts, DE) }\end{array}$ & $\begin{array}{l}\mathrm{F}^{-} \text {ompT hsd } S_{\mathrm{B}}\left(\mathrm{r}_{\mathrm{B}}^{-} \mathrm{m}_{\mathrm{B}}^{-}\right) \text {gal dcm (DE3) pRARE } \\
\left(\mathrm{Cam}^{\mathrm{R}}\right)\end{array}$ \\
\hline
\end{tabular}


Table 10. Buffers, solutions

\begin{tabular}{|c|c|}
\hline Name & Composition \\
\hline Blotting-Buffer & $25 \mathrm{mM}$ Tris, $192 \mathrm{mM}$ Glycin, $20 \%$ Methanol in $\mathrm{H}_{2} \mathrm{O}$ \\
\hline Coomassie-Staining Solution & $20 \% \mathrm{MeOH}$ in $\mathrm{H}_{2} \mathrm{O}+20 \mathrm{ml} 5 x$ Roti-Blue \\
\hline EDTA-Buffer & $1 \mathrm{mM}$ EDTA, $\mathrm{pH} 8$ in $\mathrm{H}_{2} \mathrm{O}$ \\
\hline EDTA-Buffer in PBS & $1 \mathrm{mM}$ EDTA, $\mathrm{pH} 7.4$ in PBS \\
\hline Loading buffer (SDS-Gel) & $\begin{array}{l}\text { 0,2 M Tris-HCL (pH 6,8), } 4 \% \text { SDS, } 40 \% \text { Glycerin (w/v), } \\
0,4 \% \text { Bromphenolblue, add } 10 \mathrm{ml} \mathrm{H}_{2} 0\end{array}$ \\
\hline LB-Medium & $2 \%$ LB-powder medium, add $1 \mathrm{~L} \mathrm{H}_{2} \mathrm{O}$ \\
\hline PBS-Puffer 10x & $\begin{array}{l}2,7 \mathrm{mM} \mathrm{KCl}, 1,5 \mathrm{mM} \mathrm{KH}_{2} \mathrm{PO}_{4}, 137 \mathrm{mM} \mathrm{NaCl}, 8 \mathrm{mM} \\
\mathrm{Na}_{2} \mathrm{HPO}_{4} \text {, in } \mathrm{H}_{2} \mathrm{O}\end{array}$ \\
\hline Ponceau-solution. & $0,5 \%$ Ponceau $\mathrm{S}, 1 \%$ Acetic acid, add $100 \mathrm{ml} \mathrm{H}_{2} \mathrm{O}$ \\
\hline $\begin{array}{l}\text { RIPA-Buffer }+ \\
\text { (radio immunoprecipitation } \\
\text { assay) }\end{array}$ & $\begin{array}{l}50 \mathrm{mM} \text { Tris }(\mathrm{pH} 7), 150 \quad \mathrm{mM} \text { NaCl, } 0.5 \% \\
\text { Natriumdesoxycholat, } 1 \% \text { NP40, Protease inhibitors }(100 \mu \mathrm{l}) \text {, } \\
\text { Phosphatase inhibitor cocktail } 2 \text { and } 3(100 \mu \mathrm{l}), \mathrm{NaF}(100 \mu \mathrm{l})\end{array}$ \\
\hline Lysis Buffer & $\begin{array}{l}10 \mathrm{mM} \text { HEPES }(\mathrm{pH} 7), 150 \mathrm{mM} \mathrm{NaCl}, 1 \% \text { Triton X-100, } \\
\text { Protease inhibitors }(100 \mu \mathrm{l}) \text {, Phosphatase inhibitor cocktail } 2 \\
\text { and } 3(100 \mu \mathrm{l}), \mathrm{NaF}(100 \mu \mathrm{l})\end{array}$ \\
\hline Lysis Buffer for bacterial cells & $\begin{array}{l}50 \mathrm{mM} \text { Tris- } \mathrm{HCl} \mathrm{pH} 8,20 \% \text { sucrose, } 1 \mathrm{mM} \text { EDTA, Protease } \\
\text { inhibitors }(100 \mu \mathrm{l}) \text {, Lysozyme }(0,2 \mu \mathrm{g} / \mathrm{ml})\end{array}$ \\
\hline Wash Buffer $1 \%$ Triton X-100 & $10 \mathrm{mM}$ HEPES (pH 7), $150 \mathrm{mM} \mathrm{NaCl}, 1 \%$ Triton X-100 \\
\hline $\begin{array}{l}\text { Wash Buffer } 0,1 \% \text { Triton X- } \\
100\end{array}$ & 10 mM HEPES (pH 7), 150 mM NaCl, 0,1\% Triton X-100 \\
\hline SDS-Buffer 10x & 1.9 M Glycin, $250 \mathrm{mM}$ Tris, $10 \% \mathrm{SDS}$ in $\mathrm{H}_{2} \mathrm{O}$ \\
\hline SDS-Buffer 1x & $190 \mathrm{mM}$ Glycin, $25 \mathrm{mM}$ Tris, $1 \%$ SDS in $\mathrm{H}_{2} 0$ \\
\hline SOB-Medium & $2 \%$ Pepton, $0,5 \%$ BactoYeast Extract, $10 \mathrm{mM} \mathrm{NaCl}, 2,5 \mathrm{mM}$ \\
\hline SOC-Medium & $\begin{array}{l}0,5 \% 1 \mathrm{M} \mathrm{MgCl}_{2} \text {-Lsg., } 30 \% \text { Glucose solution., add } 10 \mathrm{ml} \\
\text { SOB-Medium }\end{array}$ \\
\hline TBE-Buffer 10x & $1 \mathrm{M}$ Tris, 0,9 M Borsäure, $10 \mathrm{mM}$ EDTA pH 8,3 in $\mathrm{H}_{2} \mathrm{O}$ \\
\hline
\end{tabular}


Western Blot Stacking (4\%)

4\% Acrylamide 156 mM Tris-HCL (pH 6,8), 0,1\% SDS, 8

$\mu 1$ Temed, $60 \mu \mathrm{l}$ APS (10\%), add $4 \mathrm{ml} \mathrm{H}_{2} \mathrm{O}$

Western Blot Separating gel $\quad 8 \%$ Acrylamide, $332 \mathrm{mM}$ Tris-HCL (pH 8,8), 0,1 \% SDS, 20

(8\%) $\quad \mu 1$ Temed, $140 \mu \mathrm{l}$ APS (10\%), add $10 \mathrm{ml} \mathrm{H}_{2} \mathrm{O}$

Western Blot Separating gel $10 \%$ Acrylamide, $332 \mathrm{mM}$ Tris-HCL $(\mathrm{pH} 8,8), 0,1 \%$ SDS, (10\%) $20 \mu \mathrm{l}$ Temed, $140 \mu \mathrm{l}$ APS $(10 \%)$, add $10 \mathrm{ml} \mathrm{H}_{2} \mathrm{O}$

Western Blot Separating gel $12 \%$ Acrylamide, $332 \mathrm{mM}$ Tris-HCL (pH 8,8), 0,1 \% SDS, (12\%) $20 \mu 1$ Temed, $140 \mu \mathrm{l}$ APS $(10 \%)$, add $10 \mathrm{ml} \mathrm{H}_{2} \mathrm{O}$ PFA fixing solution for ICC $4 \%$ PFA in PBS

PBS $+0,1 \%$ BSA for ICC $\quad 0,1 \%$ BSA in PBS

Permeabilizing solution for ICC $0,1 \%$ BSA, $1 \%$ TritonX-100 in PBS

Table 11. Software

\begin{tabular}{|l|l|}
\hline Application & Name/Supplier \\
\hline BLAST Software & Vbase2 (http://www.vbase2.org) \\
NCBI Ig Blast \\
(http://www.ncbi.nlm.nih.gov/igblast) \\
IMGT (http://www.imgt.org/IMGT_vquest)
\end{tabular}


Table 12. siRNA sequences

Target, siRNA name

ADAM15, s16681

ADAM15, s16682
siRNA sequence

5'-GAUCUACUCUGGG-AGACAAtt-3'

5'-CAUUAUUUCG- CGAAUCCAAtt-3' 


\section{2 Acknowledgements}

This doctoral project was carried out in the Experimental Research Group of the Division of Rheumatology (Head: Prof. Dr. med. Harald Burkardt) affiliated with the Department of Internal Medicine II, University Hospital Frankfurt - Goethe University in Frakfurt am Main, Germany.

I want to express my gratitude for Professor Harald Burkhardt for accepting me as a $\mathrm{PhD}$ student and member of his research group and providing me with unending support, which enabled me to finish the project and obtain conclusive answers to the big questions regarding the anti-apoptotic effects of ADAM15. In particular, I appreciate the invaluable advice regarding my project, which always, at key moments allowed me to move forward.

Next, I want to thank Dr. Beate Böhm. Frankly, I can say that most of what makes me a scientist is what I learned from Dr. Böhm. I am extremely grateful for the time Dr. Böhm invested in mentoring me and I am aware that without it, even in the case of a successful doctoral project, I would not have reached to my present level of knowledge and confidence. Moreover, I hereby thank Dr. Beate Böhm for guiding this project and always being confident in it also in the moments of limited success.

I thank my research group, which I was always lucky to be part of. This includes Yuliya Fehrl, Nadine Schneider and Sylvia Cienciala but also past members: Pangrazio DeGiacomo, Verena Dresing and Tatjana Scholz. I had much fun with all of you, and this allowed me to stay motivated and to continue.

The most personal thanks I would like to give to the two most-important people in my life: my mother Katarzyna, who raised me and made me everything that I am now, whom I always wanted to make proud; and most importantly my girlfriend Kasia, for whom I do it all. Without you, nothing would make sense. 


\subsection{Publications}

\section{Published literature:}

Janczi T, Böhm BB, Fehrl Y, DeGiacomo P, Kinne RW, Burkhardt H. ADAM15 in Apoptosis Resistance of Synovial Fibroblasts: Converting Fas/CD95 Death Signals Into the Activation of Pro-survival Pathways by Calmodulin Recruitment. Arthritis and Rheumatology 2018;71:6372.

Böhm BB, Fehrl Y, Janczi T, Schneider N, Burkhardt H. Cell adhesion-induced transient interaction of ADAM15 with poly(A) binding protein at the cell membrane colocalizes with mRNA translation. PLoS One 2018; 28;13(9):e0203847 


\subsection{Curriculum vitae}

\section{Personal data}

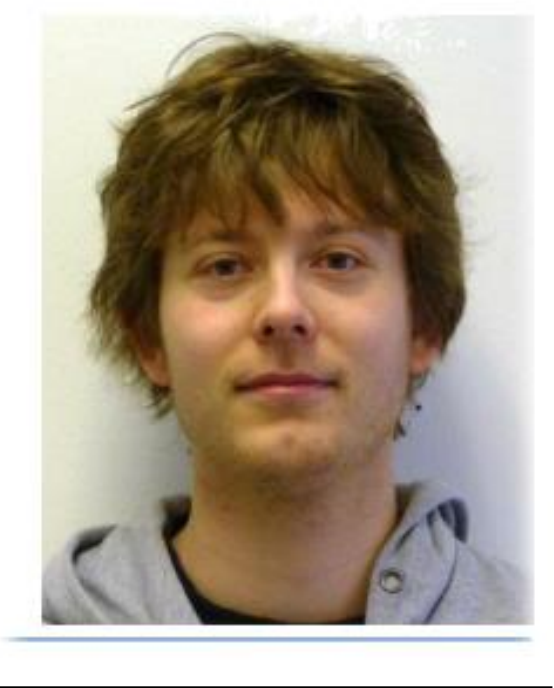

Tomasz Janczi

Tel: +491752857499

Kästrich 11

55116, Mainz

Born on the $22^{\text {nd }}$ of March 1989 in Płock, Polen

\section{Education} of Biochemistry. Degree attained: Magister (equivalent to Master of Science): Biotechnology, Final Grade: 5 (very good) ${ }^{\mathbf{1}}$

- Title of thesis: "Expression of human adenylate kinase genes in Escherichia coli cells and their reactivation"

Supervisor: Prof. Dr. Michał Komoszyński

- Poster presentation during the III KSSNP (III Kopernikańskie Sympozjum Studentów Nauk Przyrodniczych - 22-24 March 2013) titled: Nadprodukcja i oczyszczanie bakteryjnych oraz ludzkich kinaz adenylanowych (Producing and purifying human adenylate kinases) Authors: Tomasz Janczi, Magdalena Wujak, Agnieszka Błaszczak.

- - Oral presentation during the $48^{\text {th }}$ meeting of the PTBioch(Polskie Towarzystwo Biochemiczne - Polish Biochemical Society) : „The role of adenylate kinase izoenzymes 1 and 2 in regulation of blood platelet aggregation process initiated by ADP and collagen" Authors: Magdalena Wujak, Tomasz Janczi, Michał Komoszyński 

of Biochemistry. Degree attained: Licencjat (equivalent to Bachelor of Science): Biotechnology, Final Grade: 4 (good) ${ }^{\mathbf{1}}$

- Title of thesis: "Over-expression of apyrases AP 4, 5 and 6 from Solanum tuberosum in Origami strain bacteria and conditions of Escherichia coli cultures."

Supervisor: Prof. Dr. Michał Komoszyński

\section{Employment}

EMBL (The European Molecular Biology Laboratory) Hamburg, Hamburg, Germany

- Trainee (Project topic: Mechanisms of Mycobacterium tuberculosis infectivity)

Supervisor: Dr. Nabil Hanna

2014-2020

Universitätsklinikum Frankfurt, Frankfurt am Main, Germany - PhD Student (Thesis title: ADAM15 in Apoptosis Resistance of Synovial Fibroblasts: Converting Fas/CD95 Death Signals Into the Activation of Prosurvival Pathways by Calmodulin Recruitment) Supervisor: Prof. Dr. med. Harald Burkhardt 